\title{
Transfer of cognitive strategy training after stroke : no place like home?
}

Citation for published version (APA):

Geusgens, C. A. V. (2007). Transfer of cognitive strategy training after stroke : no place like home? [Doctoral Thesis, Maastricht University]. NeuroPsych Publishers. https://doi.org/10.26481/dis.20071003cg

Document status and date:

Published: 01/01/2007

DOI:

$10.26481 /$ dis.20071003cg

Document Version:

Publisher's PDF, also known as Version of record

\section{Please check the document version of this publication:}

- A submitted manuscript is the version of the article upon submission and before peer-review. There can be important differences between the submitted version and the official published version of record.

People interested in the research are advised to contact the author for the final version of the publication, or visit the DOI to the publisher's website.

- The final author version and the galley proof are versions of the publication after peer review.

- The final published version features the final layout of the paper including the volume, issue and page numbers.

Link to publication

\footnotetext{
General rights rights.

- You may freely distribute the URL identifying the publication in the public portal. please follow below link for the End User Agreement:

www.umlib.nl/taverne-license

Take down policy

If you believe that this document breaches copyright please contact us at:

repository@maastrichtuniversity.nl

providing details and we will investigate your claim.
}

Copyright and moral rights for the publications made accessible in the public portal are retained by the authors and/or other copyright owners and it is a condition of accessing publications that users recognise and abide by the legal requirements associated with these

- Users may download and print one copy of any publication from the public portal for the purpose of private study or research.

- You may not further distribute the material or use it for any profit-making activity or commercial gain

If the publication is distributed under the terms of Article $25 \mathrm{fa}$ of the Dutch Copyright Act, indicated by the "Taverne" license above, 
Transfer of cognitive strategy training after stroke: No place like home? 
(C) C.A.V. Geusgens, Maastricht 2007

$\begin{array}{ll}\text { Cover design } & \text { Pascal Geusgens } \\ \text { Cover photography } & \text { www.iStockphoto.com / Christian Anthony } \\ \text { Production } & \text { Datawyse BV, Maastricht } \\ \text { ISBN } & 978-90-75579-34-5\end{array}$

Neuropsych Publishers is a nonprofit organisation, which aims at promoting the science of 'Brain and Behaviour' and improving the application of the products of this science in health care and education. Neuropsych Publishers accomplishes these aims by publishing books, dissertations and other products of scientific activity, by disseminating educational materials and publication of tests, assessment scales and other psychometric instruments in the field of Neuropsychology, Neuropsychiatry and other areas within the domain of Brain and Behaviour.

Postal address Neuropsych Publishers

Department of Psychiatry and Neuropsychology

Maastricht University

P.O. Box 616

NL - 6200 MD Maastricht

The Netherlands

www-np.unimaas.nl 


\title{
Transfer of cognitive strategy training after stroke: No place like home?
}

\author{
PROEFSCHRIFT
}

ter verkrijging van de graad van doctor aan de Universiteit Maastricht, op gezag van de Rector Magnificus, Prof. mr. G.P.M.F. Mols, volgens het besluit van het College van Decanen, in het openbaar te verdedigen op woensdag 3 oktober 2007 om 16.00 uur

door

Chantal Adrienne Valentine Geusgens

Geboren op 9 november 1977 te Maastricht 


\section{Promotores}

Prof. dr. W.J.A. van den Heuvel

Prof. dr. J. Jolles

\section{Co-promotor}

Dr. C.M. van Heugten

\section{Beoordelingscommissie}

Prof. dr. F.R.J. Verhey, voorzitter

Prof. dr. L. Fasotti (Radboud Universiteit, Nijmegen)

Prof. dr. G.I.J.M. Kempen

Dr. J.M. Spikman (UMC Groningen)

Prof. dr. D.T. Wade

The research described in this thesis was carried out at the Institute for Rehabilitation Research (iRv), Hoensbroek, in collaboration with the Maastricht Brain and Behaviour Institute and the Department of Psychiatry \& Neuropsychology of Maastricht University, Maastricht.

This study was supported by the Netherlands Organisation for Health Research and Development (ZonMw), Rehabilitation Research Programme (grant no. 14350009) and the Institute for Rehabilitation Research (iRv). 
Here the Red Queen began again. 'Can you answer useful questions?' she said.

Taken from Through the looking-glass and what Alice found there by Lewis Carroll 



\section{Contents}

1. General introduction 9

2. Assessment of apraxia: inter-rater reliability of a new apraxia $\quad 19$ test, association between apraxia and other cognitive deficits and prevalence of apraxia in a rehabilitation setting

3. Evidence based OT guideline for assessment and treatment of apraxia in stroke patients

4. The occurrence and measurement of transfer in cognitive rehabilitation: A critical review

5. Transfer of training effects in stroke patients with apraxia: An exploratory study

6. Transfer effects of a cognitive strategy training for stroke patients with apraxia

7. Environment effects in the performance of daily tasks in healthy adults

8. General discussion 125

$\begin{array}{lr}\text { Summary } & 139\end{array}$

$\begin{array}{ll}\text { Samenvatting } & 145\end{array}$

$\begin{array}{ll}\text { Dankwoord } & 151\end{array}$

$\begin{array}{ll}\text { Curriculum Vitae } & 157\end{array}$ 

Chapter 1

General Introduction 



\section{Defining the problem}

The incidence of first ever stroke in the Netherlands has been estimated to be 2,2 per 1000 people per year. ${ }^{1}$ In this country, approximately 190.000 people have survived a stroke, ${ }^{2}$ of which a substantial number has to live with the long lasting consequences. A total of $54 \%$ of all surviving stroke patients experiences functional disabilities in daily life. ${ }^{3}$ Costs concerning the treatment and care for stroke patients are high, taking up approximately $3 \%$ of the total annual health care budget in the Netherlands. ${ }^{4}$ Due to the aging of the population, both incidence and prevalence figures have been predicted to increase over the coming years, ${ }^{1}$ resulting in an increase of stroke related healthcare costs.

The consequences of stroke can be extensive, affecting physical, emotional and cognitive functioning, and resulting in severe disability in everyday life. To attempt to decrease this disability level, stroke patients are often referred to a rehabilitation programme. This is a multidisciplinary programme, consisting of a variety of therapies that address the specific problems a patient experiences after stroke. Cognitive rehabilitation is part of the rehabilitation programme and refers to the treatment methods that are used to reduce disabilities due to cognitive impairments. ${ }^{5}$ A widely used treatment method in cognitive rehabilitation is strategy training. Research has shown the effectiveness of strategy training, by demonstrating that after training, patients function better on trained tasks, at the rehabilitation centre, which is the setting where training took place. 6,7 However, after discharge, patients often return to their own homes, where they will have to be able to apply the skills they learned in the rehabilitation centre. Yet little is known about patients' abilities to transfer these skills. Therefore, the present thesis aims to investigate transfer of treatment effects in cognitive strategy training after stroke.

\section{Key concepts}

\section{Transfer and its importance in rehabilitation}

Transfer relates to the way in which prior learning affects new learning or performance. ${ }^{8,9}$ It has often been stated that transfer is essential in all situations in which learning takes place. Transfer has even been said to be the main goal of all learning. ${ }^{8-10}$

Due to a controversy in the conventional organisation of rehabilitation treatment, transfer is of utmost importance for the clinical success of a rehabilitation programme. In the Netherlands, the expectation that a patient will be able to return home after rehabilitation treatment is a prerequisite for the patient to be admitted to a rehabilitation programme. ${ }^{11}$ Thus the optimal result of rehabilitation treatment relates to a long term goal, namely maximising independent functioning, resulting in the patients' return to their own homes and participation in society. The way in which rehabilitation is generally structured, however, is more focussed on achieving short term goals, relating to the improvement of the patients' functioning within the rehabilitation setting itself. 
This is partly due to the focus of the patients and their families. The conventional rehabilitation programme is structured in the most cost effective manner; patients are admitted to a rehabilitation centre where the required care can be provided and where a multidisciplinary rehabilitation team is present to offer therapies on a daily basis. This however implicates that for the ultimate goal of a rehabilitation programme to be met, transfer of treatment effects should occur.

To achieve this goal, two types of transfer of training effects are necessary. First, transfer from the training situation to other settings is required. For patients to function as independently as possible at home, tasks and activities which are trained in the rehabilitation setting should be transferred to the home setting. Second, transfer from trained to non-trained tasks is essential, as therapists cannot possibly teach patients to handle all the difficulties and tasks they will encounter after discharge from the rehabilitation programme and during the rest of their lives. Patients are expected to be able to act adequately in these new circumstances, based on what they have learned during their rehabilitation treatment. Hence transfer of skills from trained to non-trained tasks is expected to occur. Thus, transfer is essential for the clinical success of a rehabilitation treatment. Transfer of training effects relates to the core goal of the rehabilitation treatment as it is currently offered. Although transfer is an important topic within the field of rehabilitation practice and rehabilitation research, little is known about its occurrence.

\section{Cognitive rehabilitation and transfer}

The focus of cognitive rehabilitation is the reduction of disabilities resulting from cognitive impairments. To reduce these disabilities, three general treatment approaches can be used. These approaches are referred to as restitution, specific skills training and substitution. Restitution of function, or cognitive retraining, refers to a treatment method that is aimed at reducing the cognitive impairment itself. A 'drill and practice' approach is applied to strengthen the impaired function by frequent and lengthy repetitions of exercises addressing the specific cognitive function.5,12 For example, in memory retraining, patients are repetitively presented with lists of words which they are asked to repeat. Research has shown that although this treatment approach improves the performance on the specific cognitive task that is used during training, transfer to functional tasks does not occur. $5,12,13$

Specific skills training addresses the improvement of specific functional tasks that are impaired due to cognitive deficits. An impaired functional task is trained using repetitive practice in its functional context. ${ }^{12,14}$ For example, instead of training a patient to repeat lists of words, memory training can focus on teaching the patient the names of therapists who are involved in the rehabilitation programme. Transfer of treatment effects is unlikely to occur in specific skills training. ${ }^{12}$ Therefore, it could be argued that this approach is not the preferred type of cognitive training. However the use of specific skills training could be valuable in patients who do not have the ability to transfer knowledge to new 
tasks or settings. By using specific skills training, these patients can be taught to carry out limited tasks that do not need to be transferred.12

Substitution, or cognitive strategy training, refers to a treatment method aimed at teaching patients new, general ways to handle problems in everyday life, resulting from a cognitive impairment. ${ }^{15}$ This type of therapy is based on the assumption that restoration of cognitive functions to their pre-injury structure and efficiency is not expected to occur and that therefore, rehabilitation should aim at teaching the use of compensatory strategies. ${ }^{16}$ Compensation is achieved by changing the patients' behaviours; patients are taught to use external or internal strategies and techniques to reach their goals in alternative ways. A 'cognitive prosthesis' like a notebook that is used as a memory aid is an example of the application of an external strategy. In addition people can be encouraged to use their residual, internal skills more efficiently. ${ }^{15}$ For example, instead of repeatedly practicing the patient's memory of the names of people involved in the rehabilitation programme, a patient can be taught to write down the names in a notebook. In addition the patient could be encouraged to use internal compensation by applying rehearsal strategies or mnemonics.

Strategy training is a widely used treatment method that has proven to be effective in the rehabilitation of various cognitive deficits such as memory, executive functioning and apraxia; after training, the performance of trained tasks in the training situation shows significant improvement.6,7 In addition, it is often stated that the occurrence of transfer is expected in strategy training, as a strategy is not task specific, but relies on more general principles and hence, should be applicable in different tasks and settings. ${ }^{17}$ However, Cicerone et al. point out that relatively few studies have tried to evaluate the occurrence of transfer of cognitive strategy training by directly evaluating the transfer of treatment effects to everyday situations or behaviours. ${ }^{6,7}$

\section{Apraxia and strategy training}

Apraxia is a cognitive impairment causing an inability to carry out learned and meaningful tasks. This inability cannot be explained by primary motor or sensory impairments, nor by deficits in motivation, memory or comprehension. ${ }^{18}$ It is one of the more common cognitive consequences of stroke and like aphasia, apraxia usually occurs following left hemisphere lesions. ${ }^{19}$ Approximately half of all strokes is left sided.20,21 Apraxia is reported to be present in 30 to $50 \%$ of all left sided stroke patients. ${ }^{18,22,23}$ In literature, two general types of apraxia can be distinguished. Ideational apraxia relates to a problem affecting the concept of task performance. The action plan that is needed to perform a task is absent or disrupted, resulting in the fact that the patient does not know what to do. ${ }^{18}$ In ideomotor apraxia, the internal concept of task performance is intact, but the conversion of this action plan into the proper mode of action is disturbed. As a result, the patient does know what to do, but does not know how to do it. 18

Both types of apraxia can have a severely disabling effect on the performance of activities of daily living (ADL), causing a negative impact on everyday life. If apraxia is present after stroke, addressing this impairment is therefore an important part of the rehabilitation programme.24-28 In addition, transfer of 
training effects should occur in order for patients with apraxia to function as independently as possible in their own environments

In rehabilitation practice in the Netherlands, apraxia training is administered by occupational therapists, using a standardised therapy programme that aims to teach patients strategies to compensate for the presence of apraxia. The main principle of this programme is to maximise the patients' independent functioning by improving ADL performance, while little change is expected in the severity of the apraxia itself. By means of this programme the patient is gradually taught to use more efficient and more independent strategies. ${ }^{28}$ The effectiveness of the intervention programme has been demonstrated in a noncontrolled intervention study ${ }^{28}$ and in an experimental effect study. ${ }^{24}$ Both studies showed that independent performance of ADL tasks improved significantly after strategy training. However, in these studies ADL functioning on trained tasks was observed in the rehabilitation setting. To further assess the effectiveness of this therapy programme, evaluation of transfer of treatment effects is essential.

\section{Objective and research questions of this thesis}

The main objective of this thesis is to evaluate the occurrence of transfer of treatment effects in cognitive strategy training for stroke patients. Both transfer from trained to non-trained tasks and transfer from the rehabilitation setting to the patients' own homes will be evaluated.

The first research question to be answered is: does transfer of training occur in cognitive rehabilitation after stroke? In this thesis, transfer will be addressed in several ways. Literature will be reviewed to evaluate the current state of the assessment of transfer in cognitive rehabilitation. Next, the occurrence of transfer effects of a specific cognitive strategy training - the apraxia trainingwill be assessed.

In addition, the following research question will be addressed: what is the effect of the environment on task performance in healthy adults? In transfer of rehabilitation effects from the training situation to the home setting, stroke patients will have to deal with a change in setting. The way in which healthy adults function in such a situation is not known, although this could provide valuable information for rehabilitation practice. Therefore, we will address this issue in the present thesis.

The final questions to be answered relate to several aspects of apraxia: what is the prevalence of apraxia in a rehabilitation setting and is apraxia associated with other cognitive deficits? These questions are answered by using the apraxia test for which the following question was formulated: is the apraxia test reliable in terms of inter-rater agreement? To facilitate the assessment of transfer effects of the apraxia training, these aspects of apraxia and the apraxia test are presented. In addition, the training itself is addressed by answering the question: what are the underlying theories and specific elements comprising the cognitive strategy training for apraxia? To answer this question a description of the strategy training programme for stroke patients with apraxia is included in this thesis. 


\section{Outline of this thesis}

Chapter 2 presents a study evaluating the association between apraxia and other cognitive deficits. In addition, this study assesses the prevalence of apraxia in a rehabilitation setting, and the inter-rater reliability of the apraxia test that was used to diagnose the patients who participated in the effect studies described in chapters 5 and 6.

Chapter 3 provides an overview of the occupational therapy guideline for assessment and treatment of apraxia following left hemisphere stroke; the cognitive strategy training that was evaluated in the effect studies described in chapters 5 and 6.

Chapter 4 summarises the results of a critical literature review on the measurement and the occurrence of transfer in cognitive strategy training. The aim of this review is to evaluate whether and how previous studies measured transfer and whether transfer to everyday situations and behaviours has been found to occur.

Chapter 5 presents an exploratory study to investigate transfer of treatment effects of the strategy training for stroke patients with apraxia. In this study, transfer from trained to non-trained tasks is investigated, using data previously collected in the randomised clinical trial that evaluated the efficacy of this cognitive strategy training. 24

Chapter 6 describes a prospective effect study assessing the occurrence of transfer of treatment effects of the strategy training for stroke patients with apraxia. The occurrence of both transfer from the rehabilitation setting to the patients' homes and transfer from trained to non-trained tasks is evaluated. In addition, lasting transfer effects of the apraxia treatment programme are examined at the patients' own homes.

Chapter 7 presents the results of a study investigating the environment effects in the performance of daily tasks in healthy adults. The influence of the environment on task performance is essential in rehabilitation. Patients learn how to function independently in a rehabilitation setting, but after discharge they will have to be able to transfer these skills to other environments. In order to gain more insight in transfer of treatment effects in stroke patients, the influence of a change of settings on task performance in healthy middle aged adults is assessed.

Chapter 8 reflects the joined discussion of the results of the studies described in this thesis. In addition, methodological issues of the studies are addressed and both theoretical implications and recommendations for clinical practice are provided. 


\section{References}

1. Struijs JN, van Genugten ML, Evers SM, Ament AJ, Baan CA, van den Bos GA. Modeling the future burden of stroke in the Netherlands: Impact of aging, smoking, and hypertension. Stroke 2005;36(8):1648-55.

2. Dutch heart Foundation. Fact sheet beroerte 2006 [Fact sheet stroke 2006]. The Hague: Dutch Heart Foundation; 2006.

3. van den Bos GAM. The burden of chronic diseases in terms of disability, use of health care and healthy life expectancies. Eur J Public Health 1995;5(1):29-34

4. Evers SMAA, Struijs JN, Ament AJHA, van Genugten MLL, Jager JC, van den Bos GAM. International comparison of stroke cost studies. Stroke 2004;35(5):1209-15.

5. Wilson BA. Cognitive rehabilitation: How it is and how it might be. $\mathrm{J}$ Int Neuropsychol Soc 1997;3(5):487-96.

6. Cicerone KD, Dahlberg C, Kalmar K, Langenbahn DM, Malec JF, Bergquist TF, et al. Evidencebased cognitive rehabilitation: Recommendations for clinical practice. Arch Phys Med Rehabil 2000;81(12):1596-615.

7. Cicerone KD, Dahlberg C, Malec JF, Langenbahn DM, Felicetti T, Kneipp S, et al. Evidence-based cognitive rehabilitation: Updated review of the literature from 1998 through 2002. Arch Phys Med Rehabil 2005;86:1681-92.

8. Marini A, Genereux R. The challenge of teaching for transfer. In: McKeough A, Lupart J, Marini A, editors. Teaching for transfer: Fostering generalization in learning. Mahwah: Lawrence Erlbaum Associates; 1995. p. 1-20.

9. Haskell RE. Transfer of learning: Cognition, instruction, and reasoning. San Diego: Academic Press; 2001.

10. Byrnes JP. Cognitive development and learning in instructional contexts. Boston: Allyn and Bacon; 1996.

11. Commissie CVA-revalidatie. Revalidatie na een beroerte: Richtlijnen en aanbevelingen voor zorgverleners [Rehabilitation after stroke: Guidelines and recommendations for clinical practice]. The Hague: Dutch Heart Foundation; 2001.

12. Berg I, Schmidt I. Cognitive rehabilitation of memory disorders. In: Brouwer WH, van Zomeren AH, Berg I, Bouma A, de Haan EHF, editors. Cognitive Rehabilitation: A clinical neuropsychological approach. Amsterdam: Boom; 2002. p. 141-165.

13. Robertson IH. Does computerised cognitive rehabilitation work? A review. Aphasiology 1990;4:381-405.

14. Sohlberg MM, Mateer CA. Introduction to cognitive rehabilitation: Theory and practice. New York: Guilford; 1989.

15. Fasotti 1, Kovacs F. Slow information processing and the use of compensatory strategies. In: Chamberlain MA, editor. Traumatic brain injury rehabilitation: Services, treatments and outcomes. London: Chapman \& Hall; 1995.

16. Wilson BA. Compensating for cognitive deficits following brain injury. Neuropsychol Rev 2000;10(4):233-43.

17. Ben-Yishay Y, Diller L. Cognitive remediation in traumatic brain injury: Update and issues. Arch Phys Med Rehabil 1993;74:204-13.

18. De Renzi E. Apraxia. In: Boller F, Grafman, J, editors. Handbook of Neuropsychology. Amsterdam: Elsevier Science Publishers B.V.; 1989. p. 245-263.

19. Basso A, Capitani E, Della Sala S, Laiacona M, Spinnler H. Ideomotor apraxia: a study of initial severity. Acta Neurol Scand 1987;76(2):142-6.

20. van de Port IGL, Kwakkel G, Schepers VPM, Lindeman E. Predicting mobility outcome one year after stroke: A prospective cohort study. J Rehabil Med 2006;38(4):218-23. 
21. Madureira S, Guerreiro M, Ferro JM. Dementia and cognitive impairment three months after stroke. Eur J Neurol 2001;8(6):621-7.

22. Barbieri C, De Renzi E. The executive and ideational components of apraxia. Cortex 1988;24(4):535-43.

23. Donkervoort M, Dekker J, van den Ende E, Stehmann-Saris JC, Deelman BG. Prevalence of apraxia among patients with a first left hemisphere stroke in rehabilitation centres and nursing homes. Clin Rehabil 2000;14:130-6.

24. Donkervoort M, Dekker J, Stehmann-Saris JC, Deelman BG. Efficacy of strategy training in left hemisphere stroke patients with apraxia: A randomized clinical trail. Neuropsychol Rehabil 2001;11(5):549-66.

25. Foundas AL, Henchey R, Gilmore RL, Fennell EB, Heilman KM. Apraxia during Wada testing. Neurology 1995;45(7):1379-83.

26. Goldenberg G, Hagmann S. Therapy of activities of daily living in patients with apraxia. Neuropsychol Rehabil 1998;8(2):123-41.

27. van Heugten CM. Rehabilitation and management of apraxia after stroke. Rev Clin Gerontol 2001;11:177-84.

28. van Heugten CM, Dekker J, Deelman BG, van Dijk AJ, Stehmann-Saris JC, Kinebanian A. Outcome of strategy training in stroke patients with apraxia: a phase II study. Clin Rehabil 1998;12(4):294-303. 
Chapter 2

Assessment of Apraxia: inter-rater reliability of a new apraxia test, association between apraxia and other cognitive deficits and prevalence of apraxia in a rehabilitation setting

Published in:

Clinical Rehabilitation 2004; 18(7): 819-827

A. Zwinkels, C. Geusgens, P. van de Sande, C. van Heugten 


\begin{abstract}
Objective: To investigate the inter-rater reliability of a new apraxia test. Furthermore to examine the association of apraxia with other neuropsychological impairments and the prevalence of apraxia in a rehabilitation setting on the basis of the new test.

Design: Cross-sectional cohort study, involving 100 patients with a first stroke admitted to a rehabilitation centre in the Netherlands.

Measures: General patients characteristics and stroke related aspects. Cognitive screening involving apraxia, visuospatial scanning, abstract thinking and reasoning, memory, attention, planning and aphasia.

Results: The indices for inter-rater agreement range from excellent to poor. Significant correlations are found between apraxia and visuospatial scanning, memory, attention, planning and aphasia. The group of patients with apraxia performs significantly worse than the patients without apraxia on memory, the time needed to complete the tests for scanning and attention, and aphasia. The prevalence of apraxia is $25.3 \%$ in the total group, $51.3 \%$ in the left hemisphere stroke patients and $6.0 \%$ in the right hemisphere stroke patients. Patients with and without apraxia do not differ significantly concerning age, gender and type of stroke.

Conclusion: The apraxia test has been shown to be a reliable instrument. Apraxia is often associated with aphasia, memory problems and mental slowness. This study shows that on the basis of the apraxia test, the prevalence of apraxia among patients in the rehabilitation centre is high, especially among patients with left hemisphere lesions.
\end{abstract}




\section{Introduction}

Apraxia is one of the more frequent consequences following brain damage which can lead to severe disabilities in daily life. ${ }^{1,2,3}$ The term apraxia covers a spectrum of disorders affecting the purposeful execution of learned and meaningful skills. ${ }^{2}$ It is mostly found in stroke patients, but the deficit is also seen in patients with Alzheimer's disease, ${ }^{4,5}$ corticobasal degeneration 6 and Huntington's disease ${ }^{7}$. Apraxia usually occurs following left hemisphere lesions, and was first noticed by Liepmann ${ }^{8}$ who found approximately $50 \%$ of the left hemisphere patients in his study to be apraxic, while none of the right hemisphere patients had apraxia. Liepmann concluded that the left hemisphere is dominant for the organisation of motor control. Later studies confirmed this claim. In a study conducted by De Renzi and his colleagues ${ }^{9}, 50 \%$ of the left brain damaged patients and $20 \%$ of the right brain damaged patients were classified as apraxic. Apraxia can be associated with aphasia, for which the left hemisphere is also dominant. A correlation of 0.40 between apraxia and aphasia has been found.10,11 This association is most likely to be due to the fact that contiguous structures are involved.2,12

Despite the fact that apraxia seems to be one of the more frequent impairments after stroke, the exact prevalence is not known. The studies mentioned above are some of the rare studies found in the literature on the occurrence of apraxia. In a paper by Donkervoort, Dekker, van den Ende, Stehmann-Saris and Deelman ${ }^{13}$ a review on the prevalence of apraxia yielded only 10 studies, which mainly concerned heterogeneous and selected, rather small, patient groups. Donkervoort and her colleagues conclude that the reliability and validity of the prevalence estimates are limited and therefore present a new study on the prevalence of apraxia. The rates they found were $28 \%$ among patients with a left hemisphere stroke in rehabilitation centres and $37 \%$ in nursing homes. As in most studies however, the diagnosis of apraxia relied on clinical judgement, in the absence of standardised tests. The presence of apraxia was examined by the treating medical team based on a clear definition of apraxia. The validity of this clinical diagnosis can be questioned as the team can overestimate the cases with apraxia, or cases can be missed.

Recently a test for apraxia was developed, which can be used to objectify and support the clinical diagnosis. In an earlier study the internal consistency and diagnostic value of this new apraxia test were investigated and have shown to be good. ${ }^{14}$ In the present study the inter-rater reliability of this new test will be reported, because this is an important aspect of the quality of the test for use in clinical practice. In addition, the association of apraxia with other cognitive functions will be explored in order to gain more insight into potential cognitive profiles. Finally, the prevalence of apraxia in a rehabilitation setting is investigated on the basis of the new test. 


\section{Methods}

\section{Patients}

All patients consecutively admitted to the stroke unit of a rehabilitation centre, with a first stroke were eligible for the study, starting May 2000. Stroke patients were excluded on the basis of the following criteria: presence of other central neurological lesions or dementia before the current stroke, addiction to alcohol, drugs or medication, insufficient physical fitness to perform the cognitive screening, psychiatric disturbances interfering with neuropsychological testing, insufficient knowledge of the Dutch language or severe aphasia.

All patients received verbal and written information about the study and gave written consent to participate. The research protocol was approved by the local medical ethical committee.

\section{Assessments}

The presence of apraxia was established on the basis of an apraxia test. ${ }^{14}$ This short and simple test consists of two subtests. The first subtest was designed to evaluate the use of objects, thereby assessing ideational apraxia. Three sets of objects are presented to the patient with the same instruction: 'show me how you would use. $\therefore$ Each set contains three objects used in daily activities. The first set (key, saw and toothbrush) is presented only by verbal request, without the object present. The second set (spoon, hammer and scissors) is presented visually, with the object present. The third set (eraser, comb and screwdriver) can actually be used by the patient. The second subtest involves the assessment of the ability to imitate gestures, aiming at ideomotor apraxia. This part of the test consists of the following six gestures which have to be imitated immediately upon demonstration by the testing assistant: sticking out one's tongue, blowing out a candle, closing one's eyes, waving goodbye, saluting and making a fist. To avoid interference of motor or sensory impairments, the patient uses the healthy (i.e. non-affected) hand. The scoring procedure is as follows: 3 points for a correct and appropriate performance, 2 points for a performances which resembles the correct one but is imprecise or involves using a body part as an object, 1 point for only weak resemblance to the correct performance or a performance executed in the wrong place, and 0 points for a performance which is incorrect or not recognisable. If the performance is correct at the first trial, six points are given; if the performance is not correct, a second attempt is offered and the two scores are added. This way a maximum of 6 points per item, 54 for the subtest demonstration, 36 for the subtest imitation, and a maximum of 90 for the total test is generated. The quality of the apraxia test is good in terms of the internal consistency (Cronbach's alpha=0.96; Mokken coefficient of scalability $\mathrm{H}=0.72$; Mokken coefficient of reliability $\mathrm{Rho}=0.96)$ and the diagnostic value: the apraxia test is sufficiently discriminative to allow a differentiation between persons with apraxia and persons without apraxia (sensitivity and specificity higher than $80 \%) .{ }^{14}$ 
A Dutch letter cancellation test is used to investigate the visuospatial scanning ability of the patient. ${ }^{15}$ These tests are the most sensitive in measuring the presence of neglect. ${ }^{16}$ A piece of paper with many letters in an unstructured, chaotic pattern is presented. The patient has to locate and mark the letter $O$. The number of omissions in each visual field is scored, as well as the time needed to complete the test.

Raven's Coloured Progressive Matrices (RCPM) is a non-verbal visual test which can be used to assess the ability of abstract thinking and reasoning. ${ }^{17}$ The test consists of a set of 36 visual patterns of which one part is missing. The patient has to choose the correct piece of pattern from a set of six alternatives. The score range of the RCPM is 0 to 36 .

Memory performance was evaluated using the Rivermead Behavioural Memory Test (RBMT). 18,19,20 The RBMT is an ecologically valid memory test providing information about the effect of the memory impairment on the patient's daily life. The test consists of tasks such as remembering an appointment or a name, finding a route, and orientation in time and place. The performance of the patient can be scored on a dichotomous scale or on a three-point scale; this respectively counts up to a screening score (maximum 12) or a profile score (maximum 24).

Attention was assessed using the Trail Making Test, part A and B (TMT). ${ }^{21}$ Performance on this test generates information about the motor speed, visual scanning and flexibility/capacity of attention. In part A the patient has to connect 25 numbers by drawing lines between the numbers counting forward. In part B numbers and letters (in alphabetical order) have to be connected pairwise. The time the patient needs to complete the task is scored in seconds.

The Tower of London Test (TLT) is developed to assess the ability of planning. ${ }^{22,23}$ The patient receives a little board with three sticks and three coloured dice, placed in a starting position. A picture of a new configuration is shown and the patient has to replace the dice into the new position; the number of steps needed is told beforehand. In total 12 configurations are tested, each being more difficult. The number of attempts is scored in a reverse order (less attempts gives a higher score representing better performance); the maximum score is 36 .

The Token Test was used to measure language impairments; it is a subtest of the Aachen Aphasia Test. ${ }^{24}$ The test consists of a series of pictures with triangles and squares of different colours and sizes, which have to be selected by the patient upon verbal request by the examiner. The test is one of the most sensitive tests to differentiate between brain damaged patients with and without aphasia. A score of five or more denotes the presence of aphasia in our study.

\section{Procedure}

Within the first three weeks upon admission to the stroke unit of the rehabilitation centre, all stroke patients were screened for cognitive, emotional and behavioural problems. This cognitive screening consists of performance on a set of neuropsychological tests, behavioural observations by the therapists and nurses of the rehabilitation team, and an interview by the psychologist, also involving 
the caregiver. In this paper only the neuropsychological screening is considered. On providing consent to participate in the study, patients were screened on all cognitive assessments. Each patient was assessed by a neuropsychological assistant and a speech therapist (for the Token test) in a quiet room. On average, it took one and a half hours to complete.

The first 45 patients agreed to have two observers present during the performance on the apraxia test. In total five different raters conducted the pairwise observations; all of these raters were neuropsychological assistants working at the stroke unit. The two raters observed simultaneously, but scored their findings independently in order to establish the inter-rater reliability of the apraxia test. One of the two raters had access to the medical records beforehand because this assistant performed the complete cognitive screening.

\section{Statistical analyses}

Beforehand, a calculation was conducted to establish the number of patients needed for the reliability study: based on an expected correlation coefficient of 0.8 to be reliable, a significance level of 0.05 and a power of 0.90 , at least 30 patients were needed. The inter-rater reliability is expressed in three ways. First, the percentage of agreement was calculated which equals the number of cases for which the observers fully agree, proportional to the total number of cases. Second, Cohen's kappa 25 is calculated to account for agreement by chance. The intra-class correlation coefficient (ICC) is calculated, because it is more appropriate for determining the reliability of sumscores. The ICC is defined as the ratio of the variance among subjects over the total variance. A kappa or ICC below 0.40 is considered to indicate little agreement, between 0.41 and 0.60 indicates moderate agreement, between 0.61 and 0.80 indicates good agreement, and a kappa or ICC higher than 0.81 indicates almost perfect agreement. $26,27,28$

The performance on the test of apraxia and the other cognitive tests is presented by mean scores and standard deviations. Bivariate relationships between apraxia and the other cognitive functions are expressed by means of Pearson's product moment correlation coefficients.

On the basis of a cut-off point of 86 , the total group is divided into a group of patients with apraxia and a group of patients without apraxia. This cut-off point was based on earlier research concerning the diagnostic value of the test. ${ }^{14}$ Next, the differences on the cognitive tests between the groups are determined using t-tests for independent samples. Significance was set at 0.05. Analyses were performed using SPSS 11.0 for Windows.

\section{Results}

\section{Patients}

A total of 100 stroke patients was included in the study on the basis of the criteria during a period of two years; the first 45 patients were enrolled in the 
study of the inter-rater reliability of the apraxia test. Thirty patients were excluded on the basis of other neurological disorders $(\mathrm{N}=8)$, insufficient physical fitness $(\mathrm{N}=6)$, insufficient knowledge of the Dutch language $(\mathrm{N}=4)$, severe aphasia $(\mathrm{N}=5)$, or refusal to participate $(\mathrm{N}=7)$. The characteristics of the patients are shown in table 1 . The two subgroups of patients are comparable on all characteristics.

Table 1: Characteristics of patients

\begin{tabular}{|c|c|c|c|}
\hline & Total group & $\begin{array}{l}\text { Subgroup } \\
\text { Reliability study }\end{array}$ & Other participants \\
\hline & $\mathrm{N}(\%)$ & $\mathrm{N}(\%)$ & $\mathrm{N}(\%)$ \\
\hline Number & 100 & 45 & 55 \\
\hline \multicolumn{4}{|l|}{ Gender } \\
\hline Male & $63(63)$ & $29(64.4)$ & $34(61.8)$ \\
\hline Female & 37 (37) & $16(35.6)$ & $21(38.2)$ \\
\hline \multicolumn{4}{|l|}{ Type of stroke } \\
\hline Haemorrhage & $25(25)$ & $11(24.4)$ & $14(25.5)$ \\
\hline Infarction & $75(75)$ & $34(75.6)$ & $41(74.5)$ \\
\hline \multicolumn{4}{|l|}{ Location of stroke } \\
\hline Left hemisphere & $40(40)$ & $17(37.8)$ & $23(41.8)$ \\
\hline Right hemisphere & $50(50)$ & $23(51.1)$ & $27(49.1)$ \\
\hline Otherwise $^{1}$ & $10(10)$ & $5(11.1)$ & $5(9.1)$ \\
\hline \multicolumn{4}{|l|}{ Hand of preference } \\
\hline Right & 95 (95) & $42(93.3)$ & $53(96.4)$ \\
\hline Left & $5(5)$ & $3(6.7)$ & $2(3.6)$ \\
\hline Age $^{2}$ & $57.1(10.6 ; 23-75)$ & $58.0(10.9 ; 31-75)$ & $56.4(10.3 ; 23-73)$ \\
\hline Time since stroke $\mathrm{e}^{2,3}$ & $34.0(14.9 ; 12-83)$ & $32.9(14.2 ; 13-83)$ & $34.9(15.5 ; 12-81)$ \\
\hline
\end{tabular}

${ }_{1}^{1}$ Otherwise: basal ganglia, brain stem or both hemispheres.

2 For age and time since stroke, the mean, standard deviation and range are presented.

${ }^{3}$ Time since stroke: number of days between stroke and admission to the rehabilitation centre.

Table 2: Inter-rater reliability

\begin{tabular}{llll}
\hline & \% agreement & Kappa & ICC \\
\hline Demonstration & & & \\
Key & 95.6 & 0.69 & 0.97 \\
Saw & 97.8 & 0.90 & 0.97 \\
Toothbrush & 84.4 & 0.33 & 0.87 \\
Spoon & 80.0 & 0.42 & 0.79 \\
Hammer & 88.9 & 0.61 & 0.77 \\
Scissors & 82.2 & 0.66 & 0.88 \\
Eraser & 100 & 1.00 & 1.00 \\
Comb & 100 & 1.00 & 1.00 \\
Screwdriver & 97.8 & 0.82 & 0.99 \\
Imitation & & & 0.33 \\
Blow out candle & 93.3 & 0.36 & 0.80 \\
Closing eyes & 97.8 & 0.71 & 1.00 \\
Waving goodbye & 100 & 1.00 & 0.80 \\
Sticking out tongue & 97.8 & 0.71 & 0.59 \\
Saluting & 91.1 & 0.31 & 1.00 \\
Making a fist & 100 & 100 & 0.97 \\
Sumscore demonstration & - & - & 0.64 \\
Sumscore imitation & - & - & 0.96 \\
Total scale & - & - & \\
\hline ICC: & & &
\end{tabular}

ICC: intra-class correlation coefficient 


\section{Inter-rater reliability}

In table 2 the level of agreement among two observers, as indicated by percentages of agreement, Cohen's kappa and intra-class correlation coefficients, is shown. These data are based on the subgroup of 45 pairwise observations. All percentages of agreement for the separate items of the test are above $60 \%$, indicating satisfactory to good agreement. Correcting for chance, it appears that three items have a kappa value indicating poor reliability: demonstrating a toothbrush, blowing out a candle and saluting. One item has a kappa between 0.41 and 0.60; the other items have a kappa above 0.60. Looking at the ICC values, two items show moderate agreement. The ICC for the sumscores are satisfactory to very good: 0.97 for the demonstration sumscore, 0.64 for the imitation sumscore and 0.96 for the total scale.

\section{Association with other cognitive impairments}

Correlations between apraxia and the other cognitive domains on the basis of the total group of patients are shown in table 3. Significant relationships are found between apraxia and the scores on the Token test, the letter cancellation test (omissions right and time), the RBMT, the Tower of London, and the TMT, part A.

Table 3: Correlations between apraxia and the other cognitive tests

\begin{tabular}{lll}
\hline & N & Apraxia test \\
\hline Letter cancellation & & \\
$\quad$ Omissions left & 96 & -0.03 \\
Omissions right & 95 & $-0.270^{* *}$ \\
Time & 97 & $-0.232^{*}$ \\
Ravens Coloured Progressive Matrices & 97 & -0.021 \\
Rivermead Behavioural Memory Test & & \\
$\quad$ Screening score & 90 & $0.306^{* *}$ \\
Profile score & 90 & $0.388^{* *}$ \\
Trial Making Test & & \\
$\quad$ Part A & 95 & $-0.428^{* *}$ \\
$\quad$ Part B & 64 & -0.092 \\
Tower of London Test & 92 & $0.291^{* *}$ \\
Token test & 93 & $-0.699^{* *}$
\end{tabular}

$\mathrm{N}$ : number of subjects

* $\mathrm{p}=0.05 ; * * \mathrm{p}=0.01$; two-tailed significance

In table 4 the scores on the neuropsychological tests are shown for the total group and for the groups of patients with and without apraxia separately. Patients with apraxia perform worse on most tests in comparison to patients without apraxia and the total group. The differences between patients with and without apraxia are significant for the amount of time needed to complete the letter cancellation test $(t=2.13 ; p=0.04)$, the RBMT screening and profile scores $(\mathrm{t}=4.12 ; \mathrm{p}<0.01$ and $\mathrm{t}=4.79 ; \mathrm{p}<0.01$ respectively), the TMT part $\mathrm{A}(\mathrm{t}=2.38$; $\mathrm{p}=0.03)$ and the Token test $(\mathrm{t}=5.07 ; \mathrm{p}<0.01)$. 
Table 4: Scores on the neuropsychological tests for the total group and the patients with and without apraxia separately

\begin{tabular}{|c|c|c|c|c|c|c|}
\hline & \multicolumn{2}{|r|}{ Total group } & \multicolumn{2}{|c|}{ Patients with apraxia } & \multicolumn{2}{|c|}{ Patients without apraxia } \\
\hline & $\mathrm{N}$ & Mean (SD) & $\mathrm{N}$ & Mean (SD) & $\mathrm{N}$ & Mean (SD) \\
\hline \multicolumn{7}{|l|}{ Letter cancellation } \\
\hline Omissions left & 96 & $3.27(5.48)$ & 24 & $3.96(6.29)$ & 72 & $3.04(5.22)$ \\
\hline Omissions right & 95 & $1.57(3.20)$ & 24 & $3.00(4.54)$ & 71 & $1.08(2.54)$ \\
\hline Time & 96 & $201.14(114.43)$ & 24 & $243.58(128.64)$ & 73 & $187.19(106.66)$ \\
\hline RCPM & 97 & $26.52(6.51)$ & 23 & $25.49(6.07)$ & 74 & $26.86(6.63)$ \\
\hline \multicolumn{7}{|l|}{ RBMT } \\
\hline Screening score & 90 & $7.11(3.49)$ & 20 & $4.50(2.57)$ & 70 & $7.86(3.37)$ \\
\hline Profile score & 90 & $15.84(5.91)$ & 20 & $10.85(4.89)$ & 70 & $17.27(5.39)$ \\
\hline \multicolumn{7}{|l|}{ TMT } \\
\hline Part A & 95 & 112.88 (107.79) & 23 & $179.43(173.12)$ & 72 & $91.63(64.82)$ \\
\hline Part B & 64 & 200.14 (130.44) & 6 & 223.67 (129.66) & 58 & $197.71(131.41)$ \\
\hline Tower of London & 92 & $27.99(4.52)$ & 20 & 26.25 (5.39) & 72 & 28.47 (4.16) \\
\hline Token test & 93 & 8.58 (12.56) & 20 & 23.95 (16.95) & 73 & $4.37(6.48)$ \\
\hline
\end{tabular}

N: number of subjects; SD: standard deviation; RCPM: Raven's Cloured Progressive Matrices; RBMT: Rivermead Behavioural Memory Test; TMT Trail Making Test

\section{Prevalence of apraxia}

The mean score on the apraxia test for the total group $(\mathrm{N}=99$; one patient could not complete the test) is 86.1 ( $\mathrm{SD}=7.8$; range 47-90). The patients with a stroke in the left hemisphere $(\mathrm{N}=39)$ have a mean of $82.1(\mathrm{SD}=11.0$; range 47-90), while the right hemisphere stroke patients $(\mathrm{N}=50)$ have a mean of $88.9(\mathrm{SD}=2.1$; range 79-90). This difference is significant $(t=4.29 ; \mathrm{p}<0.01)$.

The prevalence of apraxia was based on the number of patients scoring below the cut-off point of 86 . A total of 99 patients performed the apraxia test: 25 of them scored below 86 . This equals $25.3 \%$. When the patients with apraxia $(\mathrm{N}=25)$ and without apraxia $(\mathrm{N}=74)$ are compared, there are no significant difference in age, gender or type of stroke. Considering the patients with a stroke in the left hemisphere $(\mathrm{N}=39)$, it appears that $51.3 \%(\mathrm{~N}=20)$ has apraxia. In the group of patients with a right hemisphere stroke $(\mathrm{N}=50)$, only three scored below the cut-off point $(6.0 \%)$. The group of patients with a stroke in both hemispheres, or in other areas of the brain $(\mathrm{N}=10)$ demonstrates a prevalence rate of $20 \%$.

\section{Discussion}

In the present study the inter-rater reliability of a new apraxia test was determined. Furthermore, the association between apraxia and other cognitive impairments and the prevalence of apraxia in a rehabilitation setting was examined.

The apraxia test has shown to be a reliable instrument; the indices for agreement of the sumscores are satisfactory to very good. The kappa values however, ranged from excellent to poor. Three items of the test had a low kappa value: demonstrating the use of a toothbrush, blowing out a candle, and saluting. For these items the instructions for observation are now supplemented with 
additional observational cues. For instance, the way the hand has to be positioned on the forehead when saluting, is described in more detail. These additions were provided by the neuropsychological assistants who used the test in this study.

Furthermore, the association of apraxia with other cognitive impairments was examined. Concerning the cognitive measurements, it should be noted that on some of the tests, motor performance is requested (i.e. drawing lines, replacing dice). Since apraxia involves motor behaviour, these results can be confounded. However, one of our earlier studies on the apraxia test showed only weak relationships with motor functioning. ${ }^{37}$ Apraxia was found to be correlated with aphasia, memory, and mental speed. The strong relationship of apraxia with aphasia has been shown in other studies before, albeit not as strong as we found. 10,11,32 The association between the two impairments is most probably due to the fact that contiguous structures are involved.2,12 The relationship with memory and mental speed is less obvious in the literature. However, both impairments occur frequently in stroke patients. ${ }^{33,34}$ In a recent study concerning patients with traumatic brain injury, it was found that mental speed determines the performance on attention tests; 35 in other words, it can be argued that speed of information processing is a more global impairment which frequently occurs and interferes with test performance.

The prevalence of apraxia was high among patients with a left hemisphere stroke: more than half of the patients in this study has apraxia. The prevalence among right hemisphere patients was considerably smaller. This finding confirms earlier results. $8,9,10,19,30,31$ In comparison to the study by Donkervoort 13 we found higher rates, which might be an indication of an underestimation of apraxia on the basis of clinical judgment in their study. Parallel to the study of Donkervoort, we also did not find a relationship between the prevalence of apraxia and patient characteristics such as gender, age and type of stoke.

This study has some limitations. One of the more evident limitations is the selected group of stroke patients recruited in only one rehabilitation centre. This design limits the generalisability of the results on the one hand; on the other hand, the characteristics of the patients in this study show that we did consider a rather representative population of stroke patients in rehabilitation. The prevalence rates are however potentially specific to the stroke unit because local admission criteria were used. A second limitation concerns the design of the study: we did not assess apraxia on the basis of different tests, which could have given us more information on the validity of our test. In a recent study Butler ${ }^{36}$ found poor relationships between several tests of apraxia, suggesting that not all apraxia tests are of comparable quality. These results were based on a very small number of patients $(\mathrm{N}=17)$. In an earlier study however, we did examine the diagnostic value of the apraxia test, which was good. ${ }^{14}$ In addition, the relationship between the apraxia test and standardised ADL-observations, measuring disabilities due to apraxia, was investigated in another study. ${ }^{37}$ Correlational and multivariate analyses showed that there was a strong association between these two measures as opposed to motor functioning and general measures of disabilities (i.e. Barthel Index). On the basis of these findings we 
recommended to diagnose apraxia not solely on the use of neuropsychological tests, but also on the basis of observation of the consequences of apraxia for daily life. In accordance, Butler ${ }^{36}$ argues that functional and behavioural indices in ADL-tasks should be considered as more clinically relevant than pure test scores.

Future research concerning the course of apraxia can now be initiated with this new test, whereby the patients are followed for a period of time, starting in the acute phase. This is important since apraxia has shown to be a persistent disorder which has negative consequences on ADL recovery. $30,38,39,40$ Prognostic factors should be identified.

\section{Conclusions}

A short and simple, reliable bedside test has become available to test the presence of apraxia. This test can be used to differentiate between patients with and without apraxia. Clinicians should be alert to the presence of apraxia after stroke since the prevalence rates have shown to be rather high, especially after left brain damage. Ideally, diagnosing apraxia should be done by combining the results of the apraxia test with observations of functioning in daily life tasks.

\section{Clinical messages}

Clinicians should be alert to the presence of apraxia after left hemisphere stroke. A short and simple, reliable bedside test for apraxia is now available and is recommended for use in clinical practice. Test scores should be combined with behavioural observations for a proper evaluation of apraxia and its consequences in daily life.

\section{Acknowledgements}

The authors would like to thank the psychological assistants Mieke Ploum, Marij Eussen, Henk Meurders and Basje Roberts, and the speech therapists Virginie Pielanen, Marie-Jeanne te Meij and Carine Crijns for helping with the data collection.

\section{References}

1. Bjorneby ER, Reinvang IR. Acquiring and maintaining self-care skills after stroke. The predictive value of Apraxia. Scand J Rehab Med 1985;17:75-80.

2. De Renzi E. Apraxia. In: Boller F, Grafman J, editors. Handbook of Neuropsychology. Amsterdam: Elsevier Science Publishers; 1989. p. 254-263.

3. Rothi LJG, Heilman KM. Apraxia: The neuropsychology of action. Hove: Psychology Press; 1997.

4. Taylor R. Motor Apraxia in dementia. Percept Mot Skills 1994;79:523-28. 
5. Ochipa C, Gonzalez-Rothi LJ, Heilman KM. Conceptual Apraxia in Alzheimer's disease. Brain 1992;115:1061-71.

6. Leiguarda R, Lees AJ, Merello M, Starkstein S, Marsden CD. The nature of apraxia in corticobasal degeneration. J of Neurol Neurosurg and Psych 1994;57:455-59.

7. Shelton PA, Knopman DS. Ideomotor Apraxia in Huntington's disease. Arch Neurol 1991;48:3541.

8. Liepmann H. Die Aufsatze aus dem Apraxiegebiet. Berlin: Krager; 1908.

9. De Renzi E, Motti F, Nichelli P. Imitating gestures: a quantitative approach to ideomotor apraxia. Arch Neurol 1980;37:6-18.

10. Kertesz A, Ferro JM. Lesion size and localisation in ideomotor apraxia. Brain 1984;107:921-33.

11. De Renzi E, Pieczuro A, Vignolo LA. Ideational Apraxia: A quantitative study. Neuropsychologia 1968;6:41-52.

12. Tate RL, McDonald S. What is apraxia: The clinician's dilemma. Neuropsychol Rehabil 1995;5(4):273-97.

13. Donkervoort M, Dekker J, van den Ende E, Stehmann-Saris JC, Deelman BG. Prevalence of apraxia among patients with a first left hemisphere stroke in rehabilitation centres and nursing homes. Clin Rehabil 2000;14:130-36.

14. van Heugten CM, Dekker J, Deelman BG, Stehmann-Saris JC, Kinebanian A. A diagnostic test for apraxia in stroke patients: Internal consistency and diagnostic value. Clin Neuropsychol 1999;13(1):1-11.

15. Beers K. Manual O-search test. Unpublished test manual. Hoensbroek: SRL.

16. Halligan PW, Robertson IH. The assessment of unilateral neglect. In Crawford JR, Parker DM, McKinlay WW, editors. A handbook of neuropsychological assessment. Hove, UK: Lawrence Erlbaum; 1994. p. 151-177.

17. Raven JC, Court JH, Raven J. Manual for Raven's Progressive Matrices and Vocabulary Scales. Section 1-7. JC Raven Ltd. London: HK Lewis \& Co Ltd.; 1984.

18. Wilson B, Cockburn J, Baddeley A. The Rivermead Behavioral Memory Test. Titchfield: Thames Valley Test Company; 1985.

19. Wilson BA, Cockburn J, Baddeley A, Hiorns R. The development and validation of a test battery for detecting and monitoring every day memory problems. J Clin Exp Neuropsychol 1989;11:85570 .

20. van Balen HGG, Groot-Zwaaftink AJM. Rivermead Behavioural Memory Test. Norms for the Netherlands and Belgium. Lisse: Swets \& Zeitlinger; 1987.

21. Lezak MD. Neuropsychological Assessment. 3 ed. New York: Oxford University Press; 2004.

22. Krikorian R, Bartok J, Gay N. Tower of London procedure: a standard method and developmental data. J Clin Exp Neuropsych 1994;16(6):840-50.

23. Philips LH, Wynn V, Gilhooly KJ, Della Sala S, Logie RH. The role of memory in the Tower of London Task. Memory 1999;7(2):209-31.

24. Graetz P, DeBleser R \& Willnes K. Aachen Aphasia Test. Dutch version. Lisse: Swets \& Zeitlinger; 1992.

25. Cohen J. A coefficient for agreement for nominal scales. Educ Psychol Meas 1960;20:37-46.

26. Landis JR \& Koch GG. The measurement of observer agreement for categorical data. Biometrics 1977;33:169-74.

27. Dunn G. Design and analysis of reliability studies. London: Edward Arnold; 1989.

28. Altman DG. Practical Statistics for medical research. London: Chapman \& Hall; 1991. 
29. Basso A, Faglioni P, Luzatti C. Methods in neuroanamotical research and an experimental study of limb Apraxia. In: Roy EA, editor. Neuropsychological studies of Apraxia and related disorders. Amsterdam: North-Holland; 1985.

30. Basso A, Capitani E, Della Sala S, Laiacona M, Spinnler H. Recovery from ideomotor apraxia: A study on acute stroke patients. Brain 1987;110:747-60.

31. Barbieri C, De Renzi E. The executive and ideational components of apraxia. Cortex 1988;4:53543.

32. Papagno O, Della Sala S, Basso A. Ideomotor Apraxia without aphasia and aphasia without apraxia: The anatomical support for a double dissociation. J Neurol Neurosurg Psychiatry 1993;56:286-89.

33. Tatemichi TK, Desmond DW, Stern Y, Paik M, Sano M, Bagiela E. Cognitive impairment after stroke: frequency, patterns, and relationship to functional abilities. J Neurol Neurosurg Psychiatry 1994;57:202-07.

34. Hochstenbach J, Mulder T, van Limbeek J, Donders R, Schoonderwaldt H. Cognitive decline following stroke: A comprehensive study of the cognitive decline following stroke. J Clin Exp Neuropsychol 1998;20:503-17.

35. Spikman J. Attention, mental speed and executive control after closed head injury: Deficits, recovery and outcome. Dissertation University of Groningen; 2001.

36. Butler JA. How comparable are tests of Apraxia? Clinical Rehabilitation 2002;16:389-98.

37. van Heugten CM, Dekker J, Deelman BG, van Dijk AJ, Stehmann-Saris JC, Kinebanian A. Measuring disabilities in stroke patients with apraxia: A validation study of an observational method. Neuropsychol Rehabil 2000;10(4):401-14.

38. Maher LM, Rayner AM, Foundas A, Rothi LJG, Heilman KM. Patterns of recovery in ideomotor Apraxia. Paper presented at the annual meeting of the International Neuropsychological Society. Cincinatti, OH.; 1994.

39. Poeck K. Clues to the nature of disruptions to limb praxis. In: Roy EA, editor. Neuropsychological studies of apraxia and related disorders. New York: North-Holland; 1985.

40. Foundas AL, Rayner AM, Maher LM, Rothi LJG, Heilman KM. Recovery in ideomotor Apraxia. J Clin Exp Neuropsychol 1993;15:44. 
Chapter 3

\section{Dridence-based OT guideline for assessment and treatment of apraxia in stroke patients}

Submitted for publication

C. Geusgens, C. van Heugten, J. Stehmann-Saris, J. Dekker 


\begin{abstract}
Background: Despite the high prevalence of apraxia after left hemisphere stroke and the limitations apraxia causes in the daily lives of stroke patients, in the literature not much attention had been paid to the treatment of patients with apraxia. We therefore developed a strategy training for apraxia in left hemisphere stroke patients, based on prevailing theories in neuropsychology and occupational therapy (OT) practice. In this paper the intervention will be described on the basis of the theoretical considerations and the evidence supporting the effectiveness of the intervention is summarised.

Principles illustrated: The strategy training for stroke patients with apraxia is based on models for human occupation, information processing and recovery after stroke. Task performance is divided in three phases of information processing: orientation, execution and control. Assessment and treatment are structured according to these phases.

Theory in practice: In three consecutive studies the effectiveness of the strategy training was established.

Conclusions: The OT guideline is an example of an evidence-based intervention which has been implemented successfully in Dutch OT practice. The intervention has shown to be effective in left hemisphere stroke patients with apraxia, but application of the intervention in other groups of patients experiencing similar problems in daily functioning is also possible.
\end{abstract}




\section{Introduction}

After stroke, patients can experience a wide range of physical, emotional and cognitive consequences, resulting in severe disability in everyday life. One of the more common cognitive consequences of stroke is apraxia. It is an impairment affecting the purposeful execution of learned and meaningful skills that cannot be explained by primary motor or sensory impairments, nor by deficits in motivation, memory or comprehension. ${ }^{1}$ Apraxia usually occurs following left hemisphere lesions and it is reported to be present in 30 to $50 \%$ of all left sided stroke patients. ${ }^{1-3}$ Literature generally distinguishes two types of apraxia. The first type, ideational apraxia, relates to a problem affecting the concept of task performance; the action plan that is needed to perform a task is absent or disrupted. In the second type, ideomotor apraxia, the internal concept of task performance is intact, but the conversion of this action plan into the proper mode of action is disturbed. ${ }^{1}$

Both types of apraxia can cause severe disabilities in the performance of activities of daily living (ADL), resulting in a negative impact on everyday life. 4,5 Furthermore, apraxia at the start of the rehabilitation period has been shown to predict a negative outcome in ADL functioning, one year after stroke. ${ }^{6}$ In addition, independent living one year post onset has been found to be negatively related to the presence of apraxia in the acute phase after stroke. ${ }^{7}$ If apraxia is present after stroke, addressing this impairment is therefore an important part of the rehabilitation programme. ${ }^{4,8-11}$

Van Heugten et al11 developed a standardised occupational therapy (OT) programme for left hemisphere stroke patients with apraxia, which has been implemented in Dutch rehabilitation practice. This programme aims to teach patients strategies to compensate for the presence of apraxia. The patients' independent functioning is maximised by improving ADL performance, while little change is expected in the severity of the apraxia itself. By means of the programme the patient is gradually taught to use more efficient and more independent strategies. The effectiveness of this programme has been demonstrated in three research studies. ${ }^{8,11,12}$ Based on the research findings and the experience of occupational therapists working with the guideline in clinical practice, various minor adaptations have been incorporated into the guideline by the School for Occupational Therapy of Amsterdam, and the guideline has been translated into English.

In this paper, the OT guideline for assessment and treatment of apraxia in stroke patients will be described. First, we will address the theories on which the treatment programme is based. Next, the methods of assessment and treatment will be presented and lastly, evidence for the effectiveness of the treatment programme, will be offered. 


\section{Theoretical background}

The procedure that is described in the OT guideline for assessment and treatment of apraxia in stroke patients is based on theories relating to several different fields of research, including occupational therapy, neurology, neuropsychology and rehabilitation medicine. Human occupation, as it is described in theories of OT, is the central theme in both the assessment and the treatment method presented in the guideline. Human occupation seeks to explain the occupational functioning of persons by describing how a person chooses, orders and performs in everyday occupational behaviour. ${ }^{13}$ During task performance a continuing interaction takes place between the task, the person that performs the task and the environment where the task is being performed. ${ }^{13,14}$

Theories on information processing during task performance as well as theories on recovery after stroke, and learning theories derived form rehabilitation research provide the theoretical basis of the guideline. These theories will be described more extensively.

\section{Information processing and task performance}

Prior and during task performance, people need to decide how to perform a task and how to proceed with this performance. These decisions are made based on sensory information that has to be perceived and processed. According to the framework of information processing, task performance is conceptualised as consisting of three consecutive phases that need to be completed properly in order to successfully carry out a task. ${ }^{15}$ These phases are the orientation, the execution and the control phase. In the orientation phase, people need to guide their attention to the sensory information related to the task at hand. They need to become aware of their environment, the objects that are present, and the task that they will be performing. The next step in this phase is to interpret all this information, and to combine it, in order to construct an internal concept of the task performance, specifically adjusted to the circumstances (e.g. the setting, the available objects and, if applicable, impairments) in which the task will be carried out. The internal concept consists of an action plan, describing organisation and planning of the use of the environment, objects and motor programmes, as well as an image of the preferred result of the task performance. In the execution phase, the second phase in task performance, the action plan will be carried out. Motor activities required for the task performance should be started, continued adequately and finished properly when the task has been completed. The motor actions should be smooth and the timing of the performance of the steps that make up the action plan should be appropriate. Objects should be handled adequately. In addition, an important topic in the execution phase is the use of adequate anticipatory behaviour, to prevent or control problems that might occur during task performance. The third phase of task performance, the control phase, requires people to focus their attention to the results of their actions. Both the process as well as the final result of the task performance needs to be registered, compared to the internal concept, judged, and corrected if necessary. Correcting the performance involves adapting the 
internal concept to the new situation, carrying out the new action plan, registering the results of the actions and again, if necessary correcting task performance. Thus, task performance is conceptualised as a cyclic process. By observing task performance, possible problems in information processing in the three distinctive phases can be detected.

\section{Recovery after stroke, strategy training and learning theories}

In the apraxia guideline, the term 'recovery' is used to describe the process of regaining independence in the performance of meaningful tasks, by using strategies to compensate for the disabilities due to the apraxia. Strategy training is an intervention type that is used to teach patients how to compensate for the problems resulting from their impairments. This type of intervention is based on the assumption that restoration of cognitive functions to their pre-injury structure and efficiency is not expected to occur and that therefore, rehabilitation should aim at teaching the use of compensatory strategies. ${ }^{16}$ Thus, the aim of a strategy training is to improve the disability (e.g. task performance), despite the lasting presence of the deficit (e.g. apraxia). Little improvement in the deficit itself is expected to occur.

A fundamental principle in strategy training is the use of peoples' strengths to compensate their weaknesses. Thus, when focussing on the improvement of impairments due to apraxia, other (cognitive) deficits that might be present in the patient should be taken into account as well, ensuring that the compensatory strategies will be attuned to individual patients as much as possible. A prerequisite for the use of strategy training is the patients' awareness of their impairments, since patients will not be motivated to change their behaviours if they do not recognise their functional difficulties. ${ }^{17}$ The patients' preserved cognitive functions and their awareness of their cognitive functioning (metacognition) are internal factors that influence the patients' capacity to learn new skills.

External factors that influence the learning process relate to the interventions that are used (in this guideline, the strategy training), the tasks that are used during training and the environment where the training takes place. Rehabilitation research has shown that patients are more motivated to learn a task if functional tasks are used that are relevant and meaningful to the patients and if the patients have chosen the tasks themselves. This provides better results compared to the situation in which the occupational therapists select the tasks that will be used during training. ${ }^{18}$ It is advisable to train functional tasks in their natural environment, as this environment might trigger old routines in task performance. This would suggest for example training bathing in the bathroom, as opposed to the training area at the OT department. In addition, if a patient is not expected to be able to transfer training effects, training should preferably take place in the setting where the patient is expected to be able to perform the tasks after discharge from the rehabilitation programme, e.g. the patient's own home. ${ }^{18}$ 


\section{Guideline for assessment and treatment of apraxia in stroke patients}

The guideline for assessment and treatment of apraxia in stroke patients does not impose rigid rules that should always be followed. Rather, it is meant to structure the various choices a therapist has to make while assessing and training stroke patients with apraxia. The guideline consists of an assessment instrument, the ADL observations, and a description of the process and contents of the strategy training.

\section{Assessment}

\section{Neuropsychological test}

Research has shown that the prevalence of apraxia in rehabilitation settings is underestimated if the diagnosis is made on clinical judgment alone. ${ }^{3}$ Therefore, we encourage including a neuropsychological apraxia test in the standard assessment battery for stroke patients. A short and simple test for apraxia is available and is recommended for use in clinical (rehabilitation) practice. The test consists of two subtests. The first evaluates the use of objects, assessing ideational apraxia. The second subtest involves the assessment of the ability to imitate gestures, aiming at ideomotor apraxia. The apraxia test has been shown to have good inter-rater reliability, internal consistency, diagnostic value and construct validity.3,19 The apraxia test is described in appendix 1 . If apraxia is demonstrated using this test, the OT guideline for assessment and treatment of apraxia in stroke patients can be used to further investigate the apraxia and to design the training programme.

\section{ADL observations}

Before training can start, it is necessary to assess the specific consequences of apraxia in daily life that the individual patients experience. The problems and the error types that are observed during the performance of daily tasks will be the focus of the intervention. In addition, the observations will provide valuable information on the tasks and the type of interventions that can be used during training. To evaluate the disabilities resulting from the apraxia, the assessment tool included in the guideline is used. This instrument, the ADL observations, is based on a method developed by Arnadottir, 20 and uses a standardised way to assess the level of independent functioning of the patient. Any task that relates to the patient's interest, lifestyle and remaining capacities can be used to assess task performance. Research has shown that tasks that are often used are making coffee or tea and preparing a sandwich.12,21 It is recommended that tasks will be chosen by the patient, in collaboration with the therapist. The ADLobservations have been shown to have a good inter-rater reliability, internal consistency, clinical and construct validity ${ }^{21}$ and are presented in appendix 2 . 


\section{Treatment of apraxia}

At the start of the training, the therapist needs to make several choices that relate to the content of the training. First, a task that will be used during training should be chosen. To facilitate the selection of tasks, instruments like the Canadian Occupational Performance measure (COPM) $)^{22}$ or the Activity Card Sort ${ }^{23}$ can be used. The task that will be used during training will usually be a task that has been evaluated in the assessment phase. If another task is chosen to be used during the training, ADL observations will need to be conducted first as the results of these observations will help arranging the content of the training. Second, the therapist chooses which phase of task performance (orientation, execution or control) will be addressed during the training. Each phase is linked to a specific type of intervention. If the orientation phase will be the focus of attention, the intervention that is used will be aimed at instruction, similarly a focus on the execution phase relates to an intervention aimed at providing guidance and a focus on the control phase will lead to an intervention that is aimed at providing feedback, or teaching the patient how to use feedback.

The decision about the phase that will be the focus of attention, and thus, which intervention type will be used, is based on information derived from the ADL observations and will for example depend on the patient's response to interventions that have been applied during the assessment procedure. Although most patients will experience difficulties in more than one of the three phases, only one phase will be addressed during training. Thus, the therapist will need to take over the other phase(s) in which difficulties occur. By limiting the focus of the training to one specific phase, therapists will be able to determine the exact intervention that is successful; if more than one intervention is used, no conclusions can be drawn on which one of the interventions led to an improvement. In addition, problems in one phase will often cause problems in the other phases. For example, if a patient does not possess a correct internal concept, a problem that relates to the orientation phase, the execution phase will be disturbed as well, as the patient does not know how to perform the task. In addition, the patient will not have an accurate idea about what the result of the task performance should be and will therefore not be able to complete the control phase properly. Thus, an intervention that is focused on one phase, might affect the other phases as well.

The next decision that needs to be made concerns the specific strategy that will be used during training. The strategy needs to be adjusted to the phase of task performance, and thus to the intervention type. In addition, the strategy needs to be attuned to the strengths and weaknesses of the individual patient. Based on their clinical judgment, therapists may choose any strategy they think might be useful for the patient. Again, this decision will be largely based on information derived from the ADL observations, reflecting the patient's response to specific strategies that have been tried out during the assessment. Examples of strategies include the use of verbalisation, a written action plan, pictures showing the objects needed for task performance, pictures showing the correct 
sequences of task performance and a video showing the patient's own performance.

Subsequently, the therapist rates the level of independent functioning that is expected to be achieved in four training sessions, using the scoring structure of the ADL observations. Next, treatment will be started. Therapists will evaluate the effects of their intervention after a maximum of four training sessions, by using the ADL observations to assess the patient's task performance. Results of these observations will be compared to the expected level of functioning that was registered before the start of the training. Based on this comparison, the therapist will decide how to continue training. If no improvement has occurred, or if the improvement is less than was expected, the therapist might decide to focus on a different phase, and thus change the intervention that is used, or the therapist might choose to apply a different strategy that, for example, offers more assistance or that relates to another, intact function of the patient. In addition, the therapist might decide to choose the use of a different task. If the training is shown to be effective, the therapist will have to decide whether more gain might be achieved by continuing the use of the same intervention, strategy and task. In addition, the therapist might decide to resume the training in a different environment, or the therapist might choose another strategy that could further improve the level of independent functioning by applying a strategy that offers less assistance. In addition, the therapist might conclude that the highest level of independent functioning on this task that is attainable for the patient has been achieved, and thus, a new task will be chosen.

The evaluation method used in the guideline compels therapists to closely monitor the effects of the interventions they choose to use and to consciously decide how to continue the training. The ultimate goal of this treatment method is to gradually teach patients to use more efficient strategies that will lead to a more independent functioning. The therapists register the outcome of the evaluation and the choices that were made relating to the continuation of the training. The treatment will proceed, and thus, the cycle of treatment, assessment and evaluation will start over.

\section{Evidence for effectiveness of the intervention}

The effectiveness of the treatment programme has been demonstrated in three research studies.8,11,12 The first study was a non-controlled pre-posttest intervention study. ${ }^{11}$ Thirty-three left hemisphere stroke patients with apraxia were treated for 12 consecutive weeks by means of the guideline described in the present paper. After treatment, the patients showed significant improvements on the ADL observations, which was the primary outcome measure of the study. The effect size for the improvement on the ADL observations, representing improvement on the disability level, was large (0.92) compared to the effect sizes representing improvements on the impairment level (apraxia test: 0.34 , motor test: 0.19) (see figure 1). These findings were in line with the expectations as the treatment programme is aimed at improving the disabilities due to apraxia, 
instead of the apraxia itself. The patients had learned to compensate for the problems due to the lasting presence of apraxia. ${ }^{11}$

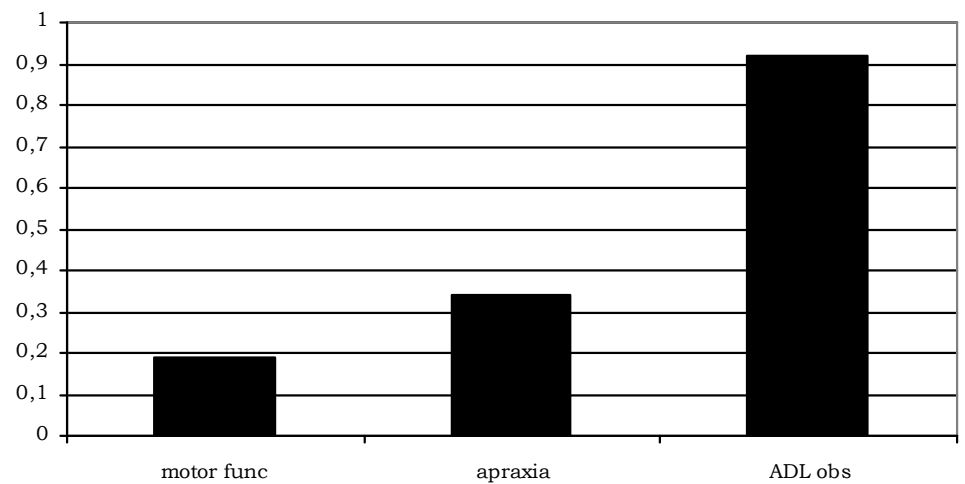

Figure 1: Effect sizes on the impairment and disability level after 12 weeks training (study 1)

Motor func: Effect size on test of motor functioning ADL obs: Effect size on ADL observations

Apraxia: Effect size on apraxia test

Outcome measures on impairment level: motor functioning and apraxia test

Outcome measure on disability level: ADL observations

The second study was a randomised clinical trial. ${ }^{8}$ A total of 113 left hemisphere stroke patients with apraxia were randomly assigned to one of two treatment groups. The experimental group received strategy training for apraxia while the control group received care as usual. The primary outcome measure of this study was the performance on the ADL observations. After an eight-week treatment period, strategy training was shown to be significantly more effective in improving ADL functioning than usual occupational therapy only. At followup, five months after baseline, both groups were comparable in ADLfunctioning, suggesting strategy training had no specific long-term effects (see figure 2). However, significantly more patients in the usual treatment group were still receiving occupational therapy at follow-up. Thus, patients in the usual treatment group needed more occupational therapy to obtain a corresponding level of improvement on ADL functioning than patients who received strategy training. ${ }^{8}$

The third study was a non-controlled study evaluating transfer effects of the strategy training in 29 left hemisphere stroke patients with apraxia. ${ }^{12}$ Both transfer from trained to non-trained tasks and transfer from the rehabilitation setting to the patients' own homes were addressed. Again, the primary outcome measure of the study was the performance on the ADL observations. After eight weeks of training, performance of trained tasks in the rehabilitation setting had significantly improved, confirming the findings of the two previous studies. In addition, patients performed trained tasks and non-trained tasks at the same level of independency at the rehabilitation centre as well as at home, indicating 
transfer of training effects to non-trained tasks and to the home setting. Transfer effects turned out to be stable over time, as was demonstrated by the evaluation of ADL functioning at home, after a five months follow-up period. ${ }^{12}$

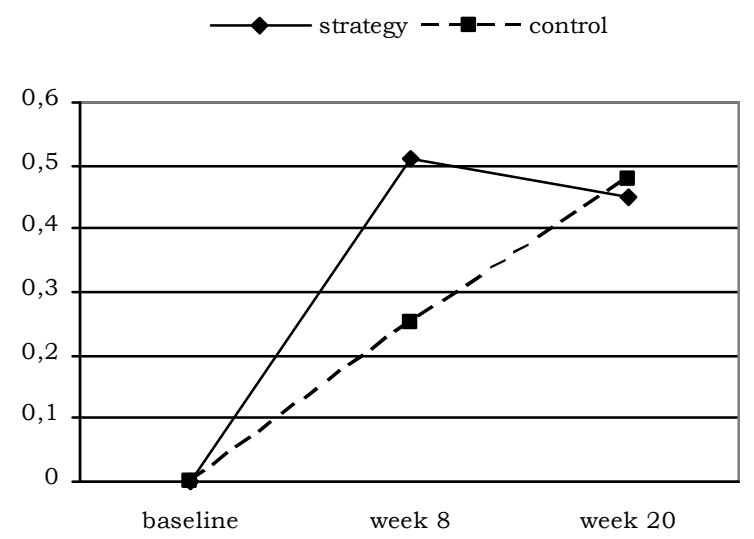

Figure 2: Effect sizes of the ADL observations for the two treatment groups in the RCT (study 2)

\section{Discussion}

Research has demonstrated the effectiveness of the OT guideline for assessment and treatment of apraxia in stroke patients. ${ }^{8,11,12}$ Based on these positive results, the training was published as a guideline for stroke rehabilitation in the Netherlands. Therefore, the use of this strategy training now is the conventional training method for stroke patients with apraxia. ${ }^{24}$ Thus, this guideline is an example of an evidence-based intervention which has been implemented successfully in Dutch OT practice.

The intervention has shown to be effective in left hemisphere stroke patients with apraxia. Although apraxia is mostly found in left hemisphere stroke patients, a deficit that causes similar problems in task performance can also occur after a right sided stroke. ${ }^{1}$ The guideline is expected to be effective in increasing independent functioning in this group of patients as well, although this assumption can not yet be supported by empirical evidence. Apraxia has also been shown to occur in the degenerative disorders Alzheimer's disease, ${ }^{25}$ corticobasal degeneration ${ }^{26}$ and Huntington's disease ${ }^{27}$. The guideline might be effective in increasing independent functioning in these groups of patients. Further research is necessary to evaluate the effectiveness of the guideline for these patient groups.

An interesting extension of the treatment considerations presented in this paper would be to apply the phases of human information processing to the treatment of other cognitive deficits. Models of attention already rely on the 
information processing approach ${ }^{28}$ but translating these models into treatment paradigms is a next step to be considered.

A point of discussion could be raised concerning the specific impact of the training. In addition to offering patients specific strategies to compensate for the problems due to apraxia, the occupational therapist is offered a very structured and systematic decision making process during treatment. From the studies presented it can not be concluded which part of the successful performance after treatment is the result of the compensatory strategies and which part is the result of the structured therapy process. As Cicerone and colleagues ${ }^{29}$ conclude in their extensive review on the effectiveness of cognitive rehabilitation, the effectiveness itself should not be questioned any longer. Instead research should focus on the specific elements of treatments which allow for the success. In addition, prognostic factors should be examined showing us which patients will benefit the most from certain treatment methods.

\section{Clinical messages}

The evidence-based OT guideline is recommended for assessment and treatment of patients with apraxia after left hemisphere stroke, especially for patients in the subacute or chronic phase after stroke. The treatment is based on teaching patients compensatory strategies in order to improve independent daily functioning, despite the probably lasting presence of apraxia. For assessment of the consequences of apraxia in daily functioning, the standardised ADL observations included in the OT guideline are recommended.

\section{Acknowledgements}

The OT guideline was developed in cooperation with the School for Occupational Therapy of Amsterdam. We would like to thank all people involved in the development, evaluation and implementation of the OT guideline in Dutch OT practice. The OT guideline is now owned by the Dutch Association of Occupational Therapy. The association has formally acknowledged the guideline and it has given the authors permission to summarise the guideline in this paper. The English version of the OT guideline was developed by order of the School for Occupational Therapy of Amsterdam. Requests for reprints of the complete guideline should be sent to the corresponding author of this paper (c.vanheugten@np.unimaas.nl). We would like to thank the following organisations for financial support of the research studies: The National Committee for the Chronically Ill People, the Netherlands Heart Foundation, the Health Insurance Funds Council, the Netherlands Oragnisation for Health Research and Development and the Institute for Rehabilitation Research 


\section{References}

1. De Renzi E. Apraxia. In: Boller F, Grafman J, editors. Handbook of Neuropsychology. Amsterdam: Elsevier Science Publishers B.V.; 1989. p. 245-263.

2. Donkervoort M, Dekker J, van den Ende E, Stehmann-Saris JC, Deelman BG. Prevalence of apraxia among patients with a first left hemisphere stroke in rehabilitation centres and nursing homes. Clin Rehabil 2000;14:130-136.

3. Zwinkels A, Geusgens C, van de Sande P, van Heugten C. Assessment of apraxie: Inter-rater reliability of a new apraxia test, association between apraxia and other cognitive deficits and prevalence of apraxia in a rehabilitation setting. Clin Rehabil 2004;18(7):819-827.

4. Goldenberg G, Hagmann S. Therapy of activities of daily living in patients with apraxia. Neuropsychol Rehabil 1998;8(2):123-141.

5. Foundas AL, Macauley BL, Raymer AM, Maher LM, Heilman KM, Gonzalez Rothi LJ. Ecological implications of limb apraxia: Evidence from mealtime behavior. $J$ Int Neuropsychol Soc $1995 ; 1(1): 62-6$.

6. Sveen U, Wyller TB, Ljunggren AE, Bautz-Holter E. Predictive validity of early cognitive assessment in stroke rehabilitation. Scand J Occup Ther 1996;3(1):20-27.

7. Friedman PJ. Stroke outcome in elderly people living alone. Disabil Rehabil 1995;17(2):90-93.

8. Donkervoort M, Dekker J, Stehmann-Saris JC, Deelman BG. Efficacy of strategy training in left hemisphere stroke patients with apraxia: A randomized clinical trail. Neuropsychol Rehabil 2001;11(5):549-566.

9. Foundas AL, Henchey R, Gilmore RL, Fennell EB, Heilman KM. Apraxia during Wada testing. Neurology 1995;45(7):1379-83

10. van Heugten CM. Rehabilitation and management of apraxia after stroke. Rev Clin Gerontol 2001;11:177-184.

11. van Heugten CM, Dekker J, Deelman BG, van Dijk AJ, Stehmann-Saris JC, Kinebanian A. Outcome of strategy training in stroke patients with apraxia: A phase II study. Clin Rehabil 1998;12(4):294-303.

12. Geusgens CAV, van Heugten CM, Cooijmans J, Jolles J, van den Heuvel WJA. Transfer effects of a cognitive strategy training for stroke patients with apraxia. J Clin Exp Neuropsychol (in press) 2007.

13. Kielhofner G. Conceptual foundations of occupational therapy. Philadelphia: F.A. Davis Company; 1997.

14. Zoltan B. Vision, perception, and cognition: A manual for the evaluation and treatment of the neurologically impaired adult. Thorofare: Slack Inc.; 1996.

15. Simon HA. Information processing models of cognition. Annual Review of Psychology 1979;30:363-396.

16. Wilson BA. Compensating for cognitive deficits following brain injury. Neuropsychol Rev $2000 ; 10(4): 233-243$.

17. Toglia JP, Kirk U. Understanding awareness deficits following brain injury. NeuroRehabilitation 2000;15(1):57-70.

18. Trombly CA, Ma H. A synthesis of the effects of occupational therapy for persons with stroke, part I: Restoration of roles, tasks, and activities. The Am J Occup Ther 2002;56:250-259.

19. van Heugten CM, Dekker J, Deelman BG, Stehmann-Saris JC, Kinebanian A. A diagnostic test for apraxia in stroke patients: Internal consistency and diagnostic value. Clin Neuropsychol 1999;13(2):182-92.

20. Arnadottir G. The brain and behaviour: Assessing cortical dysfunction through activities of daily living. St. Louis: Mosby Company; 1990. 
21. van Heugten CM, Dekker J, Deelman BG, Stehmann-Saris JC, Kinebanian A. Assessment of disabilities in stroke patients with apraxia: Internal consistency and inter-observer reliability. The Occupational Therapy Journal of Research 1999;19(1):55-73.

22. Law M, Baptiste S, Carswell A, McColl MA, Polatajko H, Pollock N. Canadian occupational performance measure. Third ed. Ottawa: CAOT Publications ACE; 1998.

23. Baum CM, Edwards D. Activity card sort: Test kit. St. Louis: Washington University at St. Louis; 2001.

24. Commissie CVA-revalidatie. Revalidatie na een beroerte: Richtlijnen en aanbevelingen voor zorgverleners [Rehabilitation after stroke: Guidelines and recommendations for clinical practice]. The Hague: Dutch Heart Foundation; 2001.

25. Taylor R. Motor apraxia in dementia. Percept Mot Skills 1994;79:523-8.

26. Leiguarda R, Lees AJ, Merello M, Starkstein S, Marsden CD. The nature of apraxia in corticobasal degeneration. J Neurol Neurosurg Psychiatry 1994;57(4):455-9.

27. Shelton PA, Knopman DS. Ideomotor apraxia in Huntington's disease. Arch Neurol 1991;48(1):3541.

28. Shiffrin RM, Schneider W. Automatic and controlled processing revisited. Psychol Review 1984;91(2):269-276.

29. Cicerone KD, Dahlberg C, Malec JF, Langenbahn DM, Felicetti T, Kneipp S, et al. Evidence-based cognitive rehabilitation: Updated review of the literature from 1998 through 2002. Arch Phys Med Rehabil 2005;86:1681-1692. 


\section{Appendix 1}

\section{Apraxia test}

Aim

Assessing the presence and severity of apraxia after stroke.

\section{Procedure}

The test consists of two subtests.

(1) Demonstration of object use: the patient is asked to demonstrate the proper use of specific objects. Objects are presented one by one. Object use is tested in three conditions:

(a) verbal request without the objects being present, the patient demonstrates pantomime object use (key, saw, toothbrush);

(b) visual presentation, the patient looks at the objects and demonstrates pantomime object use. Touching the objects is not allowed (spoon, hammer, scissors);

(c) actual object use, the objects are presented to the patient, objects can be seen, felt and touched, the patient demonstrates the actual use (eraser, comb, screwdriver).

(2) Imitation of gestures: the patient is asked to imitate 6 gestures, immediately upon demonstration by the researcher (sticking out one's tongue, blowing out a candle, closing one's eyes, waving goodbye, saluting, making a fist).

Patients use the hand ipsilateral to the side of the brain lesion, to avoid possible interference of motor and sensory impairments.

\section{Scoring}

$3=$ the performance is correct and appropriate;

2 = the performance resembles the correct performance, but is somewhat imprecise, slow, or clumsy/awkward or the patient uses a body part as an object; $1=$ the performance only weakly resembles the correct performance but it executed in the correct place, or the performance is correct but it is executed in the wrong place;

$0=$ the performance is incorrect or so incomplete that it is not recognisable.

If in the first trial, the performance is not optimal (i.e. score 2 or less), the patient is offered a second trial. The scores of both trials are added up to represent the final score per item. If the performance on the first trial is optimal, the patient is rewarded a score of 6 , the second trial is dismissed and the researcher proceeds to the next item. The maximum scores for the demonstration of object use and imitation of gestures are 54 and 36 respectively. 
The maximum total score is 90 . The diagnostic value of the test has been found to be optimal when using a cut-off score of 87 , relating to a diagnosis of apraxia if the maximum test score is 86 or less. However, either sensitivity or specificity of the test can be enlarged by adjusting the cut-off score, attuning the test to the specific aim of its use. ${ }^{19}$ 


\section{Appendix 2}

\section{ADL observations}

Aims

Assessing the presence of disabilities resulting from apraxia.

Gaining insight in the style of action of the patient and the sort of errors made.

Preparing treatment goals for specific training.

\section{Method}

The patient and the occupational therapist jointly choose two or more tasks that will be observed. The occupational therapist observes the task performance in an appropriate setting (i.e. bathing in the bathroom).

The ADL observations consist of two parts, which are rated consecutively:

(1) Overall independence score, relating to the task performance as a whole.

(2) Three scores representing the course of the task performance and relating to the three phases of task performance separately (orientation, execution and control).

\section{Scores}

All scores reflect the type of assistance or help the therapist has to provide in order for the patient to complete the task performance or each one of the three phases correctly. Thus, when scoring the ADL observations, therapists score what they themselves do, rather than what the patients do.

0 = no help needed;

1 = verbal intervention needed;

2 = physical intervention needed;

$3=$ therapist needs to take over completely.

The assessment procedure is a dynamic, interactive process, indicating that while observing the patient's functioning, several interventions will be tried out to support task performance. During the process it is of great importance that the hierarchical structure of the assistance levels is acknowledged. Therefore, a therapist is required to first wait and see how patients manage to get along by themselves, before progressing to the use of verbal or physical interventions respectively, or at the ultimate stage, to taking over one or more of the phases of task performance. 
Chapter 4

\section{The occurrence and measurement of transfer in cognitive rehabilitation: A critical review}

Published in:

Journal of Rehabilitation Medicine, 2007; 39(6): 425-439

C. Geusgens, I. Winkens, C. van Heugten, J. Jolles, W. van den Heuvel 


\begin{abstract}
Objective: To investigate the occurrence of transfer of cognitive strategy training for persons with acquired brain injury. To investigate the way in which transfer was measured.

Methods: Computer searches in PubMed, PsychINFO, Embase and CINAHL using combinations of search terms in the following categories: type of brain injury, transfer, type of disorder, type of intervention. A total of 39 papers was included in the review. The following aspects were judged: study design and participant characteristics, intervention characteristics and type of outcome measures used.

Results: Transfer outcome measures could be classified in three groups: nontrained items, standardised daily tasks and daily life. Most studies reported at least one type of transfer, however, the methodological quality of the studies was low. Cognitive strategy training in the evaluated studies focussed on seven domains of functioning: information processing, problem solving / executive functioning, memory / attention, language, neglect, apraxia and daily activities. Conclusions: Transfer of training effects of cognitive strategy training has been evaluated in a relatively small number of studies. Outcome measures used in these studies could be classified in three groups. Most studies reported the occurrence of transfer of training effects, although some serious remarks can be made concerning the methodological quality of the studies.
\end{abstract}




\section{Introduction}

The exact meaning of the terms 'transfer' and 'generalisation' lacks consensus. It is however agreed that both terms relate to the way in which prior learning affects new learning. In the context of rehabilitation, transfer of treatment effects is of great importance. The aim of a rehabilitation programme is to restore patients to their greatest potential and maximum independence, hopefully resulting in independent functioning, the return to their own home and participation in society. ${ }^{1}$ To achieve this goal, transfer of training results is necessary. For patients to function as independently as possible at home, tasks which are taught in the rehabilitation setting should be transferred to the home setting. Moreover, therapists cannot possibly train patients to handle all the difficulties and tasks they will encounter after discharge. Therefore transfer of skills from trained to non-trained tasks is of great importance to the clinical success of a therapy programme.

In recent years, strategy training has become a widely used treatment method in cognitive rehabilitation of patients with acquired brain injury (ABI). This type of therapy is based on the assumption that restoration of cognitive functions to their pre-injury structure and efficiency is not expected to occur and that rehabilitation should therefore concentrate on teaching compensatory strategies. ${ }^{1}$ Cognitive strategy training is aimed at teaching patients new, general ways to compensate for problems in everyday life, resulting from a cognitive impairment. ${ }^{2}$ Compensation can be achieved by teaching patients to use external as well as internal strategies and techniques to reach their goals in alternative ways. People with severe memory problems can, for example, use external memory aids like pagers or appointment books to enable them to remember their daily schedules. In addition people can be encouraged to use their residual, internal, skills more efficiently by applying rehearsal strategies or mnemonics. ${ }^{1}$

In recent literature on cognitive rehabilitation, it is often stated that the occurrence of transfer is expected in strategy training, as the training programme is not aimed at relearning specific tasks, but at teaching patients new ways to handle problems resulting from an impairment. ${ }^{3}$ Therefore, patients are expected to be able to use the strategies in new settings and while performing new tasks, despite the lasting presence of the cognitive deficits. Therefore cognitive strategy training is not expected to transfer to neuropsychological test results, since the aim of the training is not to improve the impairment itself. However, Cicerone et $\mathrm{al}^{4,5}$ point out that relatively few studies have tried to evaluate the occurrence of transfer by directly evaluating the transfer of treatment effects to everyday situations or behaviours.

Therefore, the objective of this paper is to investigate the occurrence of transfer of cognitive strategy training to everyday situations and behaviours. Literature on educational psychology will be reviewed beforehand to clarify the concept of 'transfer', as in rehabilitation research less attention has been paid to the definition. Next, we will discuss the results of a critical review of interven- 
tion studies evaluating transfer of cognitive strategy training. We will try to answer the following questions: (1) how was transfer measured in these studies? And (2) does transfer occur? Finally, we will reflect on the consequence of these results for clinical practice and we will give suggestions for the design of future studies aimed at evaluating transfer of treatment effects.

\section{Transfer}

The term 'transfer' is frequently used in spoken language and clinical practice. In addition, the term is commonly used in scientific research, in particular in contexts in which learning plays an important role, yet the exact meaning of this term lacks consensus. Nevertheless, it is agreed that 'transfer' relates to the use of prior learning in new contexts, or, in other words, to the way in which prior learning affects new learning or performance. ${ }^{6-12}$

Over the years, researchers have had trouble demonstrating the occurrence of transfer. This is rather unfortunate as it has often been stated that it is essential to all situations in which learning is concerned and as transfer is said to be the main goal of all learning.6,8,10 At the same time, it is also rather peculiar as transfer seems to occur frequently in everyday life, as it is by transfer of earlier experiences that people can function adequately in new situations, which are encountered almost every day. ${ }^{8}$

Despite the lack of evidence of the occurrence of transfer, educational psychology has paid much attention to the question how to promote transfer of learning. Based on literature, six prerequisites for the occurrence of transfer are:

(1) A person should know what transfer is and how it works. 8,13

(2) A person should be aware of his own functioning before he will acknowledge that a strategy is needed to improve his functioning. ${ }^{14}$

(3) A person should be able to judge when and where transfer can be applied. ${ }^{10,15}$

(4) General knowledge should be taught, as this type of knowledge is easier to transfer than specific knowledge. 15

(5) The connection between what is learned and the situation in which it is learned should be broken by practicing a strategy or skill while varying the practice situation as much as possible. $8,10,15,16$

(6) Transfer should be addressed during learning as it cannot be expected to occur automatically. 8,17

We will now turn to the review of intervention studies evaluating transfer of cognitive strategy training

\section{Methods}

A literature search was carried out in PubMed (1984 - April 2005), PsychINFO (1983 - April 2005), Embase (1989 - April 2005) and CINAHL (1982 - April 2005), using Silverplatter's Webspirs retrieval software. ${ }^{18}$ Both controlled vo- 
cabulary words and free words in the article's title, abstract or keywords were combined in our searches. Details of the search are shown in Appendix 1. The first selection of papers was based on the title and the abstract. In some studies 'transfer' was measured and discussed, but the term (or a synonym of it) was not mentioned in the title, abstract or keywords of the paper. As a result, these papers could not be retrieved in the databases. Therefore, the private libraries on cognitive rehabilitation of the authors were reviewed and papers that did mention strategy training and transfer of training effects were selected. In addition to these two search methods, the reference lists of all included studies were scanned to further identify eligible studies.

Papers that were selected based on these three search methods were read by one of three reviewers (authors $\mathrm{CvH}$, IW and CG). The following inclusion criteria were applied: (1) papers describe an intervention study; (2) papers evaluate a cognitive strategy training. Cognitive strategy training was defined as a training that aims at teaching patients new ways to execute daily activities by using either internal or external strategies to compensate for cognitive impairments; ${ }^{19}$ (3) participants are adults, clinically diagnosed as acquired brain injury (ABI) patients; (4) outcome measures for transfer are used. Studies that evaluated transfer to new tasks as well as transfer to new situations were included. Studies that evaluated transfer of training effects to neuropsychological test results were not included in this review, as the aim of a strategy training is not to improve cognitive functioning, but to teach patients ways to function as independently as possible, despite the presence of the cognitive deficits ; (5) papers are written in English. If uncertainty about the compliance with the inclusion criteria still existed after the first reading, the paper was reread by one of the other two reviewers.

All included studies were judged on the following aspects, described in an adapted version of a rating list that is recommended by van Tulder et al: ${ }^{20}$ study characteristics (design, number of participants, used type of outcome measures, used statistics), participant characteristics (age, time post onset, type of injury) and intervention characteristics (intervention strategies used, duration of intervention, trainer characteristics).

\section{Results}

A total of 83 papers was read. After checking the inclusion criteria, 39 papers, describing 41 separate studies were included in the review. Forty-four papers that did not meet the inclusion criteria, were excluded for the following reasons: papers did not describe intervention studies $(\mathrm{N}=18)$; studies did not use cognitive strategy training $(\mathrm{N}=18)$; studies did not use transfer outcome measures $(\mathrm{N}=5)$ and study participants were healthy adults $(\mathrm{N}=3)$.

Included papers were divided into six groups, based on the cognitive domains that the intervention focussed on (information processing, problem solving skills / executive functioning, memory / attention, language, neglect, apraxia). A seventh group of studies consisted of interventions that were aimed 
at the training of daily activities, not specifically aimed at a single cognitive disorder.

Table 1 displays characteristics and methodological aspects of all included intervention studies on transfer in cognitive strategy training, divided into the seven categories described above.

\section{Methods}

\section{Study design}

Most studies had single subject designs $(\mathrm{N}=20)$. Other designs that were used are randomised clinical trial designs $(\mathrm{N}=8)$, non-controlled pretest-posttest designs $(N=6)$ and non-randomised group designs $(N=6)$, of which three studies used matched groups. In one study, two randomised intervention groups and one non-randomised control group were used.

The sample sizes of the studies generally ranged from 1 participant to 46 participants, although most studies had a sample size of less than 15 participants $(\mathrm{N}=28)$. Only one larger study was found, in which 113 subjects participated. ${ }^{21}$

\section{Participant characteristics}

The mean age of the participants reported in the studies falls within a broad range $(20-84$ years), which can be attributed to the different types of injuries that the studies focussed on. Most studies focussed on stroke patients $(\mathrm{N}=24)$. Overall, participants in these studies were older than 50 years. In contrast, TBI patients formed a much younger group, with a mean age under 40 years. The time post onset at the start of the therapy also had a broad range. It varied from 14 days to 25 years. Time post onset also had large variations within studies itself, for example ranging from one month to 25 years in a randomised clinical trial. 22

\section{Intervention characteristics}

Most studies $(\mathrm{N}=23)$ did not report trainer characteristics. Studies that did mention who performed the intervention, reported varying disciplines, like occupational therapists, speech and language therapists and rehabilitation therapists. In three studies the entire rehabilitation team was reported to be involved with the cognitive training, whereas in five studies the training was reported to be conducted by the authors of the papers. The duration of the intervention ranged form one week to six months. Studies reported one to five training sessions per week. In most studies, training sessions lasted 30 to 60 minutes.

Three papers explicitly reported that during the intervention, 'training for transfer' was used.23-25 In addition, three papers reported that during training, attention was paid to the enlargement of the patient's awareness of his own deficits, ${ }^{23,26,27}$ which is an important prerequisite for the occurrence of transfer. ${ }^{14}$ All other studies did not report using techniques to promote transfer.

The various intervention types can best be described based on the cognitive domains that the intervention focussed on. 


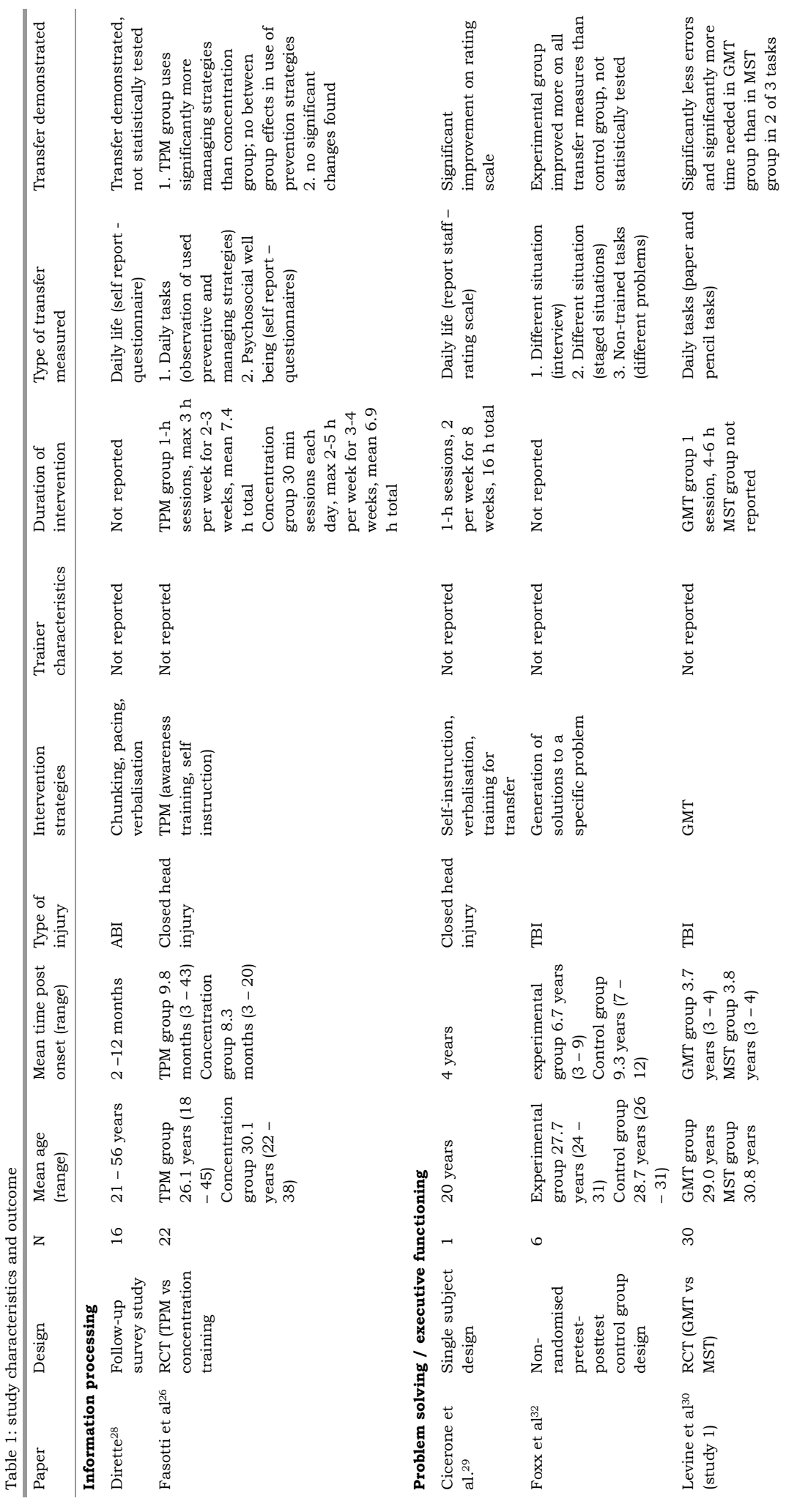




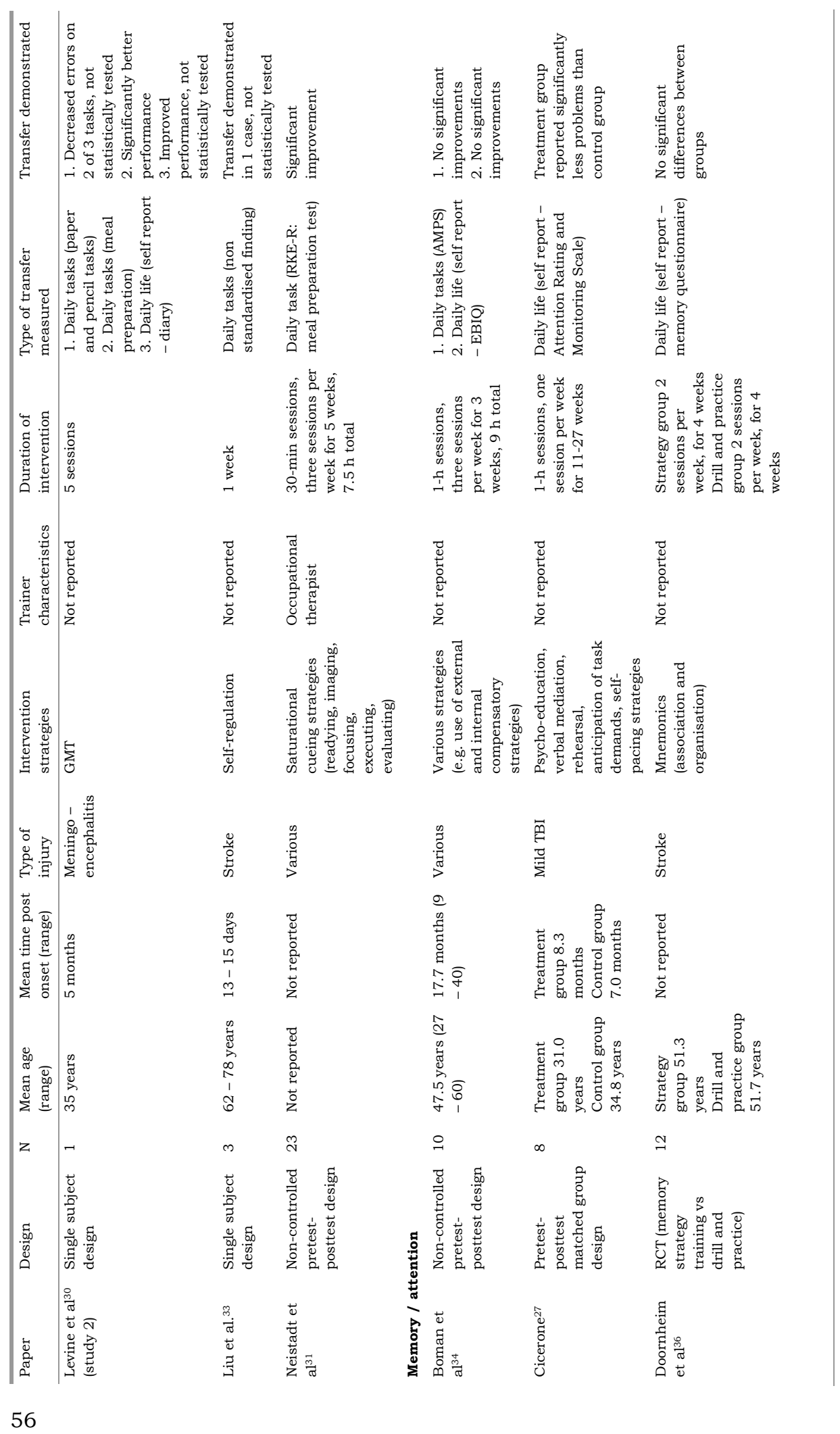




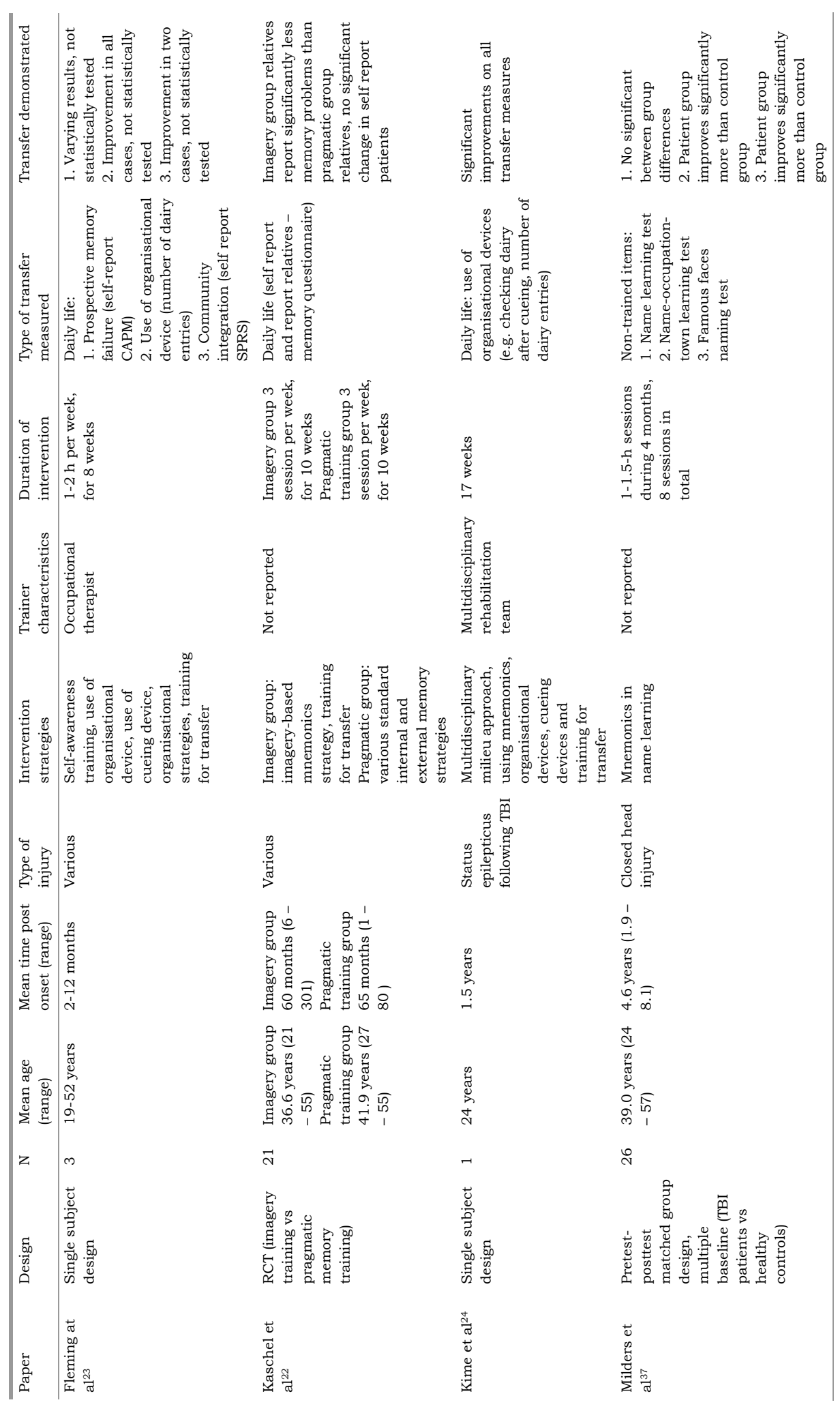




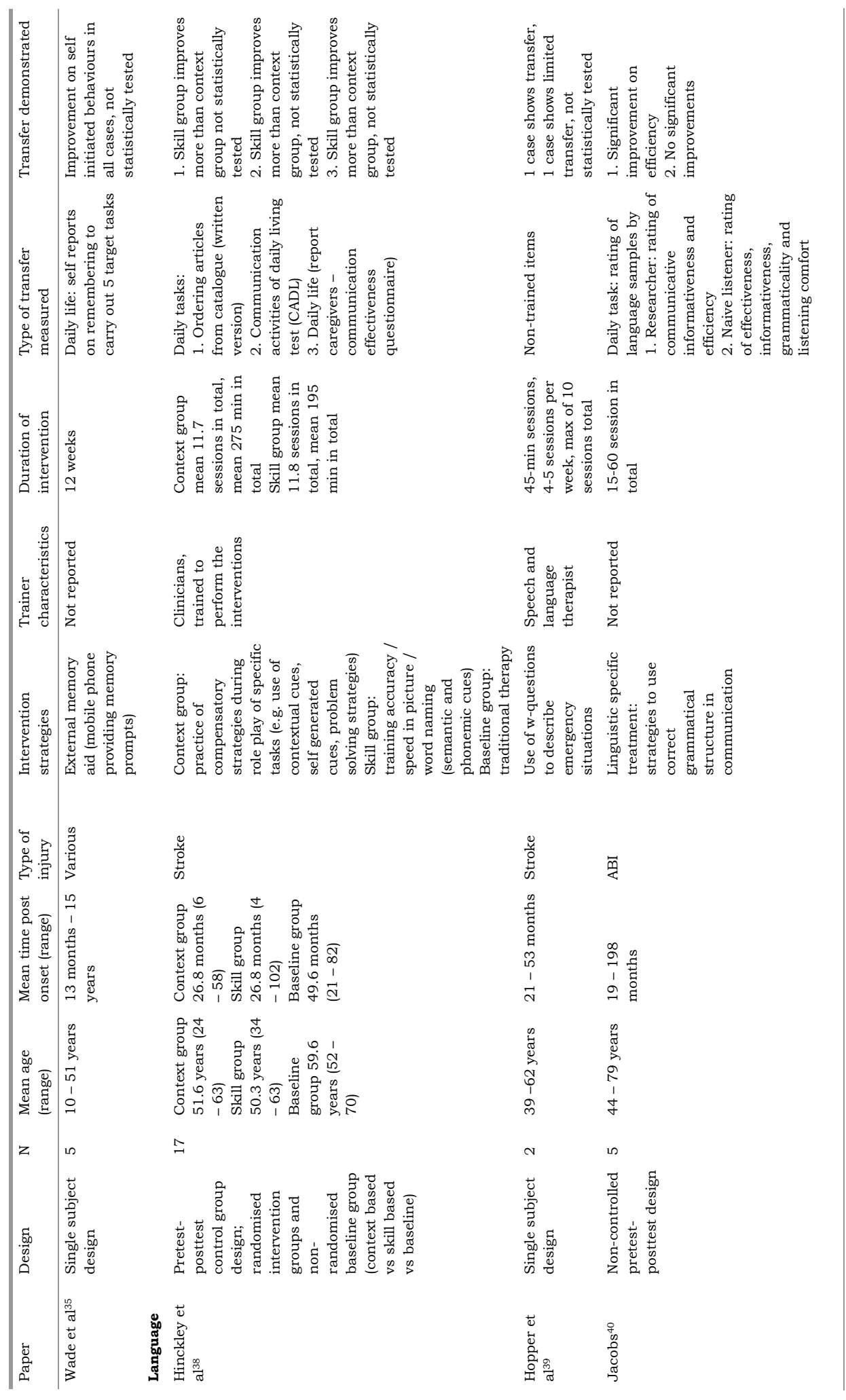




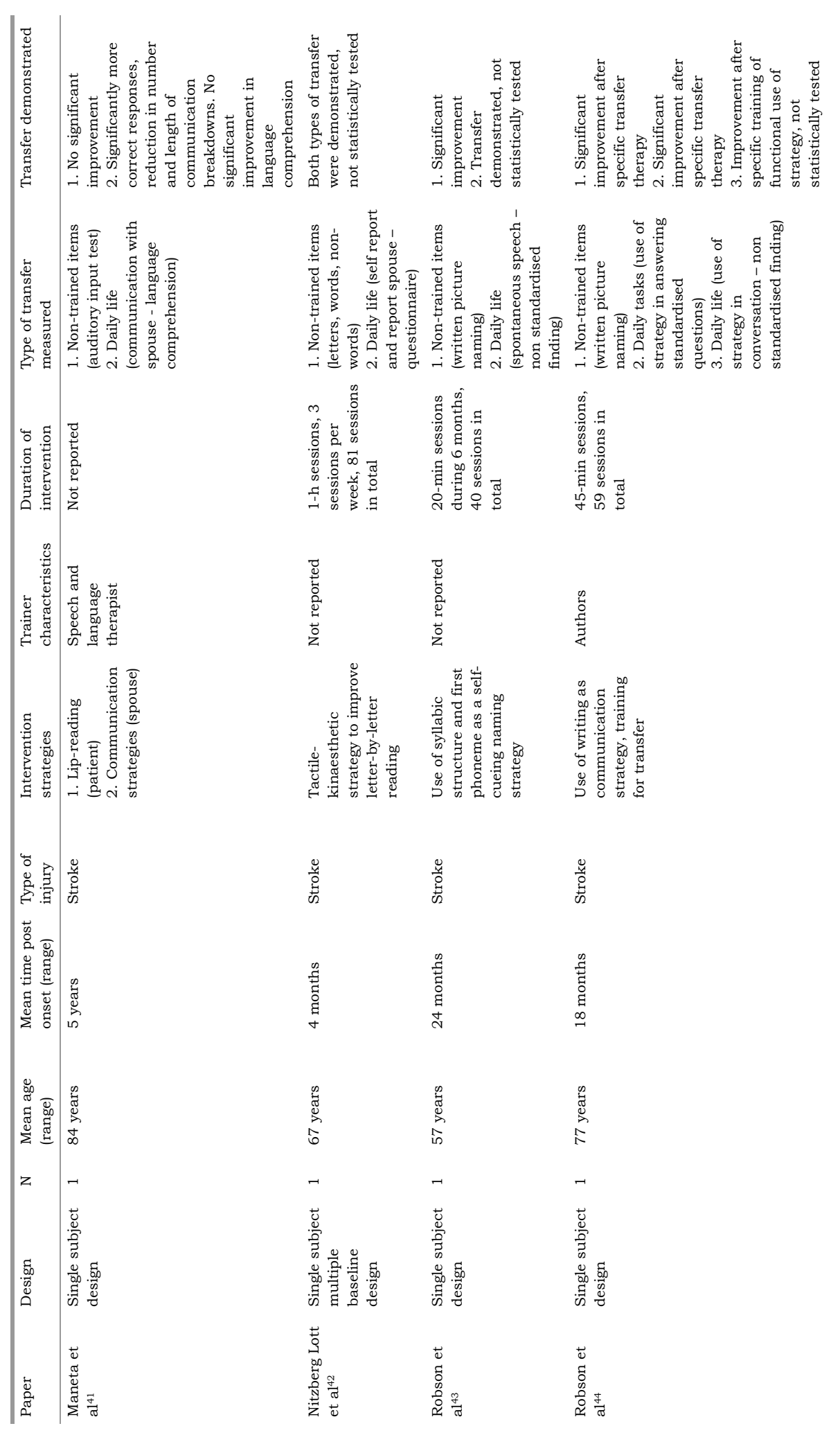




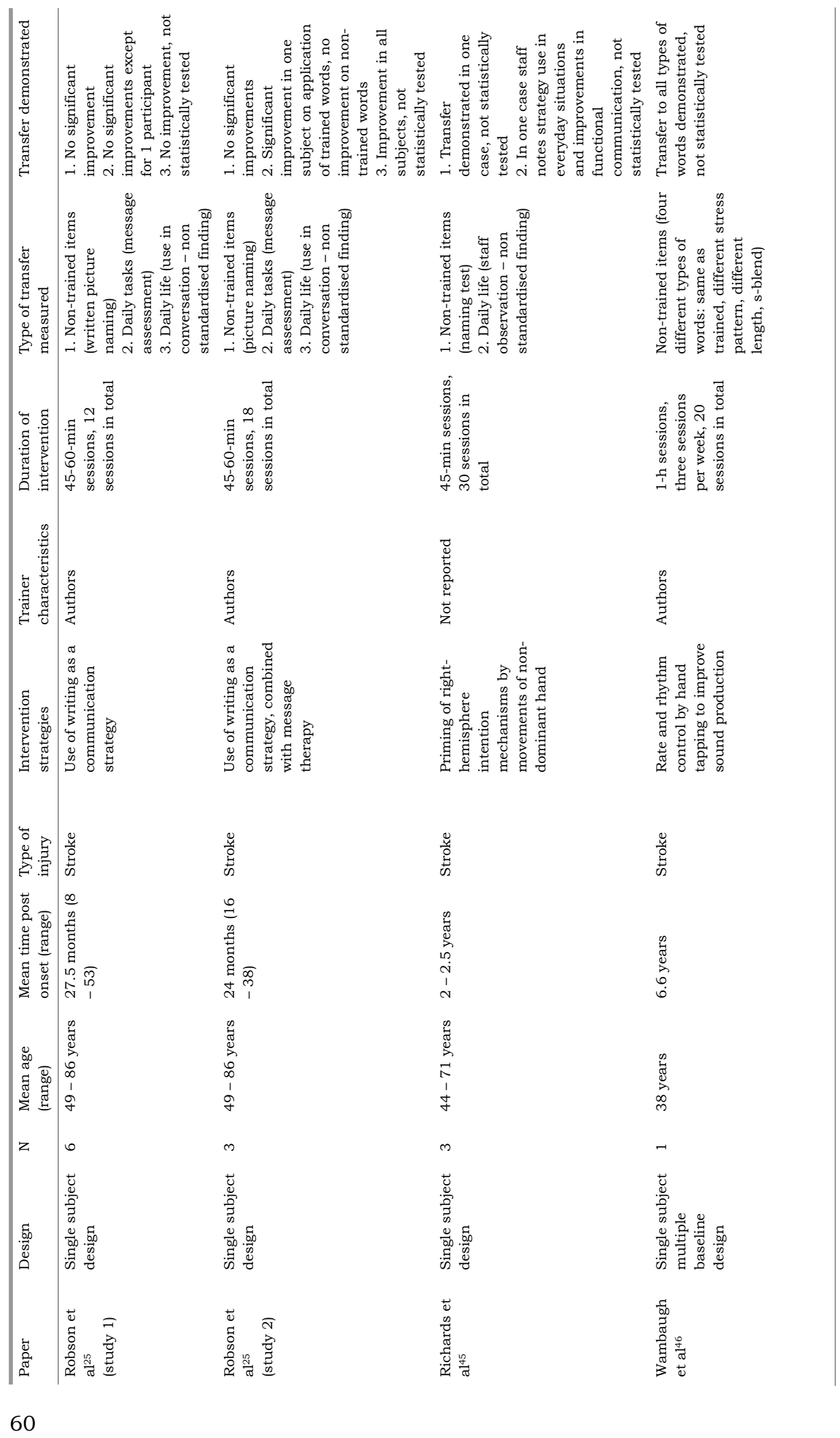




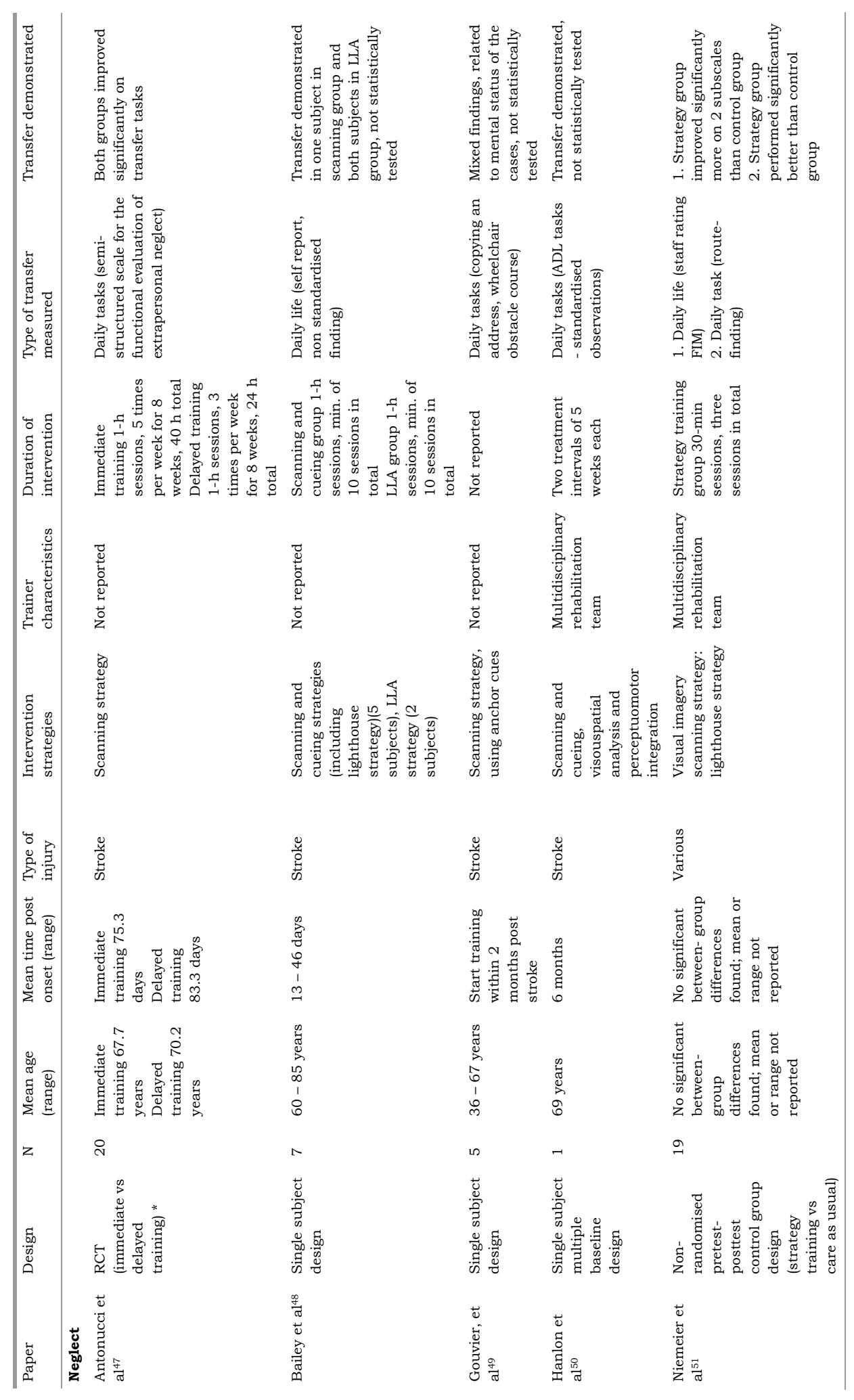




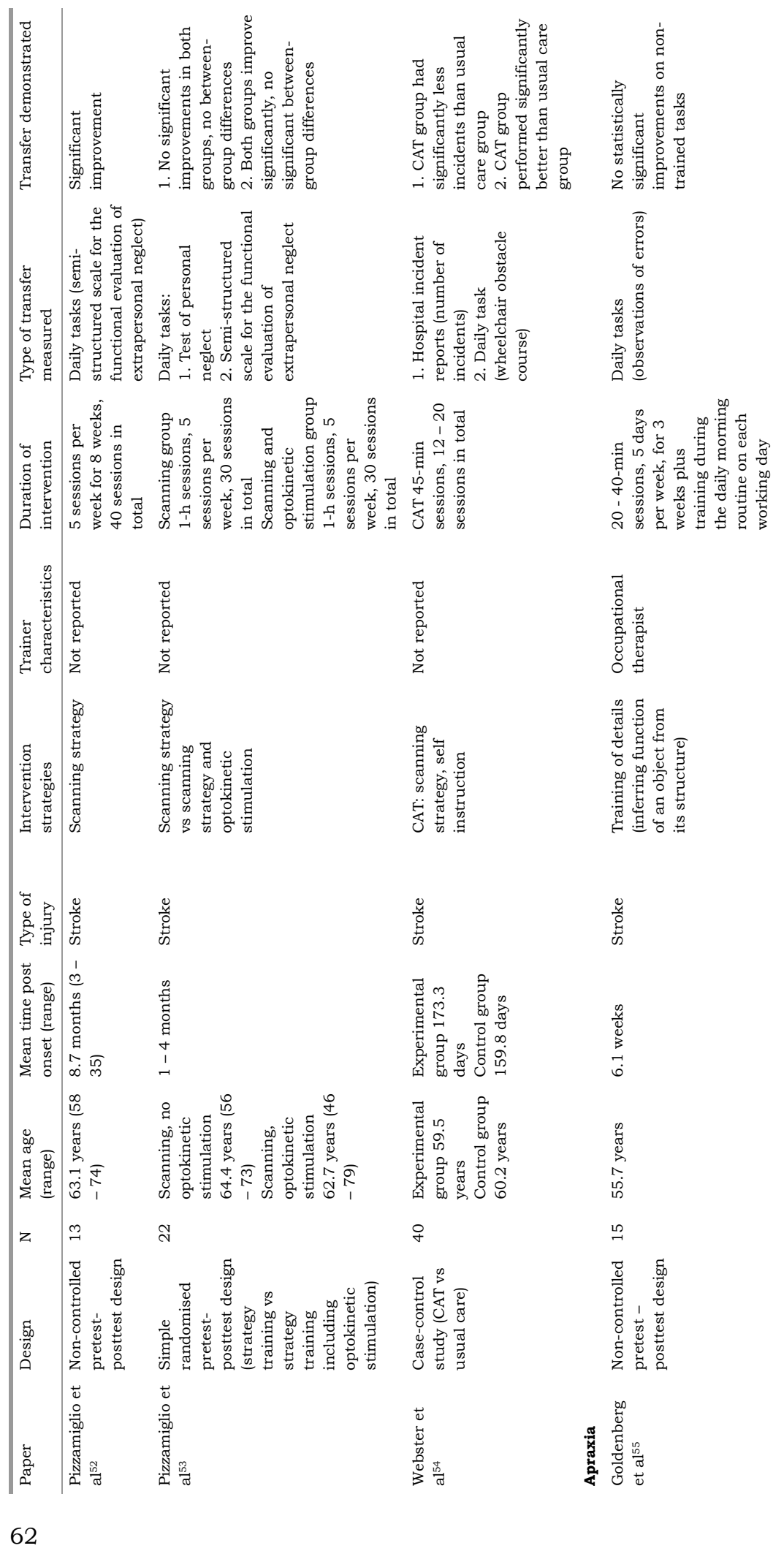




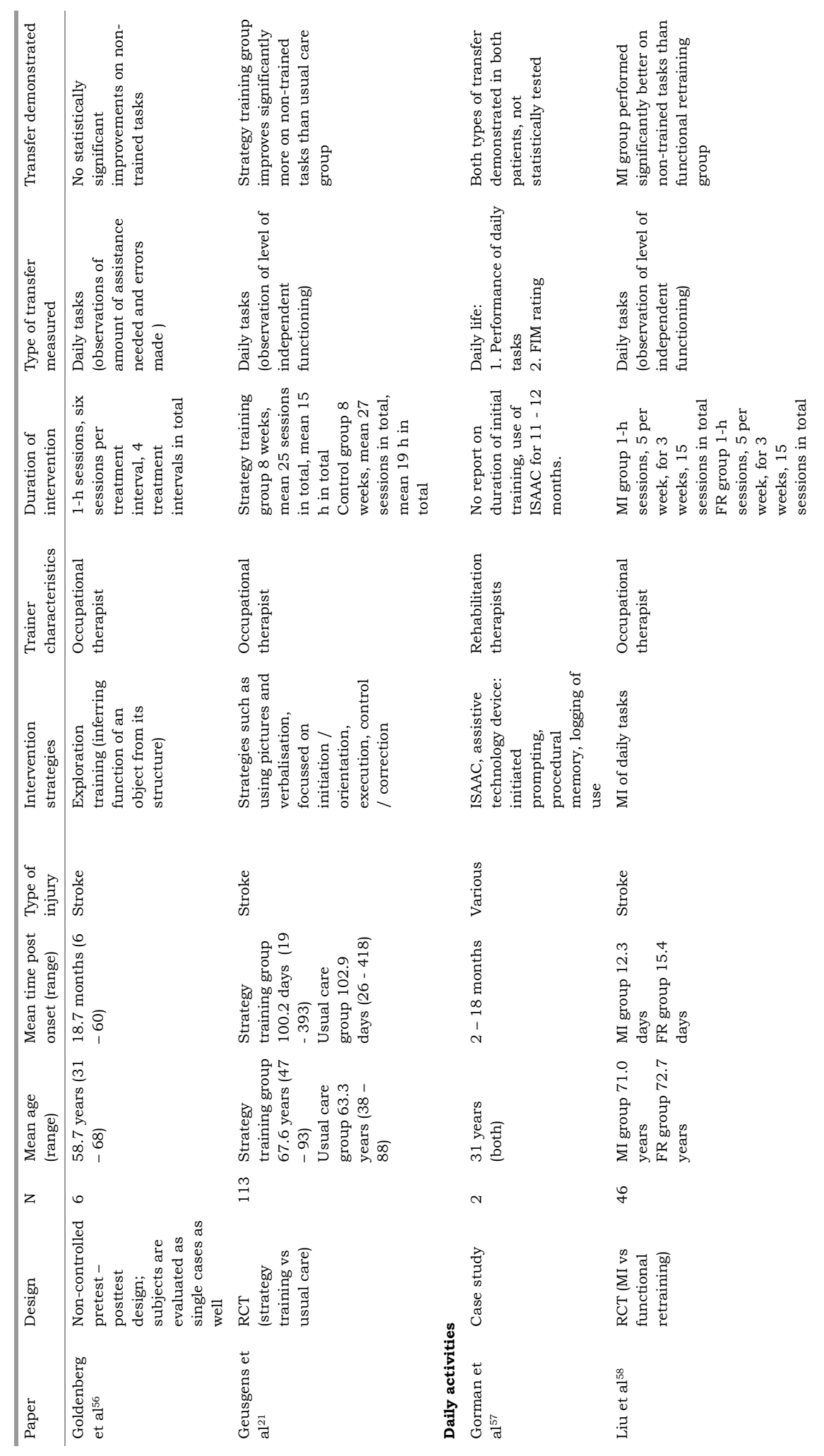




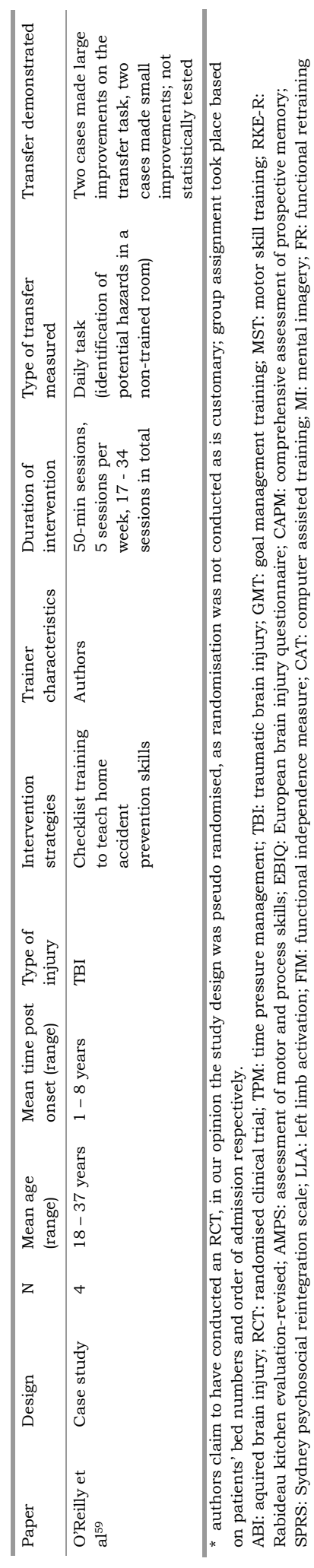


Information processing: Two studies were found describing strategies aimed at information processing. One study used strategies aimed at self-instruction by verbalisation and at chunking and pacing the amount of information that had to be processed. ${ }^{28}$ Strategies used in the other study were aimed at reducing the load on information processing capacity by generating a plan of action before the performance of a task and by verbalisation of the action plan during task performance. ${ }^{26}$

Problem solving / executive functioning: Six studies were found describing strategies aimed at problem solving and executive functioning. In all studies self-regulation or self-instruction was used, aimed at either generating or adapting a plan of action before and during the performance of a task ${ }^{29-31}$ or generating solutions to a specific problem. ${ }^{32,33}$ In most studies, overt verbalisation of the action plan was a key feature at the start of the training, generally fading into internalised speech.

Memory / attention: Eight studies were found describing strategies aimed at memory and attention. Three different strategies could be identified:

(1) Self-awareness training: information on the cognitive skills and on problems related to these skills is provided. Patients are helped to recognise the ways in which these problems affect their own situations. ${ }^{23-27}$

(2) External compensatory strategies: aimed at teaching patients to use a variety of external memory and planning aids, ranging from notebooks to cuing devices like pagers and mobile phones. $22-24,34,35$

(3) Internal compensatory strategies: aimed at teaching patients the use of internal strategies to facilitate memory function, mostly using mnemonics like associating new information to old information and structuring and organising new information. $22,24,27,34,36,37$

Most studies used a combination of these strategies.

Language: Eleven studies were found describing strategies aimed at language deficits. ${ }^{25,38-46}$ In these studies, a large variety of strategies was used. However, three types of strategies that were used in more than one study could be identified. Strategies used in the other studies are summarised in table 1.

(1) Linguistic strategies: aimed at improving the grammatical structure of spoken language, hereby increasing the informativeness of the message. 39,40

(2) External compensatory strategies: aimed at teaching patients and/or partners to use written language instead of spoken language. $25,41,44$

(3) Internal compensatory strategies: aimed at teaching patients to use selfcueing strategies like tactile-kinaesthetic information to improve letter by letter reading or deriving a word from its first phoneme. $38,42,43$

Neglect: Nine studies were found describing strategies aimed at visuospatial or perceptual neglect. In all studies one or a combination of the following strategies was used: 
(1) Scanning strategies: aimed at teaching patients to move their heads all the way from left to right. This strategy was used in all nine neglect studies, ${ }^{47-54}$ sometimes combined with one of the following strategies:

(a) Self instruction: patients verbalise the command to turn their heads all the way to the left and move them all the way to the right.

(b) Mental imagery: patients are taught to imagine their eyes are a lighthouse, scanning the sea all the way from left to right.

(2) Cueing strategies: aimed at guiding the patients' attention to an anchor cue on the left of the visual field. $48-50$ Patients are instructed to start scanning from the anchor cue. In one study, this strategy was internalised by teaching the patient to turn his head till the tip of his chin was in line with the top of his left shoulder and to move his head until the tip of his chin was in line with the top of his right shoulder. ${ }^{51}$

Apraxia: Three studies were found describing strategies aimed at apraxia. Two strategies were aimed at teaching patients to infer the function of an object from its structure. ${ }^{55,56}$ The other study was aimed at teaching strategies like verbalisation and the use of pictures to improve the internal concept of a the task, the execution of a task, or the control over a task. One of these three interventions was chosen, depending on the type of problems a patient was experiencing. ${ }^{21}$

Daily activities: Three studies were found describing strategies specifically aimed at improving the performance of daily activities. ${ }^{57-59}$ No overall strategies could be identified as the studies used widely differing interventions, namely checklist training, the use of an assistive technology device and the use of mental imagery of daily tasks.

\section{Measurement of transfer}

A variety of outcome measures was used to asses transfer. All outcome measures could be classified in one of the following three outcome types. Most studies used a combination of these outcome types.

Non-trained items ( $N=11)$ : transfer of treatment is measured by assessing performance on items similar to the items that were used during training.

Daily tasks $(N=23)$ : transfer of treatment is measured by using standardised observations of a simulated performance of daily tasks in a laboratory environment.

Daily life $(N=21)$ : transfer to daily life situations is measured. In this type of transfer measurement, three different perspectives can be distinguished:

(1) Patients (self reports): the patient judges his or her own functioning. Outcome measures are questionnaires (focussed on quality of life, the use of compensatory strategies or experienced problems due to the cognitive deficit), diary entries and non standardised remarks.

(2) Caregivers: people living with the patient judge the patient's functioning. 
Outcome measures are questionnaires focussed on experienced problems due to the cognitive deficit and non standardised remarks based on coincidental observations.

(3) Staff: members of the rehabilitation team judge the patient's functioning. Outcome measures are standardised rating scales and non standardised remarks based on coincidental observations.

\section{Outcome}

At least one type of transfer was demonstrated in 36 of the 41 evaluated studies. However, in 15 of these studies, the transfer effect was not statistically tested. As was mentioned before, most studies evaluated more than one type of transfer. Table 2 displays the data, arranged in the three types of transfer.

In a relatively large number of studies, transfer to daily life was evaluated $(\mathrm{N}=22)$. This type of transfer was demonstrated in eighteen of the twenty-two studies. However, transfer effects were not statistically tested in twelve of the eighteen studies that demonstrated transfer to daily life. Transfer to daily tasks was the most often evaluated type of transfer. Twenty-three studies evaluated this type of transfer and it was demonstrated in nineteen of these studies. Fifteen of these studies did statistically test the positive research findings; four did not. Transfer to non-trained items was demonstrated in eight studies, three of which used statistical testing.

Only twelve evaluations of all types of transfer combined did not demonstrate transfer. Ten of these negative findings were statistically corroborated, two were not. No similarities could be identified in the studies reporting negative findings.

Table 2: Number of studies that evaluated and demonstrated the three types of transfer.

\begin{tabular}{lccc}
\hline Type of transfer & $\begin{array}{c}\text { Total number of studies } \\
\text { (transfer demonstrated) }\end{array}$ & $\begin{array}{c}\text { Transfer demonstrated - } \\
\text { statistically tested }\end{array}$ & $\begin{array}{c}\text { Transfer demonstrated - } \\
\text { not statistically tested }\end{array}$ \\
\hline Non-trained items & $11(8)$ & 3 & 5 \\
Daily tasks & $23(19)$ & 15 & 4 \\
Daily life & $22(18)$ & 6 & 12
\end{tabular}

Note: A total of 39 papers, describing 41 studies was included in this review; several studies evaluated more than one type of transfer.

\section{Discussion}

We carried out a literature search to inventory studies evaluating transfer effects of cognitive strategy training, resulting in the identification of 41 studies. This is a small number of studies, compared with the large number of studies on cognitive rehabilitation that was reviewed by Cicerone et al.4,5 Many different strategies and many different outcome measures were used in the studies. However, most strategies could be classified as the classical intervention strategies used in cognitive rehabilitation. ${ }^{60}$ Outcome measures could be classified in 
three groups: non-trained items, daily tasks and daily life. The studies we evaluated include the cognitive domains that were also identified by the review of Cicerone et al.4,5 In addition, a seventh group of studies was identified, consisting of strategies that were aimed at the training of daily activities, not specifically aimed at a single cognitive disorder. In accordance with Cicerone et al, ${ }^{4,5}$ we found relatively large numbers of studies evaluating transfer of training effects in the domains of neglect, memory and language, compared with the other domains. This reflects the fact that the domains of neglect, memory and language are in general more often studied than other cognitive domains.

\section{Limitations of the review}

We acknowledge that we could have missed articles that did measure 'transfer' if the term was not mentioned in the abstract or keywords of the paper. We therefore reviewed an independent sample of articles that were included in the updated review of Cicerone et $\mathrm{al}^{5}$ containing all recently published studies on cognitive rehabilitation. Our sample consisted of $15 \%$ of the studies that were included in the updated review, that is, 13 of the 87 studies that were included by Cicerone et al. ${ }^{5}$ Studies were selected from each category in proportion to the number of studies Cicerone et al. included in the different categories they distinguished. Of these thirteen studies, three turned out to be included in our review and two studies were retrieved by our search strategy, but were not included in our review as they did not meet with our inclusion criteria. Seven studies could be excluded, based on our exclusion criteria. Thus, the conclusion of this sample is that we missed one out of thirteen studies. To our opinion, this is an acceptable result.

\section{Limitations of the evaluated studies}

\section{Methodological issues}

Many studies used single subject designs or had a small sample size. Furthermore it should be noted that many positive results were not statistically tested. This especially was the case in studies that evaluated transfer to daily life. In six studies the demonstration of transfer to daily life was based on coincidental observations of people living with the patient, or on coincidental remarks the patient made. In these studies, identifying transfer to daily life was not formulated as an aim of the study beforehand and therefore, it was not measured in a standardised way.

\section{Choice of outcome measures}

A type of transfer we excluded from this review is transfer to neuropsychological tests, measuring transfer effects of cognitive strategy training to cognitive functions. The aim of a strategy training is not to improve cognitive functioning, but to teach patients ways to function as independently as possible, despite the presence of the cognitive deficits. Therefore, little change in cognitive deficits is expected in cognitive strategy training. ${ }^{2}$ However, thirteen studies we included 
in our review, did evaluate transfer effects of strategy training to neuropsychological test results besides one of the other types of transfer we distinguished.22,23,26,27,29,31,34,36,47,48,50-52 Eleven studies did report the occurrence of transfer to neuropsychological test results. Two of these studies do report that their findings are surprising, since cognitive functioning was not expected to improve.23,26 Two other studies distinguished between neuropsychological tests in which the trained strategy could not be used versus tests in which the strategy could be used, because the components of the test reflected the focus of the training. ${ }^{22,29}$ In this way, the fact that in most neuropsychological tests, subjects are not allowed to use the strategies they learned to use, is annulled.

Evaluation of the effectiveness of a rehabilitation programme should be attuned to the results that are to be expected of this programme. When evaluating the effectiveness of a rehabilitation programme, the study should ideally be aimed at assessing transfer to daily life, as teaching patients to function as independently as possible in their own homes and in society is considered to be the primary goal of rehabilitation practice. ${ }^{1,61}$ Unfortunately, it seems hard to evaluate this type of transfer in a standardised way. Most studies that we identified as measuring transfer to daily life, made use of self reports of the patients by analysing questionnaires, diary entries and coincidental remarks the patient made. The standardisation of the latter two methods can obviously be doubted. However, one can also argue about the reliability of a self report questionnaire filled in by an ABI patient. ${ }^{62}$ Apparently there is a lack of reliable, standardised instruments to measure this type of transfer, making it very hard to evaluate the effectiveness of a rehabilitation programme.

Although, of course, demonstrating transfer to daily life is the most ideal way to prove the clinical effectiveness of a rehabilitation programme, demonstrating transfer to (simulated) daily tasks, performed in standardised laboratory settings can be seen at 'the next best thing'. We identified 23 studies evaluating this type of transfer, fifteen of which statistically demonstrated it.

\section{General conclusions}

Transfer of training effects of cognitive strategy training has been evaluated in a relatively small number of studies. Outcome measures used in these studies could be classified in three groups: non-trained items, daily tasks and daily life. Most studies reported positive results with regard to the occurrence of transfer of training effects, although some serious remarks can be made concerning the methodological quality of the studies.

\section{Recommendations for future research}

To be able to evaluate the effectiveness of cognitive strategy training more studies are needed, specifically designed to measure transfer effects. In accordance, a workshop organised by the National Center for Medical Rehabilitation Research in the USA recommends that more attention should be paid to the investigation of transfer of rehabilitation programmes; particularly to transfer of functionally important tasks in meaningful task environments. ${ }^{63}$ 
While designing a study to measure transfer effects of cognitive strategy training, two important factors should be taken into account. First, before starting the study, measuring transfer should be set as the primary aim of the study, hence making sure that transfer effects can be measured and statistically tested in a standardised way. Second, outcome measures should be chosen carefully, taking into account what the aim of the therapy is and whether reliable, standardised instruments exist to evaluate this aim. Studies aimed at evaluating transfer should use measures of activities as their primary outcome, demonstrating whether or not the strategy actually reduces limitations on activities, thus measuring transfer effects to daily tasks. In the studies we included in our review, this type of transfer was assessed by using standardised observations of a simulated performance of daily tasks in a laboratory environment. However, standardised observations of the simulated performance of daily tasks can also be made in daily settings, for example by observing a participant who performs a specific task in his own home setting. This outcome measure provides more information on the participant's functioning in daily settings, although, of course, it is not an exact reflection of the participant's performance in everyday life.

In addition, studies investigating whether and in what way transfer itself can be trained, could provide valuable information for clinical practice. The prerequisites for the occurrence of transfer derived from educational psychology that were described in the introduction of this paper, could be considered to be a good starting point for answering this question. In clinical practice several of these prerequisites are already being applied. Three of these recommendations were actively used in the studies we described. First, three studies explicitly described that during training attention was paid to the enlargement of the patient's awareness of his own deficits. ${ }^{23,26,27}$ This is an important prerequisite for the occurrence of transfer as someone must acknowledge that there is a need to adapt his behaviour. ${ }^{14} \mathrm{Next}$, it was stated that general knowledge is by definition easier to transfer than specific knowledge. ${ }^{15}$ This distinction corresponds to the distinction between strategy training and task specific training. Strategy training is said to be more generally applicable than task specific training. ${ }^{10}$ All studies included in this review evaluated transfer effects of cognitive strategy training. Lastly, a small number of studies specifically used 'training for transfer',23,24,44 corresponding with the statement that transfer does not occur automatically and that it takes place during learning, not afterwards. ${ }^{8,17}$ However, three recommendations of educational psychology do not reappear in the strategies that were described in the papers. Possibly, they have been used during training, but were not described in the papers.

The aim of this paper was to investigate the occurrence of transfer of cognitive strategy training for ABI patients. We hope that by means of this paper, clinical practitioners as well as researchers working in rehabilitation settings become more aware of the importance of transfer to the clinical success of a rehabilitation programme, and of the way in which transfer of training effects should be 
evaluated. We are certain that this awareness will make a vast difference while applying and studying rehabilitation practice.

\section{References}

1. Wilson BA. Compensating for cognitive deficits following brain injury. Neuropsychol Rev 2000;10(4):233-243.

2. Fasotti 1, Kovacs F. Slow information processing and the use of compensatory strategies. In: Chamberlain MA, editor. Traumatic brain injury rehabilitation: services, treatments and outcomes. London: Chapman \& Hall; 1995.

3. Ben-Yishay Y, Diller L. Cognitive remediation in traumatic brain injury: Update and issues. Arch Phys Med Rehabil 1993;74:204-213.

4. Cicerone KD, Dahlberg C, Kalmar K, Langenbahn DM, Malec JF, Bergquist TF, et al. Evidencebased cognitive rehabilitation: Recommendations for clinical practice. Arch Phys Med Rehabil 2000;81(12):1596-615.

5. Cicerone KD, Dahlberg C, Malec JF, Langenbahn DM, Felicetti T, Kneipp S, et al. Evidence-based cognitive rehabilitation: Updated review of the literature from 1998 through 2002. Arch Phys Med Rehabil 2005;86:1681-1692.

6. Singley MK, Anderson JR. The transfer of cognitive skill. Cambridge: Harvard University Press; 1989.

7. Marini A, Genereux R. The challenge of teaching for transfer. In: McKeough A, Lupart J, Marini A, editors. Teaching for transfer: Fostering generalization in learning. Mahwah: Lawrence Erlbaum Associates; 1995. p. 1-20.

8. Haskell RE. Transfer of learning: Cognition, instruction, and reasoning. San Diego: Academic Press; 2001.

9. Annett J. Motor skills. In: Mackintosh NJ, Colman AM, editors. Learning and skills. London: Longman; 1995. p. 56-75.

10. Byrnes JP. Cognitive development and learning in instructional contexts. Boston: Allyn and Bacon; 1996.

11. Gagne ED, Walker Yekovich C, Yekovich FR. The cognitive psychology of school learning. New York: HarperCollins College Publishers; 1993.

12. Cormier SM, Hagman JD. Introduction. In: Cormier SM, Hagman JD, editors. Transfer of learning. Contemporary research and applications. San Diego: Academic Press; 1987. p. 1-8.

13. Campione JC, Shapiro AM, Brown AL. Forms of transfer in a community of learners: Flexible learning and understanding. In: McKeough A, Lupart J, Marini A, editors. Teaching for transfer: Fostering generalization in learning. Mahwah: Lawrence Erlbaum Associates; 1995. p. 35-68.

14. Crosson B, Barco PP, Velozo CA, Bolesta MM, Cooper PV, Werts D, et al. Awareness and compensation in postacute head injury rehabilitation. J Head Trauma Rehabil 1989;4(3):46-54.

15. Salomon G, Perkins DN. Rocky roads to transfer: Rethinking mechanisms of a neglected phenomenon. Educational Psychologist 1989;24(2):113-142.

16. Pinnington LL, Ward CD. Learning and skill acquisition. In: Greenwood RJ, Barnes MP, McMillan TM, Ward CD, editors. Handbook of neuropsychological rehabilitation. Hove: Psychology Press; 2003.

17. Perkins DN, Salomon G. Teaching for transfer. Educational Leadership 1988;46:22-32.

18. OvidTechnologies. Silverplatter's information retrieval system for the world wide web. In. 5.1 ed. Sandy, Utah: Ovid Technologies; 2005.

19. Berg IJ. Memory rehabilitation for closed-head injured patients. Amsterdam: Vrije Universiteit; 1993. 
20. van Tulder MW, Assendelft WJJ, Koes BW, Bouter LM. Method guidelines for systematic reviews in the Cochrane Collaboration back review group for spinal disorders. Spine 1997;22:2323-2330.

21. Geusgens C, van Heugten C, Donkervoort M, van den Ende E, Jolles J, van den Heuvel W. Transfer of training effects in stroke patients with apraxia: An exploratory study. Neuropsychol Rehabil 2006;16(2):213-229.

22. Kaschel R, Della Sala S, Cantagallo A, Fahlbock A, Laaksonen R, Kazen M. Imagery mnemonics for the rehabilitation of memory: A randomized group controlled trial. Neuropsychol Rehabil 2002;12(2):127-153.

23. Fleming JM, Shum D, Strong J, Lightbody S. Prospective memory rehabilitation for adults with traumatic brain injury: A compensatory training programme. Brain Inj 2005;19(1):1-10.

24. Kime SK, Lamb DG, Wilson BA. Use of comprehensive programme of external cueing to enhance procedural memory in a patient with dense amnesia. Brain Inj 1996;10(1):17-25.

25. Robson J, Marshall J, Chiat S, Pring T. Enhancing communication in jargon aphasia: A small group study of written therapy. Int J Lang Commun Disord 2001;36(4):471-488.

26. Fasotti L, Kovacs F, Eling PATM, Brouwer WH. Time pressure management as a compensatory strategy training after closed head injury. Neuropsychol Rehabil 2000;10(1):47-65.

27. Cicerone KD. Remediation of 'working attention' in mild traumatic brain injury. Brain Inj 2002;16(3):185-195.

28. Dirette D. The use of cognitive strategies by adults with acquired brain injuries: Results of a twoyear post-treatment survey. The Journal of Cognitive Rehabilitation 2002;20(4):6-10.

29. Cicerone KD, Wood JC. Planning disorder after closed head injury: A case study. Arch Phys Med Rehabil 1987;68:111-115.

30. Levine B, Robertson IH, Clare L, Carter G, Hong J, Wilson BA, et al. Rehabilitation of executive functioning: An experimental-clinical validation of goal management training. J Int Neuropsychol Soc 2000;6(3):299-312.

31. Neistadt ME. A meal preparation treatment protocol for adults with brain injury. Am J Occup Ther 1994;48(5):431-438.

32. Foxx RM, Martella RC, Marchand-Martella NE. The acquisition, maintenance, and generalization of problem-solving skills by closed head-injured adults. Behav Ther 1989;20:61-76.

33. Liu KPY, Chan CCH, Lee TMC, Li LSW, Hui-Chan CWY. Self-regulatory learning and generalization for people with brain injury. Brain Inj 2002;16(9):817-824.

34. Boman I, Lindstedt M, Hemmingsson H, Bartfai A. Cognitive training in home environment. Brain Inj 2004;18(10):985-995.

35. Wade TK, Troy JC. Mobile phones as a new memory aid: A preliminary investigation using case studies. Brain Inj 2001;15(4):305-320.

36. Doornhein K, de Haan EHF. Cognitive training for memory deficits in stroke patients. Neuropsychol Rehabil 1998;8:393-400.

37. Milders M, Deelman B, Berg I. Rehabilitation of memory for people's names. Memory $1998 ; 6(1): 21-36$

38. Hinckley JJ, Patterson JP, Carr TH. Differential effects of context- and skill-based treatment approaches: Preliminary findings. Aphasiology 2001;15(5):463-476.

39. Hopper T, Holland A. Situation -specific training for adults with aphasia: An example. Aphasiology 1998;12(10):933-944.

40. Jacobs BJ. Social validity of changes in informativeness and efficiency of aphasic discourse following linguistic specific treatment (LST). Brain Lang 2001;78:115-127.

41. Maneta A, Marshall J, Lindsay J. Direct and indirect therapy for word sound deafness. Int J Lang Commun Disord 2001;36(1):91-106. 
42. Nitzberg Lott S, Friedman RB. Can treatment for pure alexia improve letter-by-letter reading speed without sacrificing accuracy. Brain Lang 1999;67:188-201.

43. Robson J, Marshall J, Pring T, Chiat S. Phonological naming therapy in jargon aphasia: Positive but paradoxal effects. J Int Neuropsychol Soc 1998;4:675-686.

44. Robson J, Pring T, Marshall J, Morrison S, Chiat S. Written communication in undifferentiated jargon aphasia: A therapy study. Int J Lang Commun Disord 1998;33(3):305-328.

45. Richards K, Singletary F, Gonzalez Rothi LJ, Koehler S, Crosson B. Activation of intentional mechanisms through utilization of nonsymbolic movements in aphasia rehabilitation. $J$ rehabil Res Dev 2002;38(4):445-454.

46. Wambaugh JL, Martinez AL. Effects of rate and rhythm control treatment on consonant production accuracy in apraxia of speech. Aphasiology 2000;14(8):851-871.

47. Antonucci G, Guariglia C, Judica A, Magnotti L, Paolucci S, Pizzamiglio L, et al. Effectiveness of neglect rehabilitation in a randomized group study. J Clin Exp Neuropsychol 1995;17(3):383-389.

48. Bailey MJ, Riddoch MJ, Crome P. Treatment of visual neglect in elderly patients with stroke: A single-subject series using either a scanning and cueing strategy or a left-limb strategy. Phys Ther 2002;82(8):782-797.

49. Gouvier WD, Bua BG, Blanton PD, Urey JR. Behavioral changes following visual scanning training: Observantions of five cases. The International Journal of Clinical Neuropsychology 1987;9(2):74-80.

50. Hanlon RE, Dobkin BH, Hadler B, Ramirez S, Cheska Y. Neurorehabilitation following right thalamic infarct: Effects of cognitive retraining on functional performance. J Clin Exp Neuropsychol $1992 ; 14(4): 433-447$.

51. Niemeier JP, Cifu DX, Kishore R. The lighthouse strategy: Improving the functional status of patients with unilateral neglect after stroke and brain injury using a visual imagery intervention. Top Stroke Rehabil 2001;8(2):10-18.

52. Pizzamiglio L, Antonucci G, Judica A, Razzano C, Zoccolotti P. Cognitive rehabilitation of the hemineglect disorder in patients with unilateral right brain damage. J Clin Exp Neuropsychol 1992;14(6):901-923.

53. Pizzamiglio L, Fasotti L, Jehkonen M, Antonucci G, Magnotti L, Boelen D, et al. The use of optokinetic stimulation in rehabilitation of the hemineglect disorder. Cortex 2004;40:441-450.

54. Webster JS, P.T. M, Rapport LJ, Morill B, Roades LA, Abadee PS. Computer-assisted training for improving wheelchair mobility in unilateral neglect patients. Arch Phys Med Rehabil 2001;82:769775 .

55. Goldenberg G, Hagmann S. Therapy of activities of daily living in patients with apraxia. Neuropsychol Rehabil 1998;8(2):123-141.

56. Goldenberg G, Daumuller M, Hagmann S. Assessment and therapy of complex activities of daily living in apraxia. Neuropsychol Rehabil 2001;11(2):147-169.

57. Gorman P, Dayle R, Hood C, Rumrell L. Effectiveness of the ISAAC cognitive prosthetic system for improving rehabilitation outcomes with neurofunctional impairment. NeuroRehabilitation 2003;18:57-67.

58. Liu KP, Chan CC, Lee TM, Hui-Chan CW. Mental imagery for promoting relearning for people after stroke: A randomized controlled trial. Arch Phys Med Rehabil 2004;85:1403-1408.

59. O'Reilly MF, Green G, Braunling-McMorrow D. Self-administered written prompts to teach home accident prevention skills to adults with brain injuries. J Appl Behav Anal 1990;24:431-446.

60. Wilson BA. Neuropsychological rehabilitation: Theory and practice. Lisse: Swets \& Zeitlinger; 2003.

61. Carney N, Chesnut RM, Maynard H, Mann NC, Patterson P, Helfand M. Effect of cognitive rehabilitation on outcomes for persons with traumatic brain injury: A systematic review. J Head Trauma Rehabil 1999;14(3):277-307. 
62. Lezak MD. Neuropsychological Assessment. 3 ed. New York: Oxford University Press; 2004.

63. Fuhrer MJ, Keith RA. Facilitating patient learning during medical rehabilitation. Am J Phys Med Rehabil 1998;77(6):557-561. 


\section{Appendix 1}

\section{Details of literature search}

Controlled vocabulary words (combinations of these terms)

\begin{tabular}{ll} 
Category & Terms \\
\hline Type of brain injury & Brain injury TBI, cerebrovascular accident, CVA, brain \\
Transfer & contusion, brain concussion \\
& Transfer (psychology), transfer (learning), generalization \\
& (psychology), generalization (learning), learning, \\
& transferability, learning environment - clinical, activities of \\
& daily living \\
& Neurobehavioral manifestations, cognitive impairment, \\
Type of disorder & cognitive defect, cognition disorders, cognition (OMAHA) \\
& Rehabilitation, cognitive rehabilitation, neuropsychological \\
Type of intervention & rehabilitation, rehabilitation - community based, home \\
& rehabilitation, education
\end{tabular}

Free text words (combinations of these terms and in combination with controlled vocabulary words)

\begin{tabular}{ll}
\hline Category & Terms \\
\hline Type of brain injury & "traumatic brain injury", stroke, contusion, CVA, "cerebro \\
& vascular accident" \\
Transfer & Transfer, generalisation, generalization, "environmental \\
& validity", "environmental valid", "activities of daily living", \\
& ADL \\
Type of disorder & "Cognit* disorder", "cognitive impairment" \\
Type of intervention & Rehabilitation, remediation, compensation, strategy, \\
& "compensatory strategy", "compensation training", \\
& "compensatory training", "strategy training", "cognitive \\
& training", "cognitive retraining", "cognitive rehabilitation", \\
& "cognitive remediation", "remediation strategy"
\end{tabular}


Chapter 5

\section{Transfer of training effects in stroke patients with apraxia: An exploratory study}

Published in:

Neuropsychological rehabilitation, 2006; 16(2): 213-229

C. Geusgens, C. van Heugten, M. Donkervoort, E. van den Ende, J. Jolles, W. van den Heuvel 


\begin{abstract}
Objective: To examine the transfer of the effects of cognitive strategy training for stroke patients with apraxia from trained to non-trained tasks. In strategy training, the occurrence of transfer is expected as the training programme is not aimed at relearning specific tasks, but at teaching patients new ways to handle the problems resulting from the impairment.

Methods: Exploratory analyses were conducted on data previously collected in a randomised clinical trial (RCT) on the efficacy of the strategy training. A total of 113 left hemisphere stroke patients were randomly assigned to a strategy training group and a group receiving occupational therapy as usual. Assessment of apraxia, motor functioning and activities of daily living (ADL) took place at baseline, after an eight-week treatment period, and five months after baseline. The primary outcome measure consisted of standardised ADL observations of trained and non-trained tasks.

Results: The analyses showed that in both treatment groups, the scores on the ADL observations for non-trained tasks improved significantly after eight weeks of training as compared with the baseline score. Change scores of non-trained activities were larger in the strategy training group as compared with the usual treatment group.

Conclusion: By using previously collected data we are able to illustrate the potential transfer of treatment effects in a large sample of stroke patients. We found indications for the occurrence of transfer, although the study was not originally designed for the purpose of evaluating transfer. Therefore these results are worth to be explored more profoundly. We will further investigate our preliminary conclusions in a new prospective study which is specifically designed to examine the transfer of training effects.
\end{abstract}




\section{Introduction}

A wide range of cognitive impairments can occur after stroke, one of which is apraxia. Apraxia is an impairment affecting the purposeful execution of learned and meaningful skills that cannot be explained by primary motor or sensory impairments, nor by deficits in motivation, memory or comprehension. ${ }^{1}$ Apraxia usually occurs following left hemisphere lesions. ${ }^{2}$ Recently the prevalence of apraxia has been investigated on the stroke unit of a rehabilitation centre in the Netherlands. A total of $51.3 \%$ of the patients with a left hemisphere stroke were found to have apraxia, as opposed to $6.0 \%$ of the patients with a right hemisphere stroke. ${ }^{3}$ It is agreed that apraxia can have a negative impact on the performance of activities of daily living (ADL), and that therefore the treatment of apraxia should be incorporated into the rehabilitation programme. ${ }^{4-10}$ Because of this growing awareness, patients in rehabilitation settings who suffer from apraxia are frequently referred to occupational therapists.

Van Heugten et $\mathrm{al}^{8}$ developed a standardised occupational therapy programme for left hemisphere stroke patients with apraxia, which is based on teaching patients strategies to compensate for the presence of apraxia. The aim of the therapy is to maximise the patients' independence by improving ADL functioning; little change is expected in the severity of the apraxia itself. This therapy programme has been evaluated in two studies, one non-controlled intervention study ${ }^{8}$ and one experimental effect study; ${ }^{4}$ both studies showed the success of the intervention.

In the experimental effect study, Donkervoort et al ${ }^{4}$ investigated ADL functioning of left hemisphere stroke patients with apraxia. The experimental group received strategy training for apraxia, while the other interventions that are normally carried out by occupational therapists were conducted as usual, the control group received the usual occupational therapy only, including the usual training for apraxia. The study showed that after an eight-week treatment period, strategy training integrated into the usual occupational therapy was more effective in improving ADL functioning in left hemisphere stroke patients than usual occupational therapy only. At the end of the follow-up period, both groups were comparable in ADL-functioning, suggesting strategy training had no longterm effects. However, significantly more patients in the usual treatment group were still receiving occupational therapy at follow-up. This finding suggests that patients in the usual treatment group needed more occupational therapy to obtain a corresponding level of improvement on ADL functioning than patients who received strategy training.

The aim of a rehabilitation programme is to restore patients to their greatest potential and maximum independence, hopefully resulting in independent functioning, the return to their own homes and participation in society. For patients to function as independently as possible at home, tasks which are taught in the rehabilitation setting should be transferred to the home setting. Moreover, therapists cannot possibly train all the difficulties and tasks a patient will encounter after rehabilitation discharge. Therefore, transfer of strategies 
from trained tasks to non-trained (related) tasks is of great importance in terms of the clinical success of a therapy programme. In strategy training, the occurrence of transfer is expected as the training programme is not aimed at relearning specific tasks, but at teaching patients new ways to handle the problems resulting from the impairment. In a recent review Cicerone points out that relatively few studies have tried to answer the transfer question by directly evaluating transfer of treatment effects to everyday situations or behaviours. Several of these studies provide evidence to support the occurrence of transfer. ${ }^{11}$ Most of these studies, however, used relatively small sample sizes. In addition, these studies evaluated strategy training for other cognitive functions than apraxia.

To our opinion, answering the transfer question is very important in terms of the clinical success of an intervention. Further analyses of the data of the experimental effect study by Donkervoort et $\mathrm{al}^{4}$ enable the exploration of transfer of the effects of strategies taught by means of the occupational therapy programme for left hemisphere stroke patients with apraxia. In the study by Donkervoort et $\mathrm{al}^{4}$ the performance on four ADL tasks was measured during a period of 20 weeks in which three tasks may have been trained, whereas it was agreed that one of the four tasks would not be trained. For more detailed information on methods and results of this study, see Donkervoort et al. ${ }^{4}$ The goal of the present study was to examine the possibility of the occurrence of transfer of a cognitive strategy training for stroke patients with apraxia.

\section{Methods}

\section{Patients}

For 2.5 years, occupational therapists at 49 Dutch institutions (15 rehabilitation centres and 34 nursing homes) reported every consecutive patient with left hemisphere stroke referred for occupational therapy. Patients were eligible if they met the following inclusion criteria: (1) a left hemisphere stroke; (2) apraxia; and (3) admittance to an inpatient care unit. Exclusion criteria mainly concerned factors of medical history (see Donkervoort et $\mathrm{al}^{4}$ for more detailed information on the exclusion criteria). The diagnosis of apraxia involved two steps. First, the patient's treating medical team made a clinical diagnosis. The patient was said to be apraxic if (a) the patient showed an inability (or restriction in the ability) to carry out purposeful tasks and (b) this inability was not the result of a primary motor or sensory impairment, or deficit of comprehension, memory or motivation. Second, before final inclusion in the study, patients were tested by a researcher for severity of apraxia. ${ }^{12}$ Patients who showed no or minimal apraxic symptoms on the apraxia test (score above 87 ) were excluded from the study.

A total of 139 patients was selected for the study by the occupational therapists; 26 patients were excluded for various reasons: a score above 87 on the apraxia test $(\mathrm{N}=11)$, withdrawal of consent $(\mathrm{N}=4)$, discharge from the institute $(\mathrm{N}=7)$ and poor condition of the patient $(\mathrm{N}=4)$. After randomisation of the remaining 113 patients, the strategy training group consisted of 56 patients and 
the usual treatment group consisted of 57 patients. Patients in the two intervention groups did not differ significantly with respect to the baseline characteristics, except for age (see table 1); patients in the strategy training group were older. All patients and their families received verbal and written information about the study and gave verbal as well as written consent to participate.

Table 1: Comparability of the intervention groups with respect to demographic and clinical characteristics $(\mathrm{N}=113)$

\begin{tabular}{|c|c|c|}
\hline & $\begin{array}{l}\text { Strategy training } \\
\quad(\mathrm{N}=56)\end{array}$ & $\begin{array}{l}\text { Usual treatment } \\
\qquad(\mathrm{N}=57)\end{array}$ \\
\hline \multicolumn{3}{|l|}{ Gender, N (\%) } \\
\hline Male & $29 / 56(52)$ & $35 / 57$ (61) \\
\hline Female & $27 / 56(48)$ & $22 / 57$ (39) \\
\hline Age at stroke, mean (SD) * & $67.6(11.7)$ & $63.3(11.6)$ \\
\hline \multicolumn{3}{|l|}{ Education, $\mathrm{N}(\%)$} \\
\hline Low & $19 / 56(34)$ & $25 / 57$ (44) \\
\hline Middle & $17 / 56(30)$ & $12 / 57(21)$ \\
\hline High & $8 / 56(14)$ & $5 / 57$ (9) \\
\hline Unknown & $12 / 56(21)$ & $15 / 57(26)$ \\
\hline Right handedness, N (\%) & $50 / 56(89)$ & $54 / 57$ (95) \\
\hline \multicolumn{3}{|l|}{ Type of stroke, $\mathrm{N}(\%)$} \\
\hline Haemorrhage & $12 / 56(21)$ & $4 / 57(7)$ \\
\hline Infarction & $42 / 56(73)$ & $48 / 57$ (84) \\
\hline Otherwise/unknown & $3 / 56(5)$ & $5 / 57$ ( 9 ) \\
\hline Time since stroke in days, mean (SD) & $100.2(63.3)$ & $102.9(70.7)$ \\
\hline \multicolumn{3}{|l|}{ Test results } \\
\hline Apraxia, mean (SD) & $57.3(21.2)$ & $62.0(17.9)$ \\
\hline Functional Motricity Test, mean (SD) & $6.5 \quad(3.9)$ & $5.3(3.5)$ \\
\hline Barthel Index, mean (SD) & 10.7 ( 4.9) & $11.2(5.0)$ \\
\hline Verbal Comprehension, mean (SD) & $32.9(8.7)$ & 32.6 ( 6.6$)$ \\
\hline
\end{tabular}

$\mathrm{N}$ : number of subjects; SD: standard deviation

* Difference between intervention groups, 2-tailed significance $\mathrm{p}<0.05$

\section{Study design}

A randomised, single blind, controlled trial design was used to compare the effect of strategy training (integrated into usual occupational therapy) with the effect of usual occupational therapy only. Patients were followed over a period of five months. During the first eight weeks patients received treatment according to their randomisation. Baseline measurements took place immediately after inclusion. After the eight-week treatment period, a second measurement took place, and the final measurement was at follow-up five months after the first assessment. During each measurement, performance on four standardised ADL tasks was evaluated. The four tasks had the same level of difficulty on the classification of tasks on the Assessment of Motor and Process Skills (AMPS), in terms of both motor and process skill abilities needed to perform these tasks. ${ }^{13}$ The four tasks were: (a) washing the face and upper body; (b) putting on a shirt or blouse; (c) preparing and eating a sandwich; (d) preparing a cup of hot chocolate. The tasks were scored on four aspects: independence, initiation, execution and control. It was agreed that task $d$ (preparing a cup of hot chocolate) would 
never be trained, whereas no agreements were made concerning the training of tasks a - c. The occupational therapists registered the content of the therapy sessions. Based on this information we were able to retrieve the actually trained and non-trained tasks for each participant.

Measurements were conducted by an independent, blinded assessor. Treatment was individualised, as tasks relevant to the patient were trained. Relevant tasks were derived from the interests of the patient and the role the patient was going to fulfil in society. No arrangements were made on the tasks that would be trained by the occupational therapists, except for the agreement not to train one of the ADL tasks that would be observed by the assessor. Treatment of patients during the follow-up period was not prescribed in specific study guidelines, except for the agreement not to train the fourth ADL task. The study protocol was approved by the ethics committees of all participating institutions.

\section{Scoring method in the present study}

For the purpose of the present study, one overall mean score for tasks that had been trained was achieved, as well as one mean score for tasks that had not been trained. The mean scores ranged from totally dependent (score 0) to totally independent (score 3).

\section{Interventions}

The experimental treatment was standardised by means of a treatment protocol, developed in an earlier study. ${ }^{8}$ The occupational therapists in the strategy training group received additional training on how to use the protocol, consisting of a full-day course followed by several booster meetings. Differences between institutions with regard to the amount of treatment, the content of the usual occupational therapy and treatment outside the occupational therapy department were controlled for by the randomisation procedure.

\section{Strategy training}

Strategy training consisted of the standardised treatment programme for left hemisphere stroke patients with apraxia, developed by van Heugten and colleagues, ${ }^{8}$ which is based on teaching patients strategies to compensate for the presence of apraxia. By means of this programme the patient is gradually taught more efficient strategies. The aim of the therapy is to maximise the patient's independence by improving ADL functioning. During a detailed diagnostic assessment of disability (standardised ADL observations), the specific problems of each individual patient are examined. These problems will be the focus of attention during therapy; an intervention is chosen in correspondence with the observed problems. ADL tasks are conceptualised as being composed of three successive phases, according to the framework of information processing: the proper plan of action and the correct objects have to be selected (initiation and orientation), followed by adequate execution of the selected plan (execution), which has to be evaluated in terms of the result, and if necessary cor- 
rected (control and correction). Corresponding to these phases, the specific interventions focus on instructions, assistance and feedback, respectively. This diagnostic assessment is strictly used for clinical purposes and is therefore independent of the study.

\section{Usual treatment}

During the trial, usual occupational therapy concentrated on (sensory)motor, perceptual and cognitive deficits of the stroke patient and aimed at increasing independent functioning in ADL tasks. In general, the main focus of the therapy was on (sensory)motor impairments (e.g. muscle tone, reflexes, controlled movements, muscle strength, contractures) and disability due to these impairments. A variety of treatment methods have been mentioned in the literature and used in daily practice. Nowadays, strategy training is incorporated more in the usual occupational therapy.

\section{Measurements}

ADL functioning

ADL functioning was measured in two ways:

1. ADL observations ${ }^{14}$ : These are a set of standardised observations, especially developed to assess disability in ADL functioning due to apraxia. The internal consistency and inter-observer reliability of this observational procedure have been found to be good.14,15 The performance on four standardised tasks mentioned earlier was observed. The tasks were scored on four aspects: independence, initiation, execution and control. Scores on the observations range from totally dependent (score 0) to totally independent (score 3).

2. Barthel ADL Index ${ }^{16,17}$ : The Barthel Index of Tasks of Daily Living is a widely used, well validated scale, which offers a simple and quick, clinically relevant method to identify the most important physical disabilities. The score on the index ranges from 0 to $20.16,17$

\section{Apraxia.}

The Apraxia Test is based on a test by De Renzi.1,12 It consists of two subtests assessing the ability to use objects or pantomime the use of objects (aimed at ideational apraxia) and the ability to imitate gestures with the non-affected ipsilateral arm (aimed at ideomotor apraxia). The maximum score of the total test is 90 , which indicates no signs of apraxic symptoms. The internal consistency, the validity and the inter-observer reliability of the test are found to be good.3,12

\section{Motor functioning}

The Functional Motor Test is a simplified version of the Action Research Arm Test. ${ }^{18}$ The test measures the voluntary functional task of the arm and hand of the affected contralateral side. It consists of four items in which the patient has to use a type of grip (pinch, grip or grasp) to pick up an object, move it forward 
and put it down again. The maximum score on the test is 12 . The internal consistency is good. ${ }^{4}$

\section{Additional measures}

The SAN-test, a standardised test assessing verbal comprehension was used to monitor the patients' understanding of the Dutch language. ${ }^{19}$ Occupational therapists completed a questionnaire (at baseline) on the demographic and clinical, stroke-related data and a questionnaire (at the post-treatment and follow-up assessment) concerning characteristics on the treatment patients received during the study, such as the amount and content of occupational therapy and other therapies received.

\section{Statistical analyses}

\section{Comparability}

Comparability of the treatment groups was assessed in four ways. First, between-group differences in functional impairments were investigated by comparing differences between the intervention groups in motor functioning, apraxia and verbal comprehension. Second, between -group differences in the amount (sessions and hours) of occupational therapy in the eight-week treatment period were investigated. Third, to see whether the proportion of trained tasks and non-trained tasks was comparable within the groups, we used chi-square tests. Fourth, to see whether the scores on trained and non-trained tasks were comparable, we investigated between-group and within-group differences for ADL functioning at baseline, using independent samples t-tests and paired samples t-tests, respectively.

\section{Transfer of training}

To assess the occurrence of transfer, first we graphically displayed the course of the ADL functioning over time. Second, the visible differences were tested. In order to evaluate outcome, change scores were calculated by subtracting baseline scores from post-treatment and follow-up scores, respectively. Change scores of trained and non-trained tasks were compared between and within the two treatment groups, by independent samples t-tests and paired samples ttests, respectively. On the basis of the results of the between-group comparison, an adjusted analysis (ANCOVA) was conducted for the change scores of nontrained tasks. In this analysis we controlled for improvement in motor functioning and apraxia, by including these variables as covariates. As the intervention groups differed with respect to age, this variable was included as a covariate as well. The course of the ADL functioning was examined by a general linear model for repeated measures. In adjusted analyses, we controlled for age and for improvement in motor functioning and apraxia. Main effects were further investigated by contrasts testing.

In all analyses, the level of significance was set at 0.05. Analyses were carried out using SPSS 11.0 for Windows. One-tailed tests were used in analyses where 
the results of the experimental group were compared with the control group, as we expected the experimental group to outperform the control group. Two-tailed tests were used in the analyses that compared trained tasks to non-trained tasks, as we did not have an assumption on the direction of these differences in advance. There was a substantial number of missing values in all analyses. This was caused by the fact that in a relatively large number of participants none of the four tasks that were observed had been trained during the research period (i.e. tables 3 and 4).

\section{Results}

\section{Comparability}

At baseline, no between-group differences in functional impairments were found (see table 1). Also, the amount (sessions and hours) of occupational therapy that patients received during the eight-week treatment period did not differ significantly between the two intervention groups (sessions: $t=-1.06, \mathrm{df}=96$; hours: $\mathrm{t}=-1.63, \mathrm{df}=97$ ). Patients in the experimental group received an average of 25 $(\mathrm{SD}=9.8)$ sessions, resulting in $15(\mathrm{SD}=7.7)$ hours of occupational therapy. The control group received an average of $27(\mathrm{SD}=15.6)$ sessions, resulting in 19 $(\mathrm{SD}=15.0)$ hours of occupational therapy. For all four tasks, the proportion of training and not training was equal in both treatment groups (see table 2), indicating that in the experimental group each task was trained in as many patients as in the control group.

The analyses showed no significant between-group differences on the ADL observations score of trained and non-trained tasks at baseline (trained tasks: $\mathrm{t}=-0.03, \mathrm{df}=68$; non-trained tasks: $\mathrm{t}=-0.747, \mathrm{df}=92$ ). However, within the total group as well as within the two individual treatment groups, patients scored lower on non-trained tasks as compared with their score on trained tasks (total group: $\mathrm{t}=5.07, \mathrm{df}=66, \mathrm{p}=.000$; strategy training group: $\mathrm{t}=3.85, \mathrm{df}=33, \mathrm{p}=.001$; usual treatment group: $\mathrm{t}=3.26, \mathrm{df}=32, \mathrm{p}=.003$ ).

Table 2: Percentage of cases in which the specific task was trained during the course of the study

\begin{tabular}{lllll}
\hline & $\begin{array}{l}\text { Strategy training } \\
(\mathrm{N}=50)\end{array}$ & $\begin{array}{l}\text { Usual treatment } \\
(\mathrm{N}=49)\end{array}$ & Chi-square & p-value \\
\hline Washing face and upper body & 50.0 & 53.1 & 0.09 & 0.761 \\
Putting on shirt/blouse & 44.0 & 57.1 & 1.71 & 0.191 \\
Preparing and eating sandwich & 42.0 & 38.8 & 0.11 & 0.744 \\
Preparing hot chocolate & $2.0 *$ & 0.0 & 0.99 & 0.320
\end{tabular}

* Preparing a cup of hot chocolate was mistakenly trained in one participant.

\section{Transfer of training}

The course of ADL functioning over time is displayed in figure 1 . At week 8 , the two individual treatment groups scored lower on the non-trained tasks than on 
the trained tasks (strategy training group: $\mathrm{t}=2.74, \mathrm{p}=.01$; usual treatment group $\mathrm{t}=3.09, \mathrm{p}=.004$ ). The same was true for test scores at week 20 (strategy training group: $\mathrm{t}=2.88, \mathrm{p}=.008$; usual treatment group: $\mathrm{t}=2.42, \mathrm{p}=.023$ ).

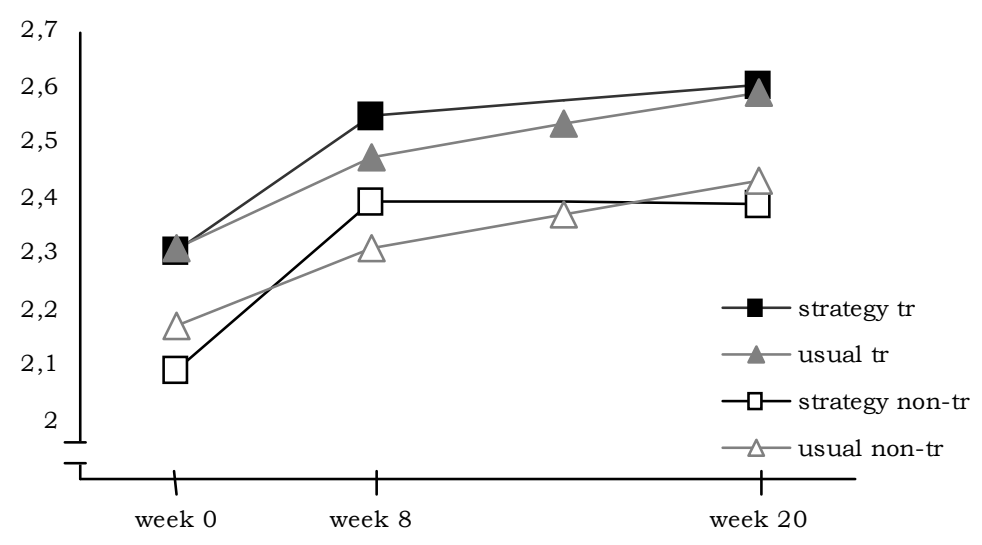

Figure 1: course of ADL observations over time in both treatment groups; overall mean scores on trained and non-trained tasks.

The change score on the ADL observations of non-trained tasks (week 8 week 0) was larger in the strategy training group than in the usual treatment group, this was a significant difference $(\mathrm{t}=1.78, \mathrm{p}=.040)$. After controlling for age and for improvement in motor functioning and apraxia, we found a significant main effect of treatment group $(\mathrm{F}(1,74)=4.59, \mathrm{p}=.035)$, although the model as a whole did not explain a significant proportion of the variance in the difference scores $(\mathrm{F}(4,74)=1.81)$. The other difference scores (i.e. non-trained tasks week 20 - week 0 and trained tasks week 8 - week 0 and week 20 - week 0) did not differ between the two treatment groups (see table 3). Within the two individual treatment groups, there were no significant differences in change scores between trained and non-trained tasks (see table 4).

Table 3: Between group difference in change scores of ADL observations of trained and non-trained tasks: strategy training vs. usual treatment

\begin{tabular}{|c|c|c|c|c|c|c|c|c|}
\hline & \multicolumn{3}{|c|}{ Strategy training group } & \multicolumn{3}{|c|}{ Usual treatment group } & \multirow[b]{2}{*}{$\mathrm{t}$} & \multirow[b]{2}{*}{$\mathrm{p}$-value } \\
\hline & $\mathrm{N}$ & Mean & (SD) & $\mathrm{N}$ & Mean & (SD) & & \\
\hline Non-trained week 8 - week 0 & 41 & 0.307 & $(0.45)$ & 40 & 0.143 & $(0.37)$ & 1.78 & 0.04 \\
\hline Non-trained week 20 - week 0 & 38 & 0.271 & $(0.54)$ & 36 & 0.241 & $(0.48)$ & 0.25 & 0.40 \\
\hline Trained week 8 - week 0 & 32 & 0.208 & $(0.53)$ & 29 & 0.108 & $(0.46)$ & 0.79 & 0.22 \\
\hline Trained week 20 - week 8 & 30 & 0.242 & $(0.54)$ & 27 & 0.218 & $(0.53)$ & 0.17 & 0.43 \\
\hline
\end{tabular}

$\mathrm{N}$ : number of subjects; SD: standard deviation; t: t-test statistic 
Table 4: Within group difference in change scores of ADL observations: trained vs. non-trained tasks

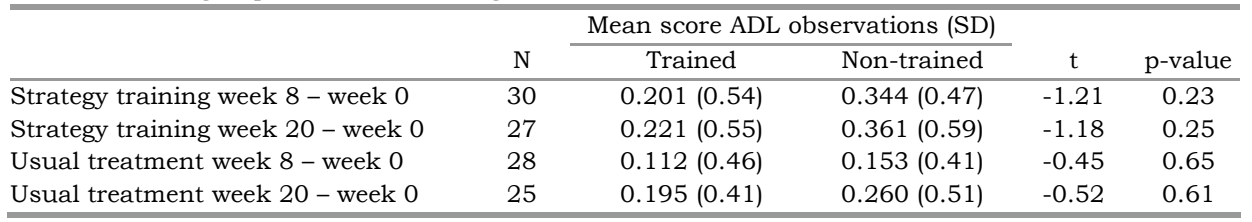

$\mathrm{N}$ : number of subjects; SD: standard deviation; t: t-test statistic

The score on ADL observations of trained tasks appeared to improve significantly over time for the group as a whole $(F(2,52)=6.15, \mathrm{p}=.004)$, and for the strategy training group alone $(\mathrm{F}(2,26)=4.25, \mathrm{p}=.025)$. The score on the trained tasks in the usual treatment group did not change over time $(F(2,24)=1.90)$. The significant main effects were caused by the differences in scores at week 8 as compared with week 0 (total group: $F(1,53)=10.41, p=.002$; strategy training group: $\mathrm{F}(1,27)=8.06, \mathrm{p}=.009)$.

The score on ADL observations of non-trained tasks also appeared to improve significantly over time for the group as a whole $(F(2,76)=16.71, p=.000)$ and for the two individual treatment groups (strategy training group $\mathrm{F}(2$, $34)=11.38, p=.000$; usual treatment group $F(2,31)=6.40, p=.05)$. The significant main effects were caused by the differences in scores at week 8 as compared with week 0 (total group: $\mathrm{F}(1,68)=31.29, \mathrm{p}=.000$; strategy training group: $\mathrm{F}(1$, $35)=23.41, p=.000$; usual treatment group: $F(1,32)=9.16, p=.005)$. When type of treatment was included in the model as a between subjects factor and after controlling for age and for improvement in motor functioning and apraxia, we found a significant main effect of time of measurement $(F(2,63)=3.44, p=.038)$. This effect was caused by the difference in scores at week 8 as compared with week 0 (contrasts analysis: $F(1,64)=5.24, p=.025$ ).

\section{Discussion}

The aim of the present study was to explore whether there are indications for the occurrence of transfer of the strategies taught by means of the occupational therapy programme for left hemisphere stroke patients with apraxia. Because both treatment groups improved significantly on non-trained tasks, transfer seemed to have occurred in the strategy training group as well as in the usual treatment group. Moreover, figure 1 shows that the improvements on trained and non-trained tasks in both treatment groups follow identical patterns. This suggests transfer effects from trained to non-trained tasks in both forms of treatment. However, we have reasons to believe that more transfer occurred in the strategy training group as compared with the usual treatment group. Change scores for non-trained tasks turned out to be larger in the strategy training group than in the usual treatment group. These findings cannot be explained by differences between the treatment groups. Patients in the two intervention groups did not differ significantly with respect to the baseline characteristics, except for age. Patients in the strategy training group were older. In the analyses, we controlled for this difference. The amount (sessions and hours) 
of occupational therapy that patients received during the first eight weeks of the study did not differ significantly between the two intervention groups.

To answer the research question we used data that was previously collected by Donkervoort et $a{ }^{4}$ In the study of Donkervoort et $\mathrm{al}^{4}$ ADL tasks were compared between the two treatment groups. The strategy training group showed significantly more improvement on ADL tasks than the usual treatment group did. The mean scores on the tasks however were not split into trained and nontrained tasks. In the new analyses that were carried in the present study, we did split the ADL tasks in trained and non-trained tasks. In these analyses the improvement on trained tasks turned out to be the same in both groups. However, the strategy training group did improve more on non-trained tasks than the usual treatment group did. This finding suggests that the difference between the improvements of the two treatment groups found by Donkervoort et al, ${ }^{4}$ was not caused by a difference in trained tasks, but by the fact that the strategy training did transfer to other (non-trained) tasks, while the usual treatment transferred less than the strategy training.

The largest improvements on trained and non-trained tasks in both treatment groups took place in the first eight weeks of the study. This was to be expected, as most of the treatment was given in this period of the study.

At baseline, after eight weeks of training and at follow-up (five months after the start of the training), both treatment groups performed more poorly on nontrained tasks than on trained tasks. These differences at the post-treatment and follow-up measurements may be explained by the effect of the therapies. However, these differences may also be caused by the differences between trained and non-trained tasks at baseline measurements within both treatment groups. A possible explanation for the difference at the baseline measurements might be that the non-trained tasks are more difficult to perform than the trained tasks, although this does not seem very plausible as the four tasks have the same level of difficulty on the classification of tasks on the Assessment of Motor and Process Skills (AMPS), in terms of both motor and process skill abilities needed to perform these tasks. ${ }^{13}$ An alternative explanation might be that the trained tasks were more automated than the non-trained tasks. Unfortunately this could not be examined in the present study. Another explanation might be that the training of some basic, trained, ADL tasks had already been initiated in the hospital phase, which precedes the start of the rehabilitation process.

\section{Previous research into transfer of apraxia training}

Transfer of therapeutic effects of apraxia training from trained to non-trained tasks has been assessed in two studies by a German research group. ${ }^{6,20}$ In both studies, no indications of transfer were found as the therapeutic results turned out to be restricted to the trained activities. However, these results were based on relatively small sample sizes ( $\mathrm{N}=15$ and $\mathrm{N}=6$ respectively) compared to our study (control group $\mathrm{N}=57$; experimental group $\mathrm{N}=56$ ). In the first study, therapy consisted of errorless completion of the whole task, combined with training of details. ${ }^{6}$ The first part of this therapy is task specific, the second part might be seen as strategy training, as in training of details, patients are taught to infer 
the function of an object from its structure. However, this strategy is aimed at handling only one of the problems in ADL functioning that can occur in patients with apraxia, namely problems in object use. Another problem that is often observed in apraxia concerns the lacking of a proper plan of action, including for example the order in which specific actions have to be conducted. In apraxia, the two problems described above can occur separately or both at the same time. When a patient lacks an action plan, he or she can not be expected to perform a non-trained activity properly on the basis of what he or she has learned about inferring function from structure. In our training programme a strategy is selected matching the specific problems that are observed. In the second study, effects of direct training of an activity were compared to effects of exploration training, aimed at teaching patients to infer function from structure. ${ }^{20}$ The direct training of an activity is very task specific, no general strategies are taught and therefore transfer is not expected to occur, as was confirmed by the study. At the same time, no transfer was found after exploration training, which can be described as a strategy training. However, exploration training turned out to have no effect on the trained tasks either. Clearly, a training that does not have an effect on trained tasks can not be expected to transfer to non-trained tasks.

\section{Spontaneous recovery versus training effects}

In the present study, spontaneous recovery of both apraxia and ADL functioning is important to consider. Over the years, there has been some discussion about the occurrence of spontaneous recovery of apraxia. It is sometimes believed that apraxia recovers spontaneously. ${ }^{21}$ However, other studies have shown apraxia to be persistent.22,23 The latter point of view was further confirmed by the data of Donkervoort et $\mathrm{al}^{4}$ in which apraxia was observed to be enduring. Spontaneous recovery of ADL functions in patients with apraxia has not been investigated as thoroughly as the recovery of apraxia itself. There is, to our knowledge, only one study that looked into this matter. In this study spontaneous recovery of ADL functions did not occur. ${ }^{6}$ In addition, in the study of Donkervoort et $\mathrm{al}^{4}$ the time post stroke was more than three months on average, which exceeds the acute phase of recovery. Moreover, spontaneous recovery was controlled for by the successful randomisation of the strategy training group and the usual treatment group, although it is important to consider spontaneous recovery in the within-group analyses we carried out.

\section{Methodological issues}

To evaluate transfer of training, we used the ADL observations. An earlier study using this instrument reported the possibility of an instrumental ceiling effect for the ADL observations. ${ }^{15}$ However, the difference in change scores we found cannot be explained by a possible ceiling effect of the ADL observations, as the baseline score in the non-trained tasks was equal in the two treatment groups. Therefore the usual treatment group should have been able to improve as much as the strategy training group did. 
In the present study, we used data that were collected for the purpose of evaluating the efficacy of the strategy training. The study was not originally designed to investigate the occurrence of transfer of the training. Therefore this study has some methodological shortcomings. In all participants, the same four tasks were observed and evaluated several times during the research period. As indicated above, it had been agreed that one of the tasks would never be trained, whereas no agreements were made concerning the training of the other three tasks. Because the therapists registered the tasks they trained, we were able to compute a mean ADL observations score for tasks that had been trained, as well as a mean score for tasks that had not been trained. For each participant there was at least one task that had not been trained, because of the agreement not to train this task. Because there were no agreements made concerning the other tasks, the mean scores for trained and non-trained tasks consisted of different numbers of scores, ranging from 0 to 4 for trained tasks and 1 to 4 for non-trained tasks. This raises two potential problems in the study. First, inequality of variances can occur. However, in our study the variances appeared not to differentiate significantly between the groups; this was checked with Levene's test for equality of variances. Second, because no agreements were made on the tasks that would be trained, in a relatively large number of participants in both groups, none of the four tasks that were observed had been trained during the research period. This resulted in a substantial number of missing values in the analyses of the mean scores of the trained tasks (15 missing cases in the strategy training group and 14 in the usual treatment group).

\section{Final conclusions and future research}

In strategy training, the occurrence of transfer is expected as the training is aimed at teaching patients general ways to handle the problems resulting from an impairment. However, to our knowledge, there are relatively few studies that have directly examined the transfer of treatment effects to everyday situations or behaviours in a large sample of patients. Despite the issues raised above, the present study does show that there are indications for the occurrence of transfer of the strategies taught by means of the occupational therapy programme for left hemisphere stroke patients with apraxia. However, more insight into transfer is necessary to be able to draw firmer conclusions. We are now conducting a prospective study that is specifically aimed at examining the occurrence of transfer of the training effects in apraxia patients. In this new study trained and non-trained tasks will be observed in each participant; thus eliminating the problem of the substantial number of missing values. 


\section{References}

1. De Renzi E. Apraxia. In: Boller F, Grafman J, editors. Handbook of Neuropsychology. Amsterdam: Elsevier Science Publishers B.V.; 1989. p. 245-263.

2. Basso A, Capitani E, Della Sala S, Laiacona M, Spinnler H. Ideomotor apraxia: A study of initial severity. Acta Neurol Scand 1987;76(2):142-6.

3. Zwinkels A, Geusgens C, van de Sande P, van Heugten C. Assessment of apraxia: Inter-rater reliability of a new apraxia test, association between apraxia and other cognitive deficits and prevalence of apraxia in a rehabilitation setting. Clin Rehabil 2004;18(7):819-827.

4. Donkervoort M, Dekker J, Stehmann-Saris JC, Deelman BG. Efficacy of strategy training in left hemisphere stroke patients with apraxia: A randomized clinical trail. Neuropsychol Rehabil 2001;11(5):549-566.

5. Foundas AL, Macauley BL, Raymer AM, Maher LM, Heilman KM, Gonzalez Rothi LJ. Ecological implications of limb apraxia: Evidence from mealtime behavior. $J$ Int Neuropsychol Soc $1995 ; 1(1): 62-6$.

6. Goldenberg G, Hagmann S. Therapy of activities of daily living in patients with apraxia. Neuropsychol Rehabil 1998;8(2):123-141.

7. van Heugten CM. Rehabilitation and management of apraxia after stroke. Rev Clin Gerontol 2001;11:177-184.

8. van Heugten CM, Dekker J, Deelman BG, van Dijk AJ, Stehmann-Saris JC, Kinebanian A. Outcome of strategy training in stroke patients with apraxia: A phase II study. Clin Rehabil 1998;12(4):294-303.

9. Poizner H, Merians AS, Clarck MA, Rothi LJ, Heilman KM. Kinematic approaches to the study of apraxic disorders. In: Rothi LJ, Heilman KM, editors. Apraxia: The neuropsychology of action. Hove: Psychology Press; 1997. p. 93-109.

10. Saeki S, Ogata H, Okubo T, Takahashi K, Hoshuyama T. Return to work after stroke. A follow-up study. Stroke 1995;26(3):399-401.

11. Cicerone KD, Dahlberg C, Kalmar K, Langenbahn DM, Malec JF, Bergquist TF, et al. Evidencebased cognitive rehabilitation: Recommendations for clinical practice. Arch Phys Med Rehabil 2000;81(12):1596-615.

12. van Heugten CM, Dekker J, Deelman BG, Stehmann-Saris JC, Kinebanian A. A diagnostic test for apraxia in stroke patients: Internal consistency and diagnostic value. Clin Neuropsychol $1999 ; 13(2): 182-92$.

13. Fisher AG. Assessment of motor and process skills: Manual. 2nd ed. Forth Collins, CO: Three Star Press; 1997.

14. van Heugten CM, Dekker J, Deelman BG, Stehmann-Saris JC, Kinebanian A. Assessment of disabilities in stroke patients with apraxia: Internal consistency and inter-observer reliability. The Occupational Therapy Journal of Research 1999;19(1):55-73.

15. van Heugten CM, Dekker J, Deelman BG, van Dijk AJ, Stehmann-Saris JC, Kinebanian A. Measuring disabilities in stroke patients with apraxia: A validation study of an observational method. Neuropsychol Rehabil 2000;10(4):401-414

16. Collin C, Wade DT, Davies S, Horne V. The Barthel ADL Index: A reliability study. Int Disabil Stud 1988;10(2):61-3.

17. Wade DT, Collin C. The Barthel ADL Index: A standard measure of physical disability? Int Disabil Stud 1988;10(2):64-7.

18. Lyle RC. A performance test for assessment of upper limb function in physical rehabilitation treatment and research. Int J Rehabil Res 1981;4(4):483-492.

19. Deelman BG, Liebrand WGB, Koning-Haanstra M, van de Burg W. De SAN test: Een afasietest voor auditief en mondeling taalgebruik: Handleiding. Lisse: Swets \& Zeitlinger; 1987. 
20. Goldenberg G, Daumuller M, Hagmann S. Assessment and therapy of complex activities of daily living in apraxia. Neuropsychol Rehabil 2001;11(2):147-169.

21. Basso A, Capitani E, Della Sala S, Laiacona M, Spinnler H. Recovery from ideomotor apraxia. A study on acute stroke patients. Brain 1987;110:747-60.

22. Donkervoort M. Apraxia following left hemisphere stroke: Prevalence, assessment and rehabilitation. Utrecht: Nivel; 2001.

23. Poeck K. Clues to the nature of disruptions to limb praxis. In: Roy EA, editor. Neuropsychological studies of apraxia and related disorders. New York: North-Holland; 1985. p. 99-109. 
Chapter 6

\section{Transfer effects of a cognitive strategy training for stroke patients with apraxia}

In press:

Journal of Clinical and Experimental Neuropsychology, 2007

C. Geusgens, C. van Heugten, J. Cooijmans, J. Jolles, W. van den Heuvel 


\begin{abstract}
Objective: To evaluate transfer effects of cognitive strategy training for stroke patients with apraxia.

Methods: During eight weeks, 29 apraxic patients received cognitive strategy training to teach them how to perform activities of daily living (ADL) as independently as possible. ADL functioning was assessed at the rehabilitation centre at baseline and after eight weeks of training. In addition, assessment took place at the patients' own homes after eight weeks of training and five months after the start of the training. The performance of both trained and non-trained tasks was observed.

Results: Patients performed trained tasks and non-trained tasks at the same level of independency at the rehabilitation centre as well as at home. These effects turned out to be stable over time.

Conclusion: The results described in this study indicate the occurrence of transfer of training effects of a cognitive strategy training for stroke patients with apraxia.
\end{abstract}




\section{Introduction}

Apraxia is one of the more common cognitive impairments that can occur after stroke. It is an impairment affecting the purposeful execution of learned and meaningful skills that cannot be explained by primary motor or sensory impairments, nor by deficits in motivation, memory or comprehension. ${ }^{1}$ Like aphasia, apraxia usually occurs following left hemisphere lesions. ${ }^{2}$ Although the exact prevalence of apraxia is not known, several studies reported apraxia to occur in 30 to $50 \%$ of all left sided stroke patients. ${ }^{1,3,4}$

Apraxia can have a disabling effect on the performance of activities of daily living (ADL), causing a negative impact on everyday life. Therefore apraxia should be addressed during a rehabilitation treatment. ${ }^{5-7}$

Van Heugten et $\mathrm{al}^{8}$ developed a standardised occupational therapy programme for left hemisphere stroke patients with apraxia, which is based on teaching patients strategies to compensate for the presence of apraxia. The aim of the therapy is to maximise the patient's independence by improving ADL functioning; little change is expected in the severity of the apraxia itself. The effectiveness of this intervention programme was shown in both a non-controlled intervention study ${ }^{8}$ and an experimental effect study. ${ }^{5}$ Both studies showed that patients were able to function more independently on ADL tasks after receiving strategy training. However, in both studies ADL functioning was observed in the rehabilitation setting, whereas the aim of a rehabilitation programme is to restore the patients functioning to their greatest potential and maximum independence, hopefully resulting in independent functioning, the return to their own homes and participation in society.

For patients to function as independently as possible at home and in society, two types of transfer of treatment effects are needed. First, tasks which are taught in the rehabilitation setting should be transferred to the home setting. Second, transfer of intervention effects from trained tasks to non-trained (related) tasks is very important in terms of the clinical success of a therapy programme, as therapists cannot possibly train all the difficulties and tasks a patient will encounter after rehabilitation discharge.

In strategy training, the occurrence of transfer effects is expected as the training programme is not aimed at relearning specific tasks, but at teaching patients new ways to handle the problems resulting from the impairment. However, a recently conducted review of literature revealed that relatively few studies on cognitive strategy training addressed the occurrence of transfer effects and that an even smaller part of these studies measured transfer in a standardised way. ${ }^{9}$ Moreover, to our knowledge, there are no studies that objectively compare the patients' functioning in the rehabilitation setting to the patients' functioning in their own homes. However, in an exploratory study, indications were found for the occurrence of transfer of the apraxia training programme from trained to non-trained tasks, although the study was not originally designed for the purpose of evaluating transfer. Patients significantly improved on non-trained tasks. This improvement was larger in the experimental group, 
receiving strategy training, than in the control group receiving apraxia treatment as usual, focusing mainly on (sensory)motor impairments (e.g. muscle tone, reflexes, controlled movements, muscle strength, contractures) and disability due to these impairments. ${ }^{10}$

The goal of the present study was twofold. First, the occurrence of both transfer from the rehabilitation setting to the patients' homes and transfer from trained to non-trained tasks was examined. For transfer effects to be demonstrated, it was hypothesised that non-trained tasks should be performed as independently as trained tasks, and that the performance at home should be as independent as the performance at the rehabilitation centre. Second, lasting transfer effects of the apraxia treatment programme were examined at the patients' own homes.

\section{Methods}

\section{Patients}

Occupational therapists of the stroke teams of 16 Dutch healthcare institutions (14 rehabilitation centres and 2 rehabilitation teams of nursing homes) reported every patient that was referred to them and who complied with the inclusion criteria of this study. Patients were eligible if they met the following inclusion criteria: (1) a left hemisphere stroke; (2) apraxia; and (3) the attending physician, the occupational therapist and the patient judged the treatment of apraxia to be necessary. Exclusion criteria were: (1) age younger than 18 years; (2) time since stroke less than four weeks or more than two years (3) a history of apraxia before the current stroke; (4) insufficient knowledge of the Dutch language (clinical judgement); (5) premorbid or present psychiatric or psychogeriatric pathologies; (6) a history of traumatic brain injury or brain tumor; (7) an alcohol or drug addiction (8) a history of stroke causing a left sided paresis that was present at the time of the study; (9) the patient had not finished primary school; (10) the patient did not agree to participate in the study.

The diagnosis of apraxia involved two steps. First, the patient's treating rehabilitation team made a clinical diagnosis. The patient was said to be apraxic if (a) the patient showed an inability (or restriction in the ability) to carry out purposeful tasks and (b) this inability was not the result of a primary motor or sensory impairment, or deficit of comprehension, memory or motivation. This diagnosis was based upon clinical judgement. There were no prescribed standardised observations or tests that the rehabilitation team had to use to come to this decision. Second, before final inclusion in the study, patients were tested by a trained neuropsychologist for severity of apraxia. ${ }^{11}$ Patients who showed no or minimal apraxic symptoms on the apraxia test (score above 85) were excluded from the study. All patients and their families received verbal and written information about the study and gave verbal as well as written consent to participate. 
Table 1: ADL tasks and number of participants that selected the tasks as trained or non-trained tasks respectively (baseline - week 8)

\begin{tabular}{lccc}
\hline Task & Trained & Non-trained & Total \\
\hline Preparing a cup of coffee / tea & 17 & 6 & 23 \\
Laying the table for 2 persons & 13 & 4 & 17 \\
Preparing bread & 9 & 6 & 15 \\
Dishwashing by hand / loading and starting the & 7 & 12 & 19 \\
dishwasher (5 to 8 pieces) & & & \\
Brushing teeth & 7 & 7 & 14 \\
Polishing shoes & 7 & 3 & 10 \\
Putting on a shirt / sweatshirt / blouse & 7 & 3 & 10 \\
Folding laundry ( 10 pieces) & 6 & 6 & 12 \\
Loading and starting washing machine & 5 & 6 & 11 \\
Washing face and upper body & 5 & 3 & 8 \\
Sweeping / mopping / vacuum cleaning & 4 & 8 & 12 \\
Watering 2 to 3 plants & 2 & 9 & 11 \\
Preparing a cup of hot chocolate & 2 & 5 & 7 \\
Hand washing 2 pieces of laundry & 2 & 1 & 3 \\
Other & 1 & 1 & 2 \\
Total & 94 & 80 & 174 \\
\hline
\end{tabular}

Note: After checking the registration of the content of the occupational therapy, not all tasks that should have been trained turned out to be trained during the eight weeks of treatment. This table displays the number of participants in whom each task was observed, separated into the number of patients in whom the task was trained and in whom it was not trained during the first eight weeks of the study period.

\section{Study design}

Immediately after inclusion, each patient selected six ADL tasks from a list containing fourteen tasks that had the same level of difficulty according to the classification of tasks of the Assessment of Motor and Process Skills (AMPS), in terms of both motor and process skill abilities needed to perform these tasks ${ }^{12}$ (see table 1). Patients were asked to select tasks that were relevant to them and that they wanted to relearn. When needed, the occupational therapist and/or a significant other could help selecting the tasks. The patient and the occupational therapist agreed to train four of the selected tasks, while the other two tasks would not be trained during the study period.

Prior to the start of the training, the performance on the six selected, standardised ADL tasks was observed at the clinic. A second measurement took place after an eight-week treatment period, in which four of the six selected tasks were trained. During this measurement, performance on the six ADL tasks was observed twice. Patients were asked to perform the tasks at the clinic, and, additionally, if the patients were living at home or if they went home for the weekend, observations of the six tasks took place at the patients' homes as well. To minimise order effects, half the number of the patients was first observed at home, while the other half was first observed at the rehabilitation centre. A follow-up measurement took place five months after the start of the training. $\mathrm{Pa}-$ tients were asked to perform the six ADL tasks at their own homes. Treatment of patients during the follow-up period (week 8 until week 20) was not prescribed in specific study guidelines, except for the agreement not to train the two non-trained ADL tasks. 
Measurements were conducted by an independent assessor (occupational therapist), who was trained in using all instruments that were applied in this study. The study protocol was approved by the ethics committees of all participating institutions.

\section{Intervention}

The intervention was a strategy training, specially designed for use by occupational therapists. The intervention was standardised by means of a treatment protocol, developed in an earlier study. ${ }^{8}$ Although the protocol was already implemented into Dutch occupational practice, the occupational therapists that participated in the study received an additional workshop to refresh their knowledge and insights into the use of the protocol.

At the rehabilitation centre, patients received eight weeks of apraxia training. The frequency of training sessions was based on the clinical judgement of the treating occupational therapist and the rehabilitation team. The intervention consisted of the standardised treatment programme for left hemisphere stroke patients with apraxia, developed by van Heugten and colleagues ${ }^{8}$, which is based on teaching patients strategies to compensate for the presence of apraxia. By means of this programme the patient is gradually taught more efficient strategies. The aim of the therapy is to maximise the patient's independence by improving ADL functioning. The specific problems of each individual patient are examined during a detailed diagnostic assessment of disability, consisting of standardised ADL observations. These problems will be the focus of attention during therapy; an intervention is chosen in correspondence with the observed problems. The treatment protocol is based on the framework of information processing. According to this framework, ADL tasks are conceptualised as being composed of three successive phases: the proper plan of action and the correct objects have to be selected (initiation and orientation phase), followed by adequate execution of the selected plan (execution phase), which has to be evaluated in terms of the result, and if necessary corrected (control and correction phase). Corresponding to these phases, the specific interventions focus on instructions, assistance and feedback, respectively. Examples of the applied strategies include the use of verbalisation and the use of pictures showing the correct order of task performance. This diagnostic assessment is strictly used for clinical purposes and is therefore independent of the study. For a more extensive description of the intervention and the strategies that can be used, we refer to the treatment protocol. ${ }^{13}$

\section{Measurements}

\section{ADL functioning}

ADL functioning was measured in two ways:

1. ADL observations ${ }^{14}$ : These are a set of standardised observations, specially developed to assess disability in ADL functioning due to apraxia. The internal consistency and inter-observer reliability of this observational procedure have 
been found to be good.14,15 Recently, the observations have been revised slightly, in order to make them even more consistent. ${ }^{13}$ The performance on six standardised tasks that were selected by the patient are observed. Each task was scored on four aspects: independence, initiation, execution and control. While rating a task, occupational therapists score the help they have to provide to the patient to allow this patient to finish the task as independently as possible. Scores on the observations range from totally dependent (score 0 ) to totally independent (score 3).

2. Barthel ADL Index ${ }^{16,17}$ :The Barthel Index of Tasks of Daily Living is a widely used, well validated scale, which offers a simple and quick, clinically relevant method to identify the most important physical disabilities. The score on the index ranges from 0 to $20.16,17$

\section{Apraxia}

The Apraxia Test is based on a test by De Renzi.1,11 It consists of two subtests assessing (1) the ability to use objects as well as pantomime the use of objects (aimed at ideational apraxia) and (2) the ability to imitate gestures with the nonaffected ipsilateral arm (aimed at ideomotor apraxia). The maximum score of the total test is 90 . A score above 85 represents no or minimal apraxic symptoms. The internal consistency, the validity and the inter-observer reliability of the test are good.4,11 The apraxia test was included in this study as a measure to describe the severity of apraxia during the course of the study.

\section{Motor functioning}

The Functional Motor Test is a simplified version of the Action Research Arm Test. ${ }^{18}$ The test measures the voluntary functional task of the arm and hand of the affected contralateral side. It consists of four items in which the patient has to use a type of grip (pinch, grip or grasp) to pick up an object, move it forward and put it down again. The maximum score on the test is 12 . The internal consistency is good. 5

\section{Additional measures}

To monitor the patients' general cognitive functioning at baseline, standardised tests assessing verbal comprehension (Stichting Afasie Nederland Test (SAN test), maximum score is 45), 19 memory (Rivermead Behavioural Memory Test (RBMT), only non-verbally mediated items, maximum standard profile score is 16) ${ }^{20,21}$ and mental status (Cognitive Screening Test (CST), maximum score is 20) 22 were used.

Occupational therapists registered the amount and contents of the therapy sessions patients received. In addition, information on demographic variables and stroke characteristics was registered.

\section{Statistical analyses}

For each patient, mean scores on the ADL observations for each of the six tasks separately were computed, based on the initiation, execution and control score. 
This procedure is in accordance with the procedures that were used in earlier studies applying the ADL observations.5,8,10 Next, for each patient a mean score for the performance on the six ADL tasks combined was computed, based on the mean score on the individual tasks. In addition, mean scores for ADL performance on trained and non-trained tasks respectively were computed for each patient, again based on the mean score on the individual tasks. These combined mean scores were used in the analyses and for computing effect sizes.

\section{Patient characteristics}

Descriptive statistics were used to present patient characteristics and test results at baseline. Independent samples t-tests were used to evaluate whether patients who were lost to follow-up differed from patients who did complete the post-treatment and follow-up observations. The following variables were compared between the two groups: age and baseline scores on the apraxia test, the ADL observations, the Barthel Index, motor functioning test, verbal comprehension test and memory test.

\section{Improvement of functioning after eight weeks of training}

A prerequisite for transfer effects to occur is the improvement of ADL functioning at the rehabilitation centre after treatment. A training programme that does not have an effect on trained tasks, in the training situation can not be expected to transfer to other situations. In addition, if non-trained tasks do not improve after eight weeks of training, transfer from trained to non-trained tasks could not have occurred. Therefore improvement of functioning at the rehabilitation centre after eight weeks of training was assessed.

Paired samples t-tests were used to evaluate improvements of ADL observations of trained tasks and non-trained tasks separately. In addition, a paired samples t-test was used to evaluate improvements in the overall mean score of the ADL observations. In these comparisons the mean ADL score at baseline was not divided into trained and non-trained tasks, as none of the six observed tasks were trained at baseline, and as there were no significant differences between tasks to be trained and non-trained tasks.

Paired samples t-tests were also used to evaluate improvements of apraxia, motor functioning and the Barthel Index. Based on the results of these comparisons, adjusted analyses were conducted for further evaluation of the treatment effects on the overall mean score of the ADL observations, as well as for the treatment effects on both trained and non-trained tasks separately. A general linear model (GLM) for repeated measures was used, in which we controlled for the changes in praxis. In addition, effect sizes were calculated by dividing the mean changes in scores by the standard deviation of the baseline score. An effect size of 0.2 is regarded as small, 0.5 as medium, and 0.8 or higher indicates a large effect. ${ }^{23}$ 


\section{Transfer of training effects after eight weeks of training}

Two types of transfer were evaluated. First, transfer to new tasks was assessed by comparing performance on trained ADL tasks to non-trained ADL tasks, both at the rehabilitation centre and at home after eight weeks of training. Second, transfer to a different situation was assessed after eight weeks of training by comparing performance at the rehabilitation centre to performance at home for the mean scores on trained and non-trained tasks separately, as well as for the overall mean score on the ADL observations. To demonstrate transfer effects, no significant differences should be found between trained tasks and non-trained tasks or between the training situation and the home setting. These differences were assessed by using paired samples t-tests. In addition, we performed posthoc power analyses, to infer beta, which represents the chance of a type II error; that is, the chance that no statistically significant differences are found, although the means do differ.

\section{Lasting transfer effects at follow-up}

Paired samples t-tests were used to evaluate lasting effects of the treatment programme for the overall mean score on the ADL observations as well as for the mean score on trained and non-trained tasks separately, performed at home, twenty weeks after the start of the training. Lasting effects could be demonstrated if the performance at follow-up was as independent as was the performance directly after eight weeks of training. Therefore, no significant differences should be found between the two observations. In addition, we performed post-hoc power analyses, to infer beta.

In all analyses, the level of significance was set at 0.05. Analyses were carried out using SPSS 11.0 for Windows. As most variables turned out not to follow a normal distribution, all analyses in which t-tests were used, were repeated using the Wilcoxon Signed Rank test. Only parametric test results will be reported in this paper, as conclusions based on the results of the parametric tests did not differ from the results of the non parametric tests, and as the t-test is robust to moderate departures from normality. ${ }^{24}$

\section{Results}

\section{Patient characteristics}

Figure 1 shows the patient flow of the study. From May 2003 until December 2005 the occupational therapists reported 73 patients for participation in the study; 44 patients were excluded or lost to follow-up for various reasons. Posttreatment observations took place both at the rehabilitation centre and at the patient's own home. A total of 22 patients was observed in both settings. Three patients were observed at home only, as they had already been discharged from the rehabilitation centre at the time of the observation. Four patients were observed at the rehabilitation centre only, as they did not return home for the 
weekends yet. At follow-up, 19 patients were observed at their own home settings, whereas 5 patients were observed at the rehabilitation centre only, as they still had not been discharged from the centre. At baseline, a total of four tasks $(1.9 \%)$ could not be observed. In week eight, six tasks $(3.8 \%)$ could not be observed in the rehabilitation centre, whereas the observations of eight tasks $(5.3 \%)$ are missing at the home setting. At follow-up, a total of seven tasks $(6.1 \%)$ could not be observed. All missing observations were due to planning problems in the rehabilitation centre or other practical problems. For subjects who had missing observations, ADL mean scores were derived from the tasks that had been observed, thus using a smaller number of observations.

A group of 29 patients (22 men and 7 women) participated in this study. The mean age at inclusion was 60.5 years (standard deviation $(\mathrm{SD})=9.1$; range 41 - 74) and the time post onset was 103.2 days ( $\mathrm{SD}=60.6$; range 36 - 285) Further patient characteristics and test results are displayed in tables 2 and 3 respectively.

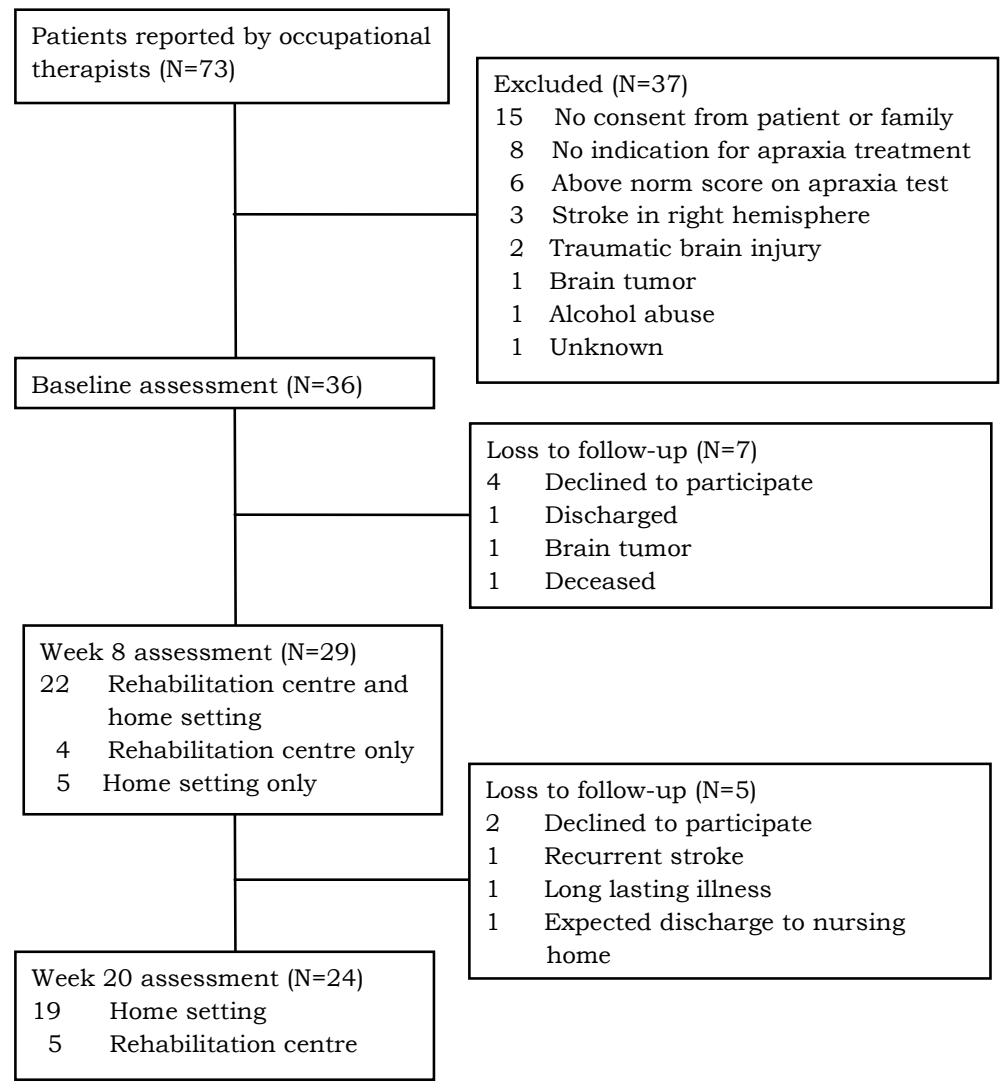

Figure 1: Flow chart of patients in the apraxia study 
Table 2: Demographic characteristics at baseline for patients who completed the observations after eight weeks of training

\begin{tabular}{lrr}
\hline & N & $\%$ \\
\hline Gender & 22 & 75.9 \\
$\quad$ Male & 7 & 24.1 \\
$\quad$ Female & & \\
Education * & 4 & 13.8 \\
$\quad$ Low & 16 & 55.2 \\
Middle & 4 & 13.8 \\
High & 5 & 17.2 \\
$\quad$ Unknown & 5 & \\
Residence before stroke & 17.2 \\
$\quad$ Living alone & 22 & 75.9 \\
$\quad$ Living with partner / children & 2 & 6.8 \\
$\quad$ Other & 26 & 89.7 \\
Right handedness & & \\
Type of stroke & 9 & 31.0 \\
$\quad$ Haemorrhage & 19 & 65.5 \\
Infarction & 1 & 3.4 \\
$\quad$ Unknown & 9 & 31.0 \\
Recurrent stroke & 20 & 70.0 \\
Hemiplegia &
\end{tabular}

$\mathrm{N}$ : number of subjects

Note: Education: low: primary school or less; middle: high school, vocational school, technical school; high: university

Table 3: Test results at baseline for patients who completed the observations after eight weeks of training $(\mathrm{N}=29)$

\begin{tabular}{lrrrrc}
\hline & N & Mean & SD & Range & Maximum score \\
\hline Apraxia & 29 & 56.9 & 22.4 & $0-85$ & 90 \\
Functional Motor Test & 29 & 8.0 & 4.4 & $3-12$ & 12 \\
Barthel Index & 29 & 14.9 & 5.2 & $5-20$ & 20 \\
Verbal comprehension & 29 & 33.9 & 5.8 & $20-43$ & 45 \\
RBMT standard profile score & $18^{*}$ & 8.5 & 3.1 & $2-14$ & 16 \\
CST & $8^{*}$ & 16.8 & 1.5 & $14-19$ & 20
\end{tabular}

N: Number of subjects; SD: standard deviation; RBMT: Rivermead Behavioural memory Test; CST: Cognitive Screening Test

* Due to severe aphasia, these tests could not be administered to all participants.

At baseline, participants that were lost to follow-up during the total study period of 20 weeks, differed significantly in the score on the Barthel index (lost: mean $(\mathrm{SD})=17.6(2.7)$; completed: mean $(\mathrm{SD})=14.74(4.7) ; \mathrm{t}=2.15, \mathrm{df}=28, \mathrm{p}=.04)$ and motor functioning (lost: mean $(\mathrm{SD})=10.7$ (3.0) ; completed: mean $(\mathrm{SD})=7.4$ (4.4); $\mathrm{t}=2.50, \mathrm{df}=27.5, \mathrm{p}=.02$ ). On both tests, participants that completed all observations scored significantly lower than participants that were lost to follow-up. Participants that were lost to follow-up during the first eight weeks of the study period did not differ on any of the observed variables, compared to participants who did complete the post-treatment measurement. There were no significant differences in age or in the scores on the apraxia test, the ADL observations, the Barthel Index, motor functioning, verbal comprehension or memory. 


\section{Improvement of functioning after eight weeks of training}

During eight weeks of training, the score on the ADL observations improved significantly in both trained and non-trained tasks. The overall mean score on the ADL observations improved as well (see table 4). The effect sizes for the ADL observations indicate large effects, with values ranging from 0.9 to 1.0 . The score on the apraxia test showed significant improvement as well. After controlling for this improvement all changes in ADL observations remained significant (overall: $\mathrm{F}(1,24)=40.31, \mathrm{p}=.000$; trained $\mathrm{F}(1,24)=25.46, \mathrm{p}=.000$; non-trained $\mathrm{F}(1,24)=51.05, \mathrm{p}=.000)$.

Table 4: improvement of functioning after eight weeks of training

\begin{tabular}{|c|c|c|c|c|c|c|}
\hline & $\begin{array}{l}\text { Baseline } \\
\text { mean (SD) }\end{array}$ & $\begin{array}{l}\text { Post-treatment } \\
\text { mean (SD) }\end{array}$ & $\mathrm{N}$ & $\mathrm{t}$ & $\mathrm{p}$ & Effect size* \\
\hline ADL obs total rehab & $1.8(0.6)$ & $2.4 \quad(0.4)$ & 26 & 7.00 & .000 & 1.0 \\
\hline ADL obs trained rehab & $1.8(0.6)$ & $2.4 \quad(0.4)$ & 26 & 5.48 & .000 & 1.0 \\
\hline ADL obs non-trained rehab & $1.8(0.6)$ & $2.3 \quad(0.5)$ & 26 & 6.57 & .000 & 0.9 \\
\hline Apraxia test & $56.9(22.4)$ & $67.3(19.6)$ & 29 & 3.99 & .000 & 0.5 \\
\hline Functional Motor test & $7.9(4.4)$ & $7.9 \quad(4.4)$ & 28 & -1.00 & .326 & -0.1 \\
\hline Barthel Index & $14.8(5.2)$ & 16.8 (4.1) & 28 & 3.70 & .001 & 0.4 \\
\hline
\end{tabular}

SD: standard deviation; $\mathrm{N}$ : number of subjects; T: t-test statistic; p: p-value

* Effect sizes were calculated by dividing the mean changes in scores by the standard deviation of the baseline score

\section{Transfer of training effects}

No significant differences were found between trained tasks and non-trained tasks, both at home and at the rehabilitation centre (home: $\mathrm{t}=0.20, \mathrm{df}=24$; rehabilitation centre: $t=0.79, \mathrm{df}=25$ ). Also, no significant differences were found between functioning at the rehabilitation centre and in the home setting, for the overall mean score on the ADL observations and for trained and non-trained tasks separately (overall: $\mathrm{t}=1.30, \mathrm{df}=21$; trained tasks $\mathrm{t}=0.81, \mathrm{df}=21$; nontrained tasks $\mathrm{t}=0.93, \mathrm{df}=21$ ) (see table 5 ). Post-hoc power analyses showed that beta was high, ranging from 0.76 to 0.94

\section{Lasting transfer effects at follow-up}

Performance on ADL observations at follow-up did not differ significantly from the performance directly after eight weeks of training (overall: $\mathrm{t}=2.08, \mathrm{df}=17$; trained tasks: $\mathrm{t}=1.78, \mathrm{df}=17$; non-trained tasks: $\mathrm{t}=1.23, \mathrm{df}=17$ ). Post-hoc power analyses showed that beta was high, ranging from 0.50 to 0.79 . All observations taken into account in these analyses took place at the patients own home. 
Table 5: Transfer effects from trained to non-trained tasks both at the rehabilitation centre and at home, after eight weeks of training

\begin{tabular}{llllll}
\hline & $\begin{array}{l}\text { Trained tasks } \\
\text { mean (SD) }\end{array}$ & $\begin{array}{l}\text { Non-trained tasks } \\
\text { mean (SD) }\end{array}$ & $\mathrm{N}$ & $\mathrm{t}$ & $\mathrm{p}$ \\
\hline ADL obs rehab & $2.4(0.41)$ & $2.3(0.52)$ & 26 & 0.79 & .439 \\
ADL obs home & $2.6(0.39)$ & $2.6(0.52)$ & 25 & 0.20 & .844 \\
\hline
\end{tabular}

$\mathrm{SD}$ : standard deviation; $\mathrm{N}$ : number of subjects; t: t-test statistic; p: p-value

\section{Discussion}

In this study, the transfer effect of cognitive strategy training for stroke patients with apraxia was evaluated. This is the first prospective larger scale study to examine this effect explicitly. By demonstrating the occurrence of transfer from trained to non-trained tasks, the results of a previous exploratory study can be confirmed. The exploratory study demonstrated transfer effects of the same strategy training as was used in the present study. ${ }^{10}$ In addition, in the present study we also found indications for the occurrence of transfer from the rehabilitation setting to the home setting. Furthermore, we demonstrated the long-term effectiveness of the training programme, for both trained and non-trained tasks.

In the present study, motor functioning remained stable over time during the eight weeks of apraxia training, and although patients did improve significantly on the test for apraxia, the improvements on ADL observations in both trained and non-trained tasks remained significant after controlling for the improvement on the apraxia test. Moreover, the effect size of the apraxia test was small compared to the effect sizes of the ADL observations of both trained and non-trained ADL tasks. This finding supports the findings of other studies evaluating strategy training for stroke patients, $, 5,8$ as well as the idea that the aim of strategy training is not to improve the impairment itself, but to teach patients new ways to handle problems resulting from an impairment. ${ }^{25}$

At baseline, patients who were lost to follow-up during the total study period of 20 weeks scored significantly higher on motor functioning and on the Barthel Index than participants that completed all observations. Thus it can be concluded that the more severely impaired patients completed the study and demonstrated lasting transfer effects.

The occurrence of transfer is of great importance in terms of the clinical success of an intervention, as it reflects the aim of a rehabilitation programme, which is for patients to function as independently as possible in their own environments and in society. Our findings show that after training, patients are indeed able to perform trained tasks and non-trained tasks at the same level of independency at the rehabilitation centre as well as at home. This finding could be explained by the fact that patients were able to apply the learned strategies in another situation (i.e. the home setting). Another possible explanation might be that old routines are triggered by the familiar home situation, making it possible for the patient to function independently without the use of a strategy. ${ }^{1}$

Relatively few studies on cognitive strategy training address the occurrence of transfer and an even smaller number of studies measure transfer in a stan- 
dardised way. ${ }^{9}$ To our knowledge, this is the first study that objectively compared patients' functioning in the rehabilitation setting to their functioning in their own homes. Two other studies evaluated transfer of therapeutic effects of apraxia training from trained to non-trained tasks. ${ }^{6,26}$ In both studies, no transfer was found as the training effects showed to be restricted to the trained tasks. However, the training methods that were evaluated in these two studies are not comparable to the apraxia training we used. In the first study, task specific training was combined with a strategy training aimed at handling only one of the problems in ADL functioning that can occur in patients with apraxia, ${ }^{6}$ whereas in our training programme for each individual patient a strategy is selected matching his/her specific problems. In the second study, task specific training was combined with a strategy training that turned out to have no effect on trained tasks. ${ }^{26}$ The differences between the intervention programmes were discussed extensively in one of our previous papers. ${ }^{10}$

Clinical relevance of these results is reflected by the fact that after eight weeks of training, the majority of participants needed less help while performing both trained and non-trained ADL tasks at the rehabilitation centre as well as at home, indicating a higher level of independent functioning of the patient. Overall change on the independence score of the ADL observations was registered for each individual patient. Improvement on the independence score represents a reduction of help or care that patients need, in order to be able to perform the ADL tasks. Inspection of these independence scores showed that directly after eight weeks of training, more than $60 \%$ of the participants showed an overall improvement on both trained and non-trained tasks, as well as in both situations, indicating that patients needed less help in the ADL task performance.

Spontaneous recovery of both apraxia and ADL functioning is important to consider when interpreting our findings. It is sometimes believed that apraxia recovers spontaneously. ${ }^{27}$ However, other studies have shown apraxia to be persistent.28,29 The latter point of view was further confirmed by the data of Donkervoort et $\mathrm{al}^{5}$ in which apraxia was observed to be enduring. Spontaneous recovery of ADL functions in patients with apraxia has not been investigated as thoroughly as the recovery of apraxia itself. There is, to our knowledge, only one study that looked into this matter. In this study spontaneous recovery of ADL functions did not occur. ${ }^{6}$ In addition, in the present study the time post stroke was more than three months on average, which exceeds the acute phase of recovery.

Our study demonstrates that after training, patients perform trained tasks and non-trained tasks at the same level of independency. Both the trained and non-trained tasks were of interest to the patients as at the start of the study, patients were asked to select six tasks that were relevant for them to relearn. Therefore, patients could have been motivated to train themselves to perform the non-trained tasks when they were at home. We have not been able to control for this effect that could occur during home visits for the weekend or after discharge from the rehabilitation centre. However, this reflects the normal course of a rehabilitation process in which patients will return to their own en- 
vironments, where they will have to learn to function as independently as possible. After discharge, patients will encounter tasks and situations that have not been trained during the rehabilitation process. Learning how to manage these tasks and situations represents the transfer of strategies that were trained at the rehabilitation centre.

Some methodological comments can be made concerning our study. First, at baseline, we did not observe ADL functioning at home. Including such a measurement would have added valuable information. As for now, no indication can be given of improvements in ADL functioning at home. However, we were not able to arrange such a measurement as patients could not go home in this phase of the rehabilitation process. Second, this study was not designed as a randomised clinical trial (RCT). However, conducting an RCT in which one group would have been subjected to a control treatment was difficult to arrange, as the use of the apraxia protocol was implemented into clinical occupational therapy (OT) practice in the Netherlands. Even if a protocol would have been used for performing the control treatment, occupational therapists would have been knowledgeable of the strategy training, making it very hard to create two independent treatment groups. In addition the RCT that was conducted previously already showed the effectiveness of the strategy training in comparison with a control treatment. 5 Based on this finding, the strategy training was published as a guideline for stroke rehabilitation in the Netherlands. ${ }^{30}$ Third, our results should be interpreted with care, as post-hoc power analyses showed that beta was large in our analyses investigating transfer effects. This suggests that differences between the ADL performances might exist although they were not demonstrated in the analyses. Factors that influence the value of beta are sample size, standard deviation and the level of significance that was set for the analyses (alpha). In our study, the sample size was small and the standard deviation was relatively large compared to the range in scores of the ADL observations. However, beta represents the chance that the two means are not exactly the same, while in clinical practice, two observations will probably never be exactly the same. Therefore, it could be useful to choose an acceptable difference. Any difference smaller than this 'acceptable difference' would be considered a meaningless difference and the two observations would still be considered equal. 31 Conducting post-hoc power analyses based on this acceptable difference would probably provide a more appropriate beta. However, choosing an acceptable difference is difficult, considering the small range of scores of the ADL observations and considering the fact that there are no standards for choosing this difference, making it subjective. Fourth, a considerable number of patients in this study was lost to follow-up. However it was decided to refrain from inputting missing data, to make sure the analyses were performed using the actual data. There is no indication of selective loss of data, because missing observations were due to practical and therefore individual reasons.

Despite these remarks, we feel that we have been able to provide more insight in the transfer of training effects of a cognitive strategy training for stroke patients with apraxia, as well as in the clinical relevance of this training programme. However, more research is necessary to evaluate transfer effects of 
cognitive rehabilitation treatment and rehabilitation programmes in general, as rehabilitation aims to teach patients ways to functioning as independently as possible, resulting in the return to their own homes and participation in society. To reach this aim, the occurrence of transfer of training effects is a requirement, as most rehabilitation treatment is not administered at the patients own homes.

\section{Acknowledgements}

The authors thank all participants and their families, as well as the rehabilitation teams of the healthcare institutions that participated in this study: the rehabilitation centres Amsterdam (Amsterdam), Het Roessingh (Enschede), Heliomare (Wijk aan Zee), De Hoogstraat (Utrecht), Rijndam (Rotterdam), Leijpark (Tilburg), Sophia (Den Haag), Blixembosch (Eindhoven), Sint Maartenskliniek (Nijmegen), De Trappenberg (Huizen), Rijnlands Revalidatiecentrum (Leiden), De Kastanjehof (Zutphen), De Tolbrug (Den Bosch), Stichting Revalidatie Limburg (Hoensbroek), and the nursing homes Stichting Antaris (Amsterdam) and Stichting Vivre (Maastricht).

\section{References}

1. De Renzi E. Apraxia. In: Boller F, Grafman J, editors. Handbook of Neuropsychology. Amsterdam: Elsevier Science Publishers B.V.; 1989. p. 245-263.

2. Basso A, Capitani E, Della Sala S, Laiacona M, Spinnler H. Ideomotor apraxia: A study of initial severity. Acta Neurol Scand 1987;76(2):142-6.

3. Donkervoort M, Dekker J, van den Ende E, Stehmann-Saris JC, Deelman BG. Prevalence of apraxia among patients with a first left hemisphere stroke in rehabilitation centres and nursing homes. Clin Rehabil 2000;14:130-136.

4. Zwinkels A, Geusgens C, van de Sande P, van Heugten C. Assessment of apraxia: Inter-rater reliability of a new apraxia test, association between apraxia and other cognitive deficits and prevalence of apraxia in a rehabilitation setting. Clin Rehabil 2004;18(7):819-827.

5. Donkervoort M, Dekker J, Stehmann-Saris JC, Deelman BG. Efficacy of strategy training in left hemisphere stroke patients with apraxia: A randomized clinical trail. Neuropsychol Rehabil 2001;11(5):549-566.

6. Goldenberg G, Hagmann S. Therapy of activities of daily living in patients with apraxia. Neuropsychol Rehabil 1998;8(2):123-141.

7. van Heugten CM. Rehabilitation and management of apraxia after stroke. Rev Clin Gerontol 2001;11:177-184.

8. van Heugten CM, Dekker J, Deelman BG, van Dijk AJ, Stehmann-Saris JC, Kinebanian A. Outcome of strategy training in stroke patients with apraxia: A phase II study. Clin Rehabil 1998;12(4):294-303.

9. Geusgens CAV, Winkens I, van Heugten CM, Jolles J, van den Heuvel WJA. The occurrence and measurement of transfer in cognitive rehabilitation: A critical review. $J$ Rehabil Med 2007;39(6):425-439.

10. Geusgens C, van Heugten C, Donkervoort M, van den Ende E, Jolles J, van den Heuvel W. Transfer of training effects in stroke patients with apraxia: An exploratory study. Neuropsychol Rehabil 2006;16(2):213-229. 
11. van Heugten CM, Dekker J, Deelman BG, Stehmann-Saris JC, Kinebanian A. A diagnostic test for apraxia in stroke patients: Internal consistency and diagnostic value. Clin Neuropsychol 1999;13(2):182-92.

12. Fisher AG. Assessment of motor and process skills: Manual. 2nd ed. Forth Collins, CO: Three Star Press; 1997.

13. Stehmann-Saris JC. Occupational therapy guideline for assessment and treatment of apraxia following left hemisphere stroke. Amsterdam: Hogeschool van Amsterdam; 2005.

14. van Heugten CM, Dekker J, Deelman BG, Stehmann-Saris JC, Kinebanian A. Assessment of disabilities in stroke patients with apraxia: Internal consistency and inter-observer reliability. The Occupational Therapy Journal of Research 1999;19(1):55-73.

15. van Heugten CM, Dekker J, Deelman BG, van Dijk AJ, Stehmann-Saris JC, Kinebanian A. Measuring disabilities in stroke patients with apraxia: A validation study of an observational method. Neuropsychol Rehabil 2000;10(4):401-414.

16. Collin C, Wade DT, Davies S, Horne V. The Barthel ADL Index: A reliability study. Int Disabil Stud 1988;10(2):61-3.

17. Wade DT, Collin C. The Barthel ADL Index: A standard measure of physical disability? Int Disabil Stud 1988;10(2):64-7.

18. Lyle RC. A performance test for assessment of upper limb function in physical rehabilitation treatment and research. Int J Rehabil Res 1981;4(4):483-492.

19. Deelman BG, Liebrand WGB, Koning-Haanstra M, van de Burg W. De SAN test: Een afasietest voor auditief en mondeling taalgebruik: Handleiding. Lisse: Swets \& Zeitlinger; 1987.

20. Wilson B, Cockburn J, Baddeley A. The Rivermead Behavioral Memory Test. Titchfield: Thames Valley Test Co.; 1985.

21. Cockburn J, Wilson B, Baddeley A, Hiorns R. Assessing everyday memory in patients with dysphasia. Br J Clin Psychol 1990;29:353-360.

22. de Graaf A, Deelman BG. De cognitieve screeningtest: Handleiding. Lisse: Swets \& Zeitlinger; 1991.

23. Cohen J. Statistical Power Analysis for the Behavioral Sciences. Hillsdale: Lawrence Erlbaum Associates; 1988.

24. Hays WL. Statistics. 5 ed. Fort Worth: Harcourt Brace College Publishers; 1994.

25. Ben-Yishay Y, Diller L. Cognitive remediation in traumatic brain injury: Update and issues. Arch Phys Med Rehabil 1993;74:204-213.

26. Goldenberg G, Daumuller M, Hagmann S. Assessment and therapy of complex activities of daily living in apraxia. Neuropsychol Rehabil 2001;11(2):147-169.

27. Basso A, Capitani E, Della Sala S, Laiacona M, Spinnler H. Recovery from ideomotor apraxia. A study on acute stroke patients. Brain 1987;110:747-60.

28. Poeck K. Clues to the nature of disruptions to limb praxis. In: Roy EA, editor. Neuropsychological studies of apraxia and related disorders. New York: North-Holland; 1985. p. 99-109.

29. Donkervoort M. Apraxia following left hemisphere stroke: Prevalence, assessment and rehabilitation. Utrecht: Nivel; 2001.

30. Commissie CVA-revalidatie. Revalidatie na een beroerte: Richtlijnen en aanbevelingen voor zorgverleners [Rehabilitation after stroke: Guidelines and recommendations for clinical practice]. The Hague: Dutch Heart Foundation; 2001.

31. Wellek S. Testing statistical hypotheses of equivalence. Boca Raton: Chapman \& Hall/CRC Press LLC; 2003. 
Chapter 7

\section{Bnvironment effects in the performance of daily tasks in healthy adults}

In revision

C. Geusgens, C. van Heugten, E. Hagedoren, J. Jolles, W. van den Heuvel 


\begin{abstract}
Objective: To examine the effect of switching from a familiar to an unfamiliar setting on household task performance in healthy, middle aged adults. To examine the influence of the cognitive functions abstract reasoning and memory on the ability to adapt to different environments.

Design: Cross sectional: participants were observed in two different settings while performing two daily tasks.

Setting: Participants' own kitchens and an unfamiliar kitchen

Participants: Thirty healthy, middle aged adults, living independently.

Main outcome measures: Rating scale to evaluate process skill abilities in task performance, inferred from the Assessment of Motor and Process Skills (AMPS). Time needed to perform each task. Neuropsychological tests to evaluate memory and abstract reasoning.

Results: Performance of both tasks took significantly more time in the unfamiliar kitchen (both tasks $\mathrm{p}<.000$ ). In both tasks, the overall score on process skill abilities was significantly lower in the unfamiliar kitchen (task 1: $\mathrm{p}<.000$; task 2: $\mathrm{p}=.017)$. Variations in process skill scores only occurred in the unfamiliar setting. Process skills observed in the participants' own kitchens were nearly optimal for both tasks. No associations between environment effects and abstract reasoning or memory were found (p-values ranging from 0.299 to 0.715 ). Conclusions: Environmental effects on task performance were found in healthy, middle aged adults. It is likely to assume that the effect of different environments on task performance will be present in stroke patients as well, resulting in important implications for rehabilitation practice. It is of great importance that during a rehabilitation programme, facilitating of transfer of training effects to other environments is addressed.
\end{abstract}




\section{Introduction}

In recent years, interest in cognitive rehabilitation has grown, providing us with numerous research articles, systematic reviews and books on the effectiveness of various treatment methods for specific cognitive impairments. ${ }^{1-4}$ These publications contributed to the development and identification of the most effective approaches within the field of cognitive rehabilitation. Based on two extensive reviews on the effectiveness of cognitive rehabilitation, Cicerone et al. 1,2 concluded that this effectiveness has now been demonstrated.

Cognitive rehabilitation aims to improve or restore cognitive functions after brain injury. ${ }^{5}$ One of the most widely used and most effective interventions in cognitive rehabilitation is strategy training. ${ }^{2}$ This type of therapy is based on the assumption that restoration of cognitive functions to their pre-injury structure and efficiency is not expected to occur, and that rehabilitation should therefore concentrate on teaching compensatory strategies. ${ }^{6}$ Cognitive strategy training is aimed at teaching patients new, general ways to compensate for problems in everyday life, resulting from a cognitive impairment; not at relearning a specific task. ${ }^{7}$ Therefore, patients are expected to be able to use the strategies in new settings and while performing new tasks, despite the lasting presence of the cognitive deficits. Thus it is assumed that transfer of strategy training will occur. However, a recently conducted review of literature revealed that relatively few studies on cognitive strategy training addressed the occurrence of transfer effects explicitly. ${ }^{8}$

The term 'transfer' refers to the use of prior learning in new contexts, or, in other words, to the way in which prior learning affects new learning or performance.9-11 It has often been stated that the occurrence of transfer is essential in learning and education. Transfer is even said to be the main goal of all learning. ${ }^{9-12}$ One of the situations in which learning plays a central role is a rehabilitation setting. The aim of a rehabilitation programme is to restore patients to their greatest potential and maximum independence, hopefully resulting in independent functioning, the return to their own homes and participation in society. ${ }^{6}$ To achieve this goal, transfer of training effects is necessary. For patients to function as independently as possible at their own homes, tasks which are taught in the rehabilitation setting should be transferred to the home setting. Therefore, transfer of treatment effects is crucial for the clinical success of a rehabilitation programme.

Whereas little is known about the ability of brain injured patients to transfer the skills they have learned during rehabilitation treatment to new situations, there are indications that the performance of daily tasks may be influenced by the environment. ${ }^{13}$ Patients with acquired brain injury, living at home showed a better performance of daily tasks in their own homes than in an unfamiliar environment, demonstrating an environment effect on task performance. After intensive rehabilitation in a clinic, the rehabilitation setting might have become a 'familiar environment', possibly making the transition from the clinic to the more 'unfamiliar' home setting problematic. ${ }^{13}$ 
Park, Fisher and Velozo ${ }^{14}$ examined the effect of home versus clinical settings on the performance of daily tasks in healthy older adults (i.e. people without a diagnosis of brain injury). Participants were asked to perform daily tasks at home as well as in an unfamiliar setting. Both motor ability and process ability (i.e. cognitive abilities needed to perform a task) were observed during task performance in both settings. Motor ability, reflecting the underlying motor skill capacities necessary to perform a task, remained stable in the two settings, whereas process abilities, reflecting the capacity to logically organise and adapt a series of actions over time in order to complete a task, were affected by the change in settings; participants performed better at home than in the unfamiliar setting. However, participants in this study were older adults, with a mean age of 82.2 years. Old age is said to influence flexibility in performance. ${ }^{15}$ Stroke patients who are admitted to rehabilitation centres are often younger than the sample described in this study, with ages usually ranging from 40 to 75 years. ${ }^{8,16}$ In order to gain more insight in transfer of rehabilitation treatment in stroke patients, it is therefore important to investigate how a change of settings affects task performance in healthy people within the same age group.

In educational psychology, it is stated that in order to use transfer, a person should be able to judge whether transfer can be applied in a specific situation. ${ }^{9,17}$ A principle or a strategy can only be transferred if it is actively decontextualised. To bridge the gap between two different situations, the similarity between the two situations must be grasped.17 This similarity can range from being concrete and obvious to being very abstract. Thus, the ability to identify similarities, that is, the ability of abstract reasoning, seems to be an important prerequisite for the occurrence of transfer. In addition, if two situations have to be compared in order to identify similarities, it can be hypothesised that memory functioning influences the occurrence of transfer. Clearly, characteristics of different situations have to be remembered in order to compare these characteristics to a new situation.

The goal of the present study is to examine the effect of switching from a familiar to an unfamiliar setting on task performance in healthy, middle aged adults. In addition it is hypothesised that the ability to adapt to different environments can be influenced by the cognitive functions abstract reasoning and memory.

\section{Methods}

\section{Participants}

Participants were recruited from the personal environment of the researchers. Healthy adults were eligible for this study if they were aged between 40 and 75 years and if they lived independently. Exclusion criteria were: (1) person does not make coffee with a regular coffeemaker; (2) history of brain injury; (3) premorbid or present neurological pathologies; (4) present motor deficits, influencing ADL task performance; (5) premorbid or present psychogeriatric pathologies;

(6) an alcohol or drug addiction; (7) lasting use of antidepressant or sedative 
medication; (8) insufficient knowledge of the Dutch language. All participants received verbal and written information about the study and gave verbal as well as written consent to participate.

\section{Study design}

Participants were observed in two different settings while performing two daily tasks; making coffee by using a regular coffee maker and preparing a sandwich. The first observations of the two tasks took place in the kitchen at the participants' own homes, the second observations took place in the (unfamiliar) kitchen at the research institution. In the participants' own kitchens, the participants used their own coffeemakers to make coffee. At the research institution, a different coffeemaker was used, reflecting the fact that the coffeemaker used during therapy at a rehabilitation centre is often not the same one as the patients use at their own homes.

The task 'making coffee' was chosen for this study because this task is said to be of average complexity according to the classification of tasks of the Assessment of Motor and Process Skills (AMPS), in terms of both motor and process skill abilities needed to perform the task. ${ }^{18}$ In addition, during the performance of this task, a person has to interact with the environment in order to complete it properly. The goal of the present study is to examine the effect of a different environment on task performance. Therefore, it is important to observe a task that requires participants to interact with this environment. Furthermore, the task 'making coffee' was the most frequently observed task in a study that evaluated transfer of training effects of stroke patients with apraxia. ${ }^{19}$ In addition, in a study in which occupational therapists (OTs) had to evaluate disabilities due to apraxia, $90 \%$ of all OTs choose to observe these disabilities while the patient performed the task 'making coffee'. ${ }^{20}$ Performance on the task 'preparing a sandwich' was expected to be less influenced by changes in the environment as interaction with the environment is less important in the performance of this task. The task was chosen because it has the same level of complexity in terms of both motor and process skills as the task 'making coffee'. ${ }^{18}$ In addition, this task was often chosen to be observed in the clinical effect study as well. ${ }^{19}$

Task performance for both tasks in both situations was rated and the time needed to perform each task was registered. In addition neuropsychological tests were used to describe cognitive functioning and patient characteristics were recorded. Participants were asked to estimate how many times a day they make coffee and in how many different settings they are used to make coffee, as these variables are expected to influence coffee-making performance in the unfamiliar setting. Measurements were conducted by an experienced occupational therapist. The study protocol was approved by the ethics committee.

\section{Observations of daily tasks}

In this study, task performance was evaluated based on the way in which process skills needed to perform a task were utilised by the participant. Park, Fisher 
and Velozo ${ }^{14}$ demonstrated that in healthy, older adults, motor skill abilities did not differ in different settings. Since in the present study, younger healthy adults were assessed, differences in motor skill abilities were not expected to occur. Therefore, only process skill abilities were observed in the present study. To observe process skill abilities, we developed a rating scale which was inferred from the Assessment of Motor and Process Skills (AMPS). ${ }^{18}$ For each task, the following nine process skill abilities were evaluated:

(1) searching / locating: the ability to look for and locate tools and materials in a structured, logical way;

(2) goal-oriented working: the ability to work in a goal-oriented way

(3) handling: the ability to support, stabilise and hold tools and materials in an appropriate and safe way;

(4) noticing / responding: the ability to respond appropriately to environmental cues;

(5) accommodating, adjusting and benefiting: the ability to adapt behaviour to solve encountered problems in an applicable way;

(6) pacing: the ability to maintain an effective rate of task performance;

(7) attending: the ability to focus attention on the task performance;

(8) initiating: the ability to start task performance or to start a new action that is part of the sequence of task performance, without hesitation;

(9) continuing and sequencing: the ability to perform actions that constitute the task in an effective and logical order, using time and energy in an efficient way.

All process skills were rated on a 4 -point scale: $1=$ severely ineffective use of process skill, resulting in unacceptable task performance; $2=$ ineffective use of process skill resulting in disturbance of task performance; 3 = questionable use of process skill, not resulting in disturbance of task performance; 4 = easy and consistent use of process skill. For both tasks, performed in each setting, the scores on the nine process skill abilities were added up, resulting in four overall process skill scores.

\section{Neuropsychological evaluation}

The Cognitive Screening Test is used to assess general mental status. The maximum score of this test is 20.21 The Apraxia Test is used to assess the presence and the severity of apraxia. The maximum score of this test is 90.22 The Auditory Verbal Learning Test is used to assess episodic memory. Fifteen words are orally presented and the subject is asked to name all words he or she remembered. This procedure is repeated five times and after 20 minutes, delayed recall and recognition are tested. ${ }^{23}$ The variable of interest in this study is the number of words recalled after the 20-minute delay, the maximum score is 15 . Raven's Standard Progressive Matrices a non-verbal test that is used to assess abstract reasoning. ${ }^{24}$ The test consists of 60 items. The total number of correct answers is the variable of interest in this study. The Auditory Verbal Learning Test and Raven's Standard Progressive Matrices were used in this study to investigate the association between transfer and memory and abstract reasoning respectively. 


\section{Statistical analyses}

Descriptive statistics were used to present participant characteristics and neuropsychological test results. To assess differences in time needed to perform each task in the two settings, paired samples t-tests were used. To evaluate differences in ADL functioning at the home setting versus the unfamiliar environment, two paired samples t-tests were used as well, assessing the effect of a different setting on the overall process skill score of making coffee and preparing a sandwich respectively. To further explore the differences in task performance, for each ADL task in both settings, the number of participants in each scorecategory was reported for all individual process skills.

To evaluate the influence of age and cognitive functioning (i.e. memory and abstract reasoning) on environment effects in task performance (i.e. task performance in unfamiliar setting vs. familiar setting), Fisher exact tests were used. These tests are applicable to data that do not follow a normal distribution and that consist of small numbers of participants. ${ }^{25}$ In order to perform these tests, dichotomous variables have to be created. For both tasks, one dichotomous variable was created, reflecting the difference between the two settings on the overall process skill scores: better performance at home vs. no difference in setting / better performance at the unfamiliar kitchen. These dichotomous variables were used to construct three $2 \mathrm{x} 2$ cross tabulations for each of the two tasks separately, investigating whether the observed differences on the overall process skill scores were related to differences within the sample referring to (1) age (less than 55 years old vs. more than 55 years old); (2) performances on the 20-minute delay condition of the Auditory Verbal Learning Test (less than nine words remembered vs. more than nine words remembered); and (3) performance on the Raven's Standard Progressive Matrices (less than 50 correct answers vs. more than 50 correct answers). The three dichotomous variables reflecting differences within the sample were created using the median of the continuous variables. Fisher's exact tests were used to evaluate possible associations within the cross tabulations. In addition, Fisher exact tests were used to evaluate whether the dichotomous variable reflecting the difference between the two settings on the overall process skill score for the task making coffee was related to (1) the number of times a day that participants make coffee (one time a day vs. more than one time a day) and (2) the number of different settings in which participants make coffee (no different settings vs. one or more different settings). Again, the dichotomous variables reflecting differences within the sample were created using the median of the continuous variables.

In all analyses, the level of significance was set at .05. Analyses were carried out using SPSS 14.0 for Windows. Most variables did not follow a normal distribution. Therefore, all analyses in which t-test were used, were repeated using the Wilcoxon Signed Rank Test. Only parametric test results are reported in this paper, as conclusions based on the results of the parametric tests were the same as those based on the results of the nonparametric tests. In addition, the $\mathrm{t}$-test is robust to moderate departures from normality. ${ }^{26}$ 


\section{Results}

\section{Participant characteristics}

Participants were recruited from November 2005 until June 2006. A total of 30 subjects participated in this study. The mean age of the participants was 54.6 years (standard deviation $(\mathrm{SD})=10.7$ ). The majority of the participants had a high education (university) and were women. On average, participants used their coffeemakers at home 1.7 times a day $(\mathrm{SD}=1.2)$. Participant characteristics are displayed in table 1 . Table 2 shows the neuropsychological test results. Based on the scores on the apraxia test, no participant could be diagnosed as apraxic. Mean scores on the Auditory Verbal Learning Test and the mean number of correct answers on the Raven's Standard Progressive Matrices were in line with the norm scores for healthy people in the same age category and with the same level of education. ${ }^{27,28}$

Table 1: Participant characteristics

\begin{tabular}{lrr}
\hline & $\mathrm{N}$ & $\%$ \\
\hline Gender & 6 & 20.0 \\
$\quad$ Men & 24 & 80.0 \\
$\quad$ Women & & \\
Education * & 2 & 6.7 \\
$\quad$ Low & 11 & 36.7 \\
Middle & 16 & 53.3 \\
High & 1 & 3.3 \\
$\quad$ unknown & & \\
Use different coffeemakers & 20 & 66.7 \\
$\quad$ Yes & 10 & 33.3 \\
$\quad$ No &
\end{tabular}

N: Number of subjects

* Education: low: primary school or less; middle: high school, vocational school, technical school; high: university

Table 2: Neuropsychological test result

\begin{tabular}{lrrr}
\hline & Mean & \multicolumn{1}{c}{ SD } & \multicolumn{1}{c}{ Range } \\
\hline Apraxia Test & 89.2 & 1.46 & $86-90$ \\
Auditory verbal Learning Test - immediate recall & 44.4 & 11.18 & $23-69$ \\
Auditory verbal Learning Test - delayed recall & 8.8 & 3.58 & $2-15$ \\
Raven Standard Progressive Matrices & 48.7 & 6.83 & $30-59$ \\
Cognitive Screening Test & 18.6 & 1.21 & $16-20$ \\
\hline \hline
\end{tabular}

SD: standard deviation

\section{Environment effects}

Both making coffee and preparing a sandwich took significantly more time in the unfamiliar kitchen compared to the participants' own kitchens (making coffee: $\mathrm{t}=4.74, \mathrm{df}=28, \mathrm{p}<.000$; preparing sandwich: $\mathrm{t}=4.54, \mathrm{df}=29, \mathrm{p}<.000$ ). In both tasks, the overall score on process skill abilities was significantly lower in the unfamiliar kitchen compared to the participants' own kitchens (making 
coffee: $\mathrm{t}=4.07, \mathrm{df}=29, \mathrm{p}<.000$; preparing sandwich: $\mathrm{t}=2.54, \mathrm{df}=29, \mathrm{p}=.017$ ) (see table 3).

Table 3: Effect of different settings on both the overall process skill score and the time needed to perform the ADL tasks

\begin{tabular}{|c|c|c|c|c|c|c|c|c|}
\hline & \multicolumn{2}{|c|}{ Home } & \multicolumn{2}{|c|}{ Unfamiliar kitchen } & \multirow[b]{2}{*}{$\mathrm{N}$} & \multirow[b]{2}{*}{$\mathrm{t}$} & \multirow[b]{2}{*}{ df } & \multirow[b]{2}{*}{$\mathrm{p}$-value } \\
\hline & Mean & SD & Mean & SD & & & & \\
\hline \multicolumn{9}{|c|}{ Overall process skill score } \\
\hline Making coffee & 35.97 & 0.18 & 34.90 & 1.40 & 30 & 4.07 & 29 & .000 \\
\hline Preparing sandwich & 35.90 & 0.40 & 35.43 & 0.97 & 30 & 2.54 & 29 & .017 \\
\hline \multicolumn{9}{|l|}{ Time needed (sec) } \\
\hline Making coffee & 60.50 & 16.61 & 100.60 & 42.91 & 29 & 4.74 & 28 & .000 \\
\hline Preparingsandwich & 61.83 & 18.46 & 89.50 & 30.98 & 30 & 4.54 & 29 & .000 \\
\hline
\end{tabular}

SD: standard deviation N: number of subjects; t: t-test statistic; df: degrees of freedom; sec seconds;

Table 4 shows the number of participants in each score-category for all individual process skills on both tasks. Variations in process skill scores only occur in the unfamiliar setting. Process skills observed in the participants' own kitchens are nearly optimal for both tasks.

Fisher's exact tests did not show any associations between the differences in overall process skill scores of the two separate tasks and (1) age group (making coffee: $p=1.00$; preparing a sandwich: $p=.682$ ) (2) performances on the 20minute delay condition of the Auditory Verbal Learning Test (making coffee: $\mathrm{p}=.715$; preparing a sandwich: $\mathrm{p}=.682$ ); and (3) performance on the Raven's Standard Progressive Matrices (making coffee: $\mathrm{p}=.299$; preparing a sandwich: $\mathrm{p}=.417$ ) (see tables 5 and 6). In addition, no significant associations were found between the difference between the two settings on the overall process skill score for the task making coffee and (1) the number of times a day that participants make coffee $(p=.299)$ or (2) the number of different settings in which participants make coffee $(p=1.00)$ (see tables 5 and 6). 
Table 4: Number of participants in each score-category for all individual process skills on both 'making coffee' and 'preparing bread'.

\begin{tabular}{|c|c|c|c|c|}
\hline & \multicolumn{2}{|r|}{ Coffee } & \multicolumn{2}{|c|}{ Sandwich } \\
\hline & Own kitchen & Unfamiliar kitchen & Own kitchen & Unfamiliar kitchen \\
\hline \multicolumn{5}{|l|}{ Searching / locating } \\
\hline Consistent & 30 & 25 & 29 & 21 \\
\hline Questionable & 0 & 4 & 1 & 7 \\
\hline Ineffective & 0 & 1 & 0 & 2 \\
\hline Severely ineffective & 0 & 0 & 0 & 0 \\
\hline \multicolumn{5}{|c|}{ Continuing / sequencing } \\
\hline Consistent & 29 & 21 & 30 & 28 \\
\hline Questionable & 1 & 9 & 0 & 2 \\
\hline Ineffective & 0 & 0 & 0 & 0 \\
\hline Severely ineffective & 0 & 0 & 0 & 0 \\
\hline \multicolumn{5}{|l|}{ Initiating } \\
\hline Consistent & 30 & 27 & 29 & 30 \\
\hline Questionable & 0 & 3 & 1 & 0 \\
\hline Ineffective & 0 & 0 & 0 & 0 \\
\hline Severely ineffective & 0 & 0 & 0 & 0 \\
\hline \multicolumn{5}{|l|}{ Goal oriented working } \\
\hline Consistent & 30 & 28 & 30 & 29 \\
\hline Questionable & 0 & 2 & 0 & 1 \\
\hline Ineffective & 0 & 0 & 0 & 0 \\
\hline Severely ineffective & 0 & 0 & 0 & 0 \\
\hline \multicolumn{5}{|l|}{ Attending } \\
\hline Consistent & 30 & 30 & 30 & 30 \\
\hline Questionable & 0 & 0 & 0 & 0 \\
\hline Ineffective & 0 & 0 & 0 & 0 \\
\hline Severely ineffective & 0 & 0 & 0 & 0 \\
\hline \multicolumn{5}{|l|}{ Handling } \\
\hline Consistent & 30 & 22 & 29 & 29 \\
\hline Questionable & 0 & 6 & 1 & 0 \\
\hline Ineffective & 0 & 2 & 0 & 1 \\
\hline Severely ineffective & 0 & 0 & 0 & 0 \\
\hline \multicolumn{5}{|l|}{$\begin{array}{l}\text { Accommodating / } \\
\text { adjusting / benefiting }\end{array}$} \\
\hline Consistent & 30 & 27 & 30 & 30 \\
\hline Questionable & 0 & 3 & 0 & 0 \\
\hline Ineffective & 0 & 0 & 0 & 0 \\
\hline Severely ineffective & 0 & 0 & 0 & 0 \\
\hline \multicolumn{5}{|l|}{ Pacing } \\
\hline Consistent & 30 & 30 & 30 & 30 \\
\hline Questionable & 0 & 0 & 0 & 0 \\
\hline Ineffective & 0 & 0 & 0 & 0 \\
\hline Severely ineffective & 0 & 0 & 0 & 0 \\
\hline \multicolumn{5}{|l|}{ Noticing / sequencing } \\
\hline Consistent & 30 & 30 & 30 & 29 \\
\hline Questionable & 0 & 0 & 0 & 1 \\
\hline Ineffective & 0 & 0 & 0 & 0 \\
\hline Severely ineffective & 0 & 0 & 0 & 0 \\
\hline
\end{tabular}


Table 5: Making coffee: Cross tabulations for the number of observations on the differences in overall process skill score

\begin{tabular}{lcc}
\hline & $\begin{array}{c}\text { Better performance } \\
\text { at home }\end{array}$ & $\begin{array}{c}\text { No difference / better performance } \\
\text { in unfamiliar setting }\end{array}$ \\
\hline $\begin{array}{l}\text { Age } \\
\text { Less than 55 years }\end{array}$ & 7 & 8 \\
More than 55 years & 7 & 8 \\
ALVT delayed recall & 5 & 9 \\
Less than nine words & 9 & 7 \\
More than nine words & 5 & 9 \\
Raven & 9 & 7 \\
Less than 50 correct & & 9 \\
More than 50 correct & 5 & 7 \\
Making coffee: frequency & 9 & 7 \\
$\quad$ One time a day & 7 & 9 \\
More than one time a day & 7 & \\
Making coffee: different settings & & \\
No different settings & & \\
One or more different settings & &
\end{tabular}

ALVT: Auditory Verbal Learning Test

Table 6: Preparing a sandwich: Cross tabulations for the number of observations on the differences in overall process skill score

\begin{tabular}{lcc}
\hline Age & $\begin{array}{c}\text { Better performance } \\
\text { at home }\end{array}$ & $\begin{array}{c}\text { No difference / better performance } \\
\text { in unfamiliar setting }\end{array}$ \\
Less than 55 years & 12 & 3 \\
More than 55 years & 10 & 5 \\
ALVT delayed recall & 10 & 5 \\
Less than nine words & 12 & 3 \\
More than nine words & 9 & 5 \\
Raven & 13 & 3 \\
Less than 50 correct & & \\
More than 50 correct & &
\end{tabular}

ALVT: Auditory Verbal Learning Test

\section{Discussion}

The aim of this study was to investigate the environmental effects on task performance in healthy middle aged adults. Participants were observed in both their own kitchen and an unfamiliar kitchen while performing two daily tasks. Performances of both tasks took significantly more time in the unfamiliar kitchen. In addition in both tasks, the overall score on process skill abilities was significantly lower in the unfamiliar kitchen. Variations in process skill scores only occurred in the unfamiliar setting. Process skills observed in the participants' own kitchens are nearly optimal for both tasks.

Our results show that the daily functioning of healthy, middle aged adults with a high educational level is influenced by the environment. This finding supports the finding of Park et $\mathrm{al}^{14}$ who showed that in healthy older adults, process skill abilities in the performance of daily tasks are affected by the environment. Since mental flexibility decreases after stroke, ${ }^{29}$ it can be expected 
that the functioning of stroke patients will be affected by the environment in a similar, if not a more severe way. Indeed, a study by Darragh et al ${ }^{13}$ showed indications for environment effects on the performance of daily tasks in brain injured adults. Patients living at home showed a better performance of daily tasks in their own homes than in an unfamiliar environment. After intensive inpatient rehabilitation, the rehabilitation setting might have become a 'familiar environment', possibly making the transition from the clinic to the more 'unfamiliar' home setting problematic. ${ }^{13}$ This results in important implications for rehabilitation practice, where patients have to learn how to apply skills that were trained in the rehabilitation setting in their now 'unfamiliar' home setting. Apparently, transfer can not be expected to occur automatically. Therefore it is of great importance that during a rehabilitation programme, facilitating of transfer is addressed.

It was hypothesised that the ability to adapt to different environments can be influenced by the cognitive functions abstract reasoning and memory. Although literature on educational psychology states that abstract reasoning is necessary in transfer, 9,17 and although it can be inferred that memory must play an important role in transfer as well, we did not find an association between environment effects and abstract reasoning or memory. The sample's mean scores on the neuropsychological tests used in this study were in line with the norm scores for these tests. Individual scores on the two tests did however show a relatively wide range of scores. Therefore, our findings can not be explained by the use of tests that are not sensitive enough to individual differences within our sample. In reference to our findings, it might however be interesting to consider the ecological validity of the neuropsychological tests that were used in this study. These tests measure the neuropsychological constructs 'memory' and 'abstract reasoning'. However, measuring a construct does not automatically have to relate to the way in which participants use these constructs in daily life. Recently, the way in which neuropsychological tests can predict everyday functioning is being questioned. ${ }^{30}$ Possibly, the tests that were used in the present study are not ecologically valid enough to reflect the way in which participants use their abstract reasoning and memory functions while performing daily tasks. This might explain why we did not find associations between environment effects and abstract reasoning or memory

No associations were found between an environment effect for the task 'making coffee' and either the number of times a day that participants make coffee or the number of different settings in which participants are used to make coffee. These finding suggests that neither the number of times that this specific task is performed nor the number of different environments in which the task is performed affects the ease with which someone performs the task in an unfamiliar environment.

A methodological shortcoming of this study relates to our primary outcome measure. To evaluate task performance, we assessed the way in which process skills needed to perform a task were utilised by the participants. These process skill abilities were rated on a scale which was inferred from the Assessment of Motor and Process Skills (AMPS). ${ }^{18}$ Although the AMPS is a reliable and vali- 
dated test, ${ }^{14}$ no assumptions can be made on the psychometric characteristics of the inferred rating scale that was used in the present study. In addition, although we found statistically significant differences between the task performances in the two different environments, it should be noted that these differences were very small. Although the rating scale that was used in this study had a range of scores from 0 to 36 , it showed a ceiling effect with all mean scores observed in this study ranging from 34.90 to 35.97 .

\section{Conclusions}

This study shows that task performance in healthy, middle aged adults is affected by the setting in which the task is performed. It is likely to assume that the effect of different environments on task performance will be present in stroke patients as well, resulting in important implications for rehabilitation practice. It is of utmost importance that during a rehabilitation programme, facilitating of transfer is addressed.

\section{References}

1. Cicerone KD, Dahlberg C, Kalmar K, Langenbahn DM, Malec JF, Bergquist TF, et al. Evidencebased cognitive rehabilitation: Recommendations for clinical practice. Arch Phys Med Rehabil 2000;81:1596-615.

2. Cicerone KD, Dahlberg C, Malec JF, Langenbahn DM, Felicetti T, Kneipp S, et al. Evidence-based cognitive rehabilitation: Updated review of the literature from 1998 through 2002. Arch Phys Med Rehabil 2005;86:1681-1692.

3. Brouwer WH, van Zomeren AH, Berg I, Bouma A, de Haan EHF, editors. Cognitive rehabilitation: A clinical neuropsychological approach. Amsterdam: Boom; 2002.

4. Halligan PW, Wade DT, editors. Effectiveness of rehabilitation for cognitive deficits. Oxford: Oxford University Press; 2005.

5. Prigatano GP. A history of cognitive rehabilitation. In: Halligan PW, Wade DT, editors. Effectiveness of rehabilitation for cognitive deficits. Oxford: Oxford University Press; 2005. p. 3-10.

6. Wilson BA. Compensating for cognitive deficits following brain injury. Neuropsychol Rev 2000;10:233-243.

7. Fasotti 1, Kovacs F. Slow information processing and the use of compensatory strategies. In: Chamberlain MA, editor. Traumatic brain injury rehabilitation: Services, treatments and outcomes. London: Chapman \& Hall; 1995.

8. Geusgens CAV, Winkens I, van Heugten CM, Jolles J, van den Heuvel WJA. The occurrence and measurement of transfer in cognitive rehabilitation: A critical review. $J$ Rehabil Med 2007;39(6):425-439.

9. Byrnes JP. Cognitive development and learning in instructional contexts. Boston: Allyn and Bacon; 1996.

10. Marini A, Genereux R. The challenge of teaching for transfer. In: McKeough A, Lupart J, Marini A, editors. Teaching for transfer: Fostering generalization in learning. Mahwah: Lawrence Erlbaum Associates; 1995. p. 1-20.

11. Singley MK, Anderson JR. The transfer of cognitive skill. Cambridge: Harvard University Press; 1989. 
12. Haskell RE. Transfer of learning: Cognition, instruction, and reasoning. San Diego: Academic Press; 2001.

13. Darragh AR, Sample P, Fisher AG. Environment effect on functional task performance in adults with acquired brain injuries: Use of the Assessment of Motor and Process Skills. Arch Phys Med Rehabil 1998;79:1998.

14. Park S, Fisher AG, Velozo CA. Using the assessment of motor and process skills to compare occupational performance between clinic and home settings. Am J Occup Ther 1994;48:697-709.

15. van der Elst W, van Boxtel MP, van Breukelen GJ, Jolles J. The concept shifting test: Adult normative data. Psychol Assess 2006;18(4):424-432.

16. Schepers VP, Visser-Meily AM, Ketelaar M, Lindeman E. Prediction of social activity one year poststroke. Arch Phys Med Rehab 2005;86(7):1472-1476.

17. Salomon G, Perkins DN. Rocky roads to transfer: Rethinking mechanisms of a neglected phenomenon. Educational Psychologist 1989;24(2):113-142.

18. Fisher AG. Assessment of motor and process skills: Manual. 2nd ed. Forth Collins, CO: Three Star Press; 1997.

19. Geusgens CAV, van Heugten CM, Cooijmans J, Jolles J, van den Heuvel WJA. Transfer effects of a cognitive strategy training for stroke patients with apraxia. J Clin Exp Neuropsychol (in press) 2007.

20. van Heugten CM, Dekker J, Deelman BG, Stehmann-Saris JC, Kinebanian A. Assessment of disabilities in stroke patients with apraxia: Internal consistency and inter-observer reliability. The Occupational Therapy Journal of Research 1999;19(1):55-73.

21. de Graaf A, Deelman BG. De cognitieve screeningtest: Handleiding. Lisse: Swets \& Zeitlinger; 1991.

22. van Heugten CM, Dekker J, Deelman BG, Stehmann-Saris JC, Kinebanian A. A diagnostic test for apraxia in stroke patients: Internal consistency and diagnostic value. Clin Neuropsychol 1999;13(2):182-92.

23. Brand PA, Jolles J. Learning and retrieval rate of words presented auditorily and visually. J Gen Psychol 1985;112:201-210.

24. Raven JC, Court JH, Raven J. Manual for Raven's Progressive Matrices and Vocabulary Scales. Londen: H.K. Lewis \& Co. Ltd.; 1984.

25. Agresti A. An introduction to categorical data analysis. New York: John Wiley \& sons, Inc.; 1996.

26. Hays WL. Statistics. 5 ed. Fort Worth: Harcourt Brace College Publishers; 1994.

27. van der Elst W, van Boxtel MP, van Breukelen GJ, Jolles J. Rey's verbal learning test: Normative data for 1855 healthy participants aged 24-81 years and the influence of age, sex, education and mode of presentation. J Int Neuropsychol Soc 2005;11:290-302.

28. Bouma A, Mulder J, Lindeboom J. Neuropsychologische diangostiek: Handboek. Lisse: Swets \& Zeitlinger; 1996.

29. Sachdev PS, Brodaty H, Valenzuela MJ, Lorentz PS, Looi JCL, Wen W, Zagami AS. The neuropsychological profile of vascular cognitive impairment in stroke and TIA patients. Neurology 2004;62(6):912-919.

30. Chaytor N, Schmitter-Edgecombe M. The ecological validity of neuropsychological tests: A review of literature on everyday cognitive skills. Neuropschol Rev 2003;13(4):181-197. 
Chapter 8

General discussion 

The long term goal of a rehabilitation programme is maximising independent functioning, resulting in the patients' return to their own homes and participation in society. Conventionally, however, rehabilitation treatment takes place in a rehabilitation setting, and tends to be focussed on achieving short term goals, relating to the improvement of the patients' functioning within the rehabilitation setting itself. This organisation of rehabilitation treatment therefore implicates that, to reach the ultimate goal of a rehabilitation programme, transfer of treatment effects should occur.

The main objective of this thesis was to evaluate the occurrence of transfer of treatment effects in cognitive strategy training for stroke patients. In this chapter an overview of the main results of the study will be presented. In addition several methodological and theoretical considerations will be addressed and recommendations for clinical practice as well as for further research will be put forward.

\section{Main findings}

\section{Does transfer of cognitive strategy training occur?}

Overall, the papers presented in this thesis demonstrated the occurrence of transfer of treatment effects of cognitive strategy training. The prospective effect study was specifically designed to evaluate the occurrence of a strategy training for left hemisphere stroke patients with apraxia. This study showed that after eight weeks of cognitive strategy training, patients performed trained tasks and non-trained tasks at the same level of independent functioning at the rehabilitation centre as well as at home, indicating transfer of training effects. The level of independent functioning in the home setting proved to be stable over time for both trained and non-trained tasks. These results confirmed the findings of the exploratory study that was carried out on data previously collected in a randomised clinical trial (RCT) that evaluated the efficacy of the strategy training. The literature review showed that a relatively small number of studies on cognitive strategy training evaluated the occurrence of transfer of training effects. Although most studies that did address this issue reported positive results with regard to the occurrence of transfer, some serious remarks concerning the methodological quality of the studies should be made. These remarks relate to small numbers of participants, the absence of statistically tested results and problems in choosing appropriate outcome measures attuned to the results that are expected of the training.

\section{Does the environment influence task performance?}

Environment effects on the performance of daily tasks were demonstrated to occur in healthy, middle aged adults, matching in age with the population of patients treated in rehabilitation programmes. Task performance took significantly more time in an unfamiliar kitchen than in the participants' own kitchens. In addition, process abilities, reflecting the capacity to logically organise 
and adapt a series of actions over time in order to complete a task, were significantly affected by the change in settings; participants performed better at home than in the unfamiliar setting.

\section{Apraxia: prevalence, assessment and treatment}

In a rehabilitation population, over half of all left hemisphere stroke patients $(51 \%)$ scored insufficiently on a neuropsychological apraxia test, as opposed to $6 \%$ of the patients with a right hemisphere stroke. Besides a good internal consistency and diagnostic value the apraxia test proved to have a good inter-rater reliability. In addition, apraxia was shown to be associated with aphasia, memory problems and mental slowness. The occupational therapy (OT) guideline for assessment and treatment of left hemisphere stroke patients with apraxia was described, focussing on the content of the training and the underlying principles of treatment. Transfer effects of this cognitive strategy training were assessed in the effect studies presented in this thesis.

\section{Methodological considerations}

\section{RCT design vs. non-controlled design}

An RCT design is often seen as the 'golden standard' when evaluating the effectiveness of clinical interventions. ${ }^{1,2}$ Indeed, an RCT offers a method to balance the influence of all other variables except the treatment method, by randomly allocating participants to the different treatment groups. However, for good reasons, the prospective effect study in this thesis was not designed as an RCT. A previously conducted study evaluating the strategy training did use an RCT design and demonstrated this treatment method to be more effective than what used to be the conventional treatment method. ${ }^{3}$ In addition, the exploratory study that was carried out on data collected in this RCT showed that transfer of training effects from trained to non-trained tasks was significantly larger in the strategy training group than in the control group. An RCT establishing the effects of the training versus a control group was therefore not necessary to conduct and a pre-post design was chosen instead. In addition, as a result of the positive findings of the RCT, ${ }^{3}$ the training was published as a guideline for stroke rehabilitation in the Netherlands and thus, the use of this strategy training now is the conventional training method for stroke patients with apraxia. ${ }^{4}$ Therefore, it would have been difficult to arrange an RCT in which one group would have been subjected to a control treatment, as the use of the apraxia strategy training now is the standard training used in the rehabilitation of stroke patients with apraxia. Occupational therapists would have been knowledgeable of the strategy training, making it very hard to create two independent treatment groups. 


\section{Baseline measurement in home setting}

One of the aims of the prospective effect study was to evaluate transfer of training effects from the rehabilitation setting to the patients' own homes. In order to show transfer to the home setting, it is important to demonstrate that the patients' functioning in the home setting is as independent as their functioning in the situation in which training took place. However, by not including a baseline observation in the home setting in our study, we can not be sure how independently patients would have been functioning in their own homes at baseline, without having received any strategy training. Therefore, no objective results on the improvements in ADL functioning at home can be given. Instead we focussed on the differences between functioning at home versus the rehabilitation setting after the treatment period. When designing the study, a baseline observation in the home setting was planned. However, while setting up the study in cooperation with all participating institutions, arranging this baseline observation in the patients' own homes turned out to be unachievable. At inclusion in the study, all participants except two were in an inpatient rehabilitation programme. The reason for them to be admitted to a rehabilitation centre, instead of being in an outpatient programme, reflects the fact that these patients could not yet go home in this phase of the rehabilitation process. Therefore, we were not able to arrange an observation in the patients' own homes at baseline.

\section{Theoretical considerations}

\section{Transfer and awareness of deficits}

As was stated before, the way in which conventional rehabilitation treatment is structured, implicates that transfer of treatment effects should occur if patients are to function as independently as possible in their own environments. Whether patients will be able to implement the use of a compensatory strategy in daily life has been stated to be dependent on whether patients are aware of their limitations. Patients will not be motivated to change their behaviours if they do not recognise their functional difficulties. ${ }^{5}$ However, recognising that these difficulties exist is not the only prerequisite for transfer of treatment effects. According to Crosson et al., three hierarchical levels of awareness can be identified. ${ }^{6}$ The first level, intellectual awareness, relates to the knowledge that a particular function is impaired. The second level, emergent awareness, is the ability to recognise a problem when it occurs. The third and most profound level of awareness is anticipatory awareness. This awareness relates to the ability to recognise that, as a result of the deficit, a problem is likely to occur in a specific situation. Patients will only be able to independently implement compensatory strategies if they possess this third level of awareness. 6,7

Unfortunately, after brain injury, patients often show a lack of awareness regarding the existence or the severity of deficits. ${ }^{8}$ This lack of awareness can be grouped in three categories, relating to the cause of the awareness problem. First, biological changes in the brain can affect the patient's awareness of defi- 
cits, as is often observed after frontal lobe damage. In this case, site and size of the lesion are important variables. Second, unawareness of deficits can be caused by a lack in provided information on brain injury and its consequences, affecting the patient's knowledge about the deficits. Third, denial, an emotionally based problem, affects the awareness of deficits. ${ }^{8}$

Since awareness is considered to be of great importance for successful rehabilitation, increasing awareness during therapy and training is an important aim of a rehabilitation programme. As a result, patients might acknowledge the need to learn how to use compensatory strategies.7,9 Clearly, the intervention type that is used to increase awareness will have to be matched to the type of awareness problems patients are experiencing (i.e. awareness problem related to a biological, a knowledge or an emotional basis). ${ }^{8}$ However, using interventions to increase awareness does not ensure that the highest level of awareness will be reached, and thus, that patients will be able to transfer the trained strategies to new tasks and settings.

If a patient is not able to transfer skills to new tasks or to different settings, the conventional rehabilitation treatment does not seem to suffice. A different rehabilitation programme would be indicated, focussing on specific skills training that teaches patients how to perform specific functional tasks in the environment in which they will later have to be able to perform these tasks. In this way, patients can be taught to carry out limited tasks that do not need to be transferred. ${ }^{10}$ Thus, this would imply providing training at home, but also possibly at work and in society.

\section{Environment effects on task performance}

The influence of the environmental context has been acknowledged by theories on task performance that are used in occupational therapy. This is especially of interest for assessment and training of task performance that takes place in rehabilitation settings. These settings are contrived and differ from the natural environmental contexts in which patients are used to perform tasks. ${ }^{11}$ However, contrasting ideas have been put forward on the way in which these differences in environments affect task performance. On the one hand, it has been suggested that patients might perform better in a contrived setting, due to the fact that these settings provide structure by controlling aspects of the environment that might be disruptive to the person. ${ }^{11}$ This would result in an overestimation of the patients' functioning in the natural environment. On the other hand, the unfamiliarity of a contrived setting can lead to confusion and inefficient functioning, affecting task performance in a negative way and resulting in an underestimation of the patients' function in the natural environment. ${ }^{11,12}$ Yet another view on the influence of the environment in rehabilitation practice states that after an intensive inpatient rehabilitation programme, the rehabilitation setting has become the patient's 'familiar environment'. The patient has become used to the structured, contrived environment making the transition from the clinic to the more 'unfamiliar' home setting problematic. ${ }^{13}$ In addition, when patients learn to use a compensatory strategy, they learn how to perform a task in a new, alternative way. Thus, performing a familiar task in the familiar home 
setting could still be considered unfamiliar since patients have not performed the task before in this way in their own environment.

The results of the study evaluating task performance in healthy middle aged adults, presented in this thesis, confirm the negative influence of an unfamiliar setting on task performance. It was hypothesised that the functioning of stroke patients would be affected by the environment in a similar, if not a more severe way. However, the results of the study evaluating transfer of treatment effects of the strategy training for stroke patients with apraxia showed no differences in task performance between the rehabilitation setting and the home setting. If after inpatient rehabilitation, the participants' home settings have become unfamiliar settings, this result would confirm the occurrence of transfer of treatment effects from the rehabilitation setting to the home setting.

However, it needs to be indicated that the study assessing the environment effect on task performance in healthy adults evaluated process skill abilities during task performance, reflecting the capacity to logically organise and adapt a series of actions over time in order to complete a task. In contrast, the study assessing the occurrence of transfer effects in stroke patients with apraxia evaluated the level of independent functioning during task performance. Process skill abilities can be disturbed, without affecting the level of independent functioning. For example, if participants notice a problem in process skill abilities and if they manage to adjust their task performance adequately and independently, the level of independent functioning will still be optimal. No differences were found in the level of independent functioning in patients' task performances in the rehabilitation setting and in the home setting. However, based on these findings, it can not be inevitably assumed that therefore, no differences in task performance exist. By looking more closely at task performance in the patient group, using measurements for process skills abilities, differences between the settings might have become apparent.

\section{Substitution or restitution of functions?}

Substitution, or a compensatory approach in rehabilitation, is based on the assumption that restoration of cognitive functions to their pre-injury structure and efficiency is not expected to occur and that therefore, rehabilitation should aim at teaching the use of compensatory strategies. ${ }^{14}$ The occurrence of transfer is expected in strategy training, as a strategy is not task specific, but relies on more general principles and hence, should be applicable in different tasks and settings. ${ }^{15}$ In contrast, restitution of function, or cognitive retraining, is stated to show little transfer to functional tasks. ${ }^{10}$ As a result, rehabilitation programmes in Europe often make use of a compensatory approach to reduce disabilities resulting from a cognitive impairment. 16

Recently, however, a discrepancy can be observed between clinical practice, emphasising the use of a compensatory approach and scientific research, taking up a more restitutional perspective. Currently researchers are assessing the effects of rehabilitation on neurological changes and brain plasticity after brain injury. It has been stated that within the field of neurorehabilitation, there is an incomplete understanding about the neurophysiology underlying interven- 
tions. ${ }^{17}$ Traditionally, evaluation of the effectiveness of a rehabilitation treatment uses behavioural methods. However, these methods can not fully distinguish whether improvement occurs due to restitution or substitution of function. Therefore, interest in functional neuroimaging is growing, as physical measures of brain structure and function are needed in order to determine which mechanism underlies functional recovery after rehabilitation. 17,18

A review on neuroimaging studies of motor recovery after stroke reports that a small number of studies has investigated the effect of interventions on brain activation patterns. ${ }^{19}$ Based on these studies, the authors conclude that it is possible to influence motor network reorganisation after stroke by applying motor training procedures. In addition, it was concluded that training-induced brain plasticity can occur. ${ }^{19}$ Strangman et al. show that research has not yet addressed the association between cognitive rehabilitation, functional recovery and neuroimaging techniques. They do, however, argue that approaches that are effective in motor rehabilitation might be applicable in cognitive rehabilitation as well; appropriately designed tasks, specifically activating certain brain areas might aid in recovery of cognitive function. ${ }^{17}$

This view is partly in line with a connectionist model that has been proposed by Robertson and Murre to explain outcome after brain injury.20 According to this model, mild lesions, resulting in networks with a small number of lost connections, recover independently by normal synaptic turnover and Hebbian principles of learning. Severe lesions, resulting in the loss of more than a critical number of neurons (more than 80-90 percent), will not show restitution. Therefore, reducing disability caused by this type of lesions will fully rely on compensation of function by other brain areas. This is the type of recovery that has extensively been described by Luria. ${ }^{21}$ However, Robertson and Murre propose that moderate lesions, resulting in intermediate loss of connections could be recovered through guided recovery. ${ }^{20}$ Rehabilitation programmes can be seen as a form of guided recovery. By specific coactivation of disconnected neurons within the neural network, Hebbian principles of learning can re-establish lost connections, leading to recovery of function. ${ }^{18,20}$ Thus, this model indicates that while restitution or recovery of function can not be expected to occur in all brain injured patients, there might be a substantial number of patients that could benefit from this type of approach. Until now this model is based on theoretical assumptions and thus verification in rehabilitation research is needed to establish the practical consequences of the model.

However, it is important to emphasise that the disabilities that patients experience after stroke are not solely dependent on the biological cause, or pathology, and the impairments that result from the stroke. Contextual factors have an important modulating effect on the disabilities. ${ }^{22}$ The International Classification of Functioning (ICF) offers a way to describe the interaction between a health condition, the individual and contextual factors. ${ }^{23}$ This framework demonstrates that curing a disease or restoring an impaired function does not inevitably have to result in the resolving of the impairment. Contextual factors that are taken into account by the ICF relate to the personal, the physical and the social context. The personal context describes mental characteristics of 
the person that influence the way that people deal with their health condition, such as expectations, attitudes and beliefs. In addition, the physical context relates to the availability of external, physical objects, as well as the presence of other people as carers or helpers. The social context refers to external, abstract constructs such as culture, society, the laws, but also family and friends. ${ }^{22}$

\section{Recommendations for clinical practice}

The papers presented in this thesis demonstrated occurrence of transfer of treatment effects of cognitive strategy training. However, environment effects on the performance of daily tasks in healthy, middle aged adults have also been shown to occur. The effect of different environments on task performance will likely be present in stroke patients as well. Therefore, it is important that therapists working with brain injured patients are aware of the environment effects that may impede the occurrence of transfer of treatment effects from the rehabilitation setting to the home setting. To facilitate discharge from the rehabilitation setting to the patients' own homes, it is important that the connection between what is learned and the situation in which it is learned is broken down. This could be established by practicing a strategy or skill while varying the practice situation as much as possible.

In addition, the patients' awareness of their cognitive deficits has been shown to be fundamental if patients are expected to implement new strategies independently. Furthermore, most patients will be more motivated to learn new strategies if they are aware of their deficits and acknowledge that these new strategies are necessary to improve their functioning. Thus, increasing awareness is an important starting point in rehabilitation practice. Interventions used to increase awareness should be attuned to the causes of the awareness problems patients are experiencing. An awareness problem related to a biological basis can be addressed by gradually confronting patients with their limitations and by providing feedback on their performances. In contrast, an intervention relating to an awareness problem caused by a lack of knowledge on brain injury and its consequences should focus on providing education on brain injury. However, if an awareness problem is primarily caused by emotional factors, resulting in denial of the consequences of brain injury, providing counselling would be more appropriate, using, for example, a cognitive behavioural approach.

The intervention studies in this thesis relate to the evaluation of the occurrence of transfer effects of a strategy training for stroke patients with apraxia. The results of these studies confirmed the assumption that transfer is expected in strategy training. ${ }^{15}$ In addition, it is in line with research findings within the field of educational psychology, demonstrating that general knowledge is better transferred than specific knowledge. ${ }^{24,25}$ Since general knowledge, relating to teaching more general strategies, is more widely applicable than specific knowledge, like the retraining of specific tasks, transfer is more likely to occur in strategy training. Therefore, the use of strategy training in cognitive rehabilitation is recommended, if occurrence of transfer is an aim of the training. Trans- 
fer of strategy training for other cognitive deficits than apraxia needs to be evaluated, although this thesis strengthens the general assumption that transfer effects of strategy training occur.

If a patient is not able to transfer skills to new tasks or to different settings, the conventional rehabilitation treatment does not seem to suffice. A different rehabilitation programme would be indicated, focussing on specific skills training that teaches patients how to perform specific functional tasks in the environment in which they will later have to be able to perform these tasks. In this way, patients can be taught to carry out limited tasks that do not need to be transferred. ${ }^{10}$ A recent study showed that a combination of domiciliary therapy and inpatient rehabilitation can be useful as well in patients with moderate to severe cognitive impairments. ${ }^{26}$ Thus, this would imply providing training at home, but also possibly at work and in society.

The prevalence of apraxia in rehabilitation settings is underestimated if the diagnosis is made on clinical judgment alone. Since apraxia has been demonstrated to have a negative impact on every day life, it is important that patients with apraxia are correctly identified at the start of the rehabilitation process, in order that this cognitive deficit can be addressed during rehabilitation. Therefore, it is necessary to include a neuropsychological apraxia test in the standard assessment battery for stroke patients. A short, simple and reliable test for apraxia is now available and is recommended for use in clinical (rehabilitation) practice. If apraxia is demonstrated using this test, a behavioural observation is needed to assess the specific consequences of apraxia in daily life that each individual patient experiences.

Apraxia is associated with aphasia, memory problems and mental slowness. A fundamental issue in applying strategy training is making use of peoples' strengths to compensate for their weaknesses. In addition, when addressing a specific impairment, a therapist can not solely focus on this impairment alone. Other cognitive impairments always have to be taken into account as they will influence the treatment methods that can be used for each specific patient. Thus, when focussing on impairments due to apraxia, therapists should take into account other cognitive deficits that might be present in the patient as well. It is therefore important that therapists are aware of these associations, making them alert to the possible comorbidity that will affect the rehabilitation process. The treatment method that was evaluated in this thesis offers sufficient alternatives to attune compensatory strategies to the specific deficits and impairments of the individual patients.

\section{Recommendations for future research}

Despite this study, still little is known about transfer in brain injured patients. It is likely that transfer in brain injured patients differs from transfer in healthy adults. However, since there is a lack of studies looking into this difference, both rehabilitation research and practice should make use of previous research within the field of educational psychology. Within this field of research, many studies have evaluated transfer in school settings. Transfer mechanisms might 
not be completely similar in healthy people compared to brain injured patients, but knowledge on transfer in healthy people does offer a valuable starting point in rehabilitation research and in the development of treatment methods that show transfer. Currently, the theories and recommendations on promoting transfer based on educational research are the best we have in rehabilitation research and practice. It would therefore be of great importance for the progress of rehabilitation to evaluate to what extent these theories apply to brain injured patients and to assess what other theories could be applicable to this specific group of patients. Based on this information, new interventions that facilitate the transfer of treatment effects can be designed or existing interventions can be adapted.

The results presented in this thesis strengthen the general notion that transfer of treatment effects is expected to occur in cognitive strategy training. However, it is important to further investigate the occurrence of transfer effects of other specific strategy training programmes.

To better adjust rehabilitation treatment to individual patients, it is essential that more insight is gained in the characteristics that can identify patients that will be able to transfer skills. Characteristics that can influence the occurrence of transfer will need to be evaluated further, such as the patients' awareness of their own deficits and the presence of specific cognitive impairments that could hinder the occurrence of transfer. For example a memory problem might impede the transfer of a strategy training, as patients might forget the strategy itself. Based on this knowledge a distinction should be made between patients that are expected to be able to show transfer on the one hand, and those who are expected not to be able to do so on the other hand. Both groups would require rehabilitation programmes that are structured in different ways, and that are more specifically attuned to the capacity of the individual patients. Following the same line of thought, further research into the neural mechanisms that underlie functional recovery after stroke, might allow us to identify patients that could possibly benefit from a restitutive as opposed to a substitutive approach in rehabilitation. Again, this distinction would enable the possibility to better adjust a rehabilitation programme to the characteristics of the individual patients.

The ultimate goal of a rehabilitation programme is maximising independent functioning, resulting in the patients' return to their own homes and participation in society. Since the ecological validity of neuropsychological tests, assessing cognitive impairments, has been questioned, 27 research investigating the effectiveness of a rehabilitation programme should focus on evaluating the patients' disability levels. Therefore, standardised, ecologically valid instruments that can measure the occurrence of transfer to daily life are needed. It would be interesting to study whether such instruments could be developed. However, the lacking of these instruments reflects the fact that it is hard to assess transfer to daily life in a standardised, reliable way, as was shown in the literature review. The best solution to this problem is to observe the simulated performance of daily tasks. The most appropriate setting to carry out these observations would be the natural, daily setting. This setting can differ based on the actual 
aim of the rehabilitation programme; the primary aim will probably be the patient's return home, requiring measurements taking place at home, but improving functioning at work, for example, could very well be an aim as well, implying that measurements should take place at the work setting.

\section{References}

1. Bailey DM. Research for the health professional. A practical guide. Philadelphia: F.A. Davis Company; 1997.

2. Badenoch D, Heneghan C. Evidence-based medicine toolkit. London: BMJ Books; 2002.

3. Donkervoort M, Dekker J, Stehmann-Saris JC, Deelman BG. Efficacy of strategy training in left hemisphere stroke patients with apraxia: A randomized clinical trail. Neuropsychol Rehabil 2001;11(5):549-66.

4. Commissie CVA-revalidatie. Revalidatie na een beroerte: Richtlijnen en aanbevelingen voor zorgverleners [Rehabilitation after stroke: Guidelines and recommendations for clinical practice]. The Hague: Dutch Heart Foundation; 2001.

5. Toglia JP, Kirk U. Understanding awareness deficits following brain injury. NeuroRehabilitation 2000;15(1):57-70.

6. Crosson B, Barco PP, Velozo CA, Bolesta MM, Cooper PV, Werts D, et al. Awareness and compensation in postacute head injury rehabilitation. J Head Trauma Rehabil 1989;4(3):46-54.

7. The society for cognitive rehabilitation. Recommendations for best practice in cognitive rehabilitation therapy: Acquired brain injury. Surrey: The society for cognitive rehabilitation; 2004.

8. Sohlberg MM, Mateer CA. Cognitive rehabilitation: An integrative neuropsychological approach. New York: The Guilford Press; 2001.

9. Prigatano GP. Disturbances of self-awareness and rehabilitation of patients with traumatic brain injury: A 20-year perspective. J Head Trauma Rehabil 2005;20(1):19-29.

10. Berg I, Schmidt I. Cognitive rehabilitation of memory disorders. In: Brouwer WH, van Zomeren AH, Berg I, Bouma A, de Haan EHF, editors. Cognitive Rehabilitation: A clinical neuropsychological approach. Amsterdam: Boom; 2002. p. 141-165.

11. Dunn W. Measurement issues and practice. In: Law M, Baum C, Dunn W, editors. Measuring occupational performance: Supporting best practice in occupational therapy. Thorafare: Slack Inc.; 2005. p. 21-32.

12. Park S, Fisher AG, Velozo CA. Using the assessment of motor and process skills to compare occupational performance between clinic and home settings. Am J Occup Ther 1994;48(8):697-709.

13. Darragh AR, Sample P, Fisher AG. Environment effect on functional task performance in adults with acquired brain injuries: Use of the Assessment of Motor and Process Skills. Arch Phys Med Rehabil 1998;79:418-23

14. Wilson BA. Compensating for cognitive deficits following brain injury. Neuropsychol Rev 2000;10(4):233-43.

15. Ben-Yishay Y, Diller L. Cognitive remediation in traumatic brain injury: Update and issues. Arch Phys Med Rehabil 1993;74:204-13.

16. Prigatano GP. A history of cognitive rehabilitation. In: Halligan PW, Wade DT, editors. Effectiveness of rehabilitation for cognitive deficits. Oxford: Oxford University Press; 2005. p. 3-10.

17. Strangman G, O'Neil-Pirozzi TM, Burke D, Cristina D, Goldstein R, Rauch SL, et al. Functional Neuroimaging and cognitive rehabilitation for people with traumatic brain injury. Am J Phys med Rehabil 2005;84(1):62-75. 
18. Robertson IH. The neural basis for a theory of cognitive rehabilitation. In: Halligan PW, Wade DT, editors. Effectiveness of rehabilitation for cognitive deficits. Oxford: Oxford University Press; 2005. p. 281-291.

19. Calautti C, Baron JC. Functional neuroimaging studies of motor recovery after stroke in adults: A review. Stroke 2003;34:1553-66.

20. Robertson IH, Murre JMJ. Rehabilitation of brain damage: Brain plasticity and principles of recovery. Psychol Bull 1999;125(5):544-75.

21. Luria AR. Restoration of function after brain injury. Oxford: Pergamon; 1963.

22. Wade DT. Applying the WHO ICF framework to the rehabilitation of patients with cognitive deficits. In: Halligan PW, Wade DT, editors. Effectiveness of rehabilitation for cognitive deficits. Oxford: Oxford University Press; 2005. p. 31-42.

23. WHO. The international classification of function, disability, and health (ICF). Geneva: World Health Organisation; 2001.

24. Salomon G, Perkins DN. Rocky roads to transfer: Rethinking mechanisms of a neglected phenomenon. Educational Psychologist 1989;24(2):113-42.

25. Haskell RE. Transfer of learning: Cognition, instruction, and reasoning. San Diego: Academic Press; 2001.

26. Boonstra AM, Wijbrandi W, Spikman JM. Domiciliary therapy during inpatient rehabilitation treatment for patients with an acquired brain injury: A preliminary study. Int $J$ Rehabil Res 2005;28(3):211-8

27. Chaytor N, Schmitter-Edgecombe M. The ecological validity of neuropsychological tests: A review of literature on everyday cognitive skills. Neuropsychol Rev 2003;13(4):181-97. 
Summary 

The main goal of this thesis was to evaluate the occurrence of transfer of treatment effects in cognitive strategy training for stroke patients in general, and more specifically, to investigate the occurrence of transfer of a training programme for stroke patients with apraxia. Both transfer from trained to nontrained tasks and transfer from the rehabilitation setting to the patients' own homes have been evaluated.

In this thesis, transfer has been addressed in several ways. Literature has been reviewed to evaluate the current state of the assessment of transfer in cognitive rehabilitation, and the occurrence of transfer effects of the apraxia training, a specific cognitive strategy training, has been assessed. In addition, a study evaluating environment effects on task performance in healthy adults has been described. To facilitate the assessment of transfer effects of the apraxia training, several aspects of apraxia and the apraxia test have been presented first and a description of the strategy training programme for stroke patients with apraxia has been given.

In chapter 1 background information was provided on transfer, stroke, strategy training and apraxia. In addition, the rationale, the aims and the outline of the thesis are presented.

In chapter 2 the inter-rater reliability of a neuropsychological apraxia test was evaluated. This test was used to diagnose the patients who participated in the effect studies described in this thesis. In addition, the association between apraxia and other cognitive deficits was assessed and the prevalence of apraxia in a rehabilitation setting was evaluated. The results of the cognitive screening of 100 consecutive first ever stroke patients were used in this study. The screening took place upon the patients' admission to a rehabilitation centre and covered the main cognitive functions (praxis, visuospatial scanning, abstract thinking and reasoning, memory, attention, planning and language). The apraxia test was shown to have a good inter-rater reliability. In addition, apraxia was found to be associated with aphasia, memory problems and mental slowness. Based on the performance on the apraxia test, more than half of all left hemisphere stroke patients $(51.3 \%)$ could be diagnosed as apraxic, as opposed to $6 \%$ of the patients with a right hemisphere stroke. It was concluded that the prevalence of apraxia in rehabilitation settings is underestimated if the diagnosis is made on clinical judgment alone.

In chapter 3 the occupational therapy (OT) guideline for assessment and treatment of left hemisphere stroke patients with apraxia was described. Transfer effects of this cognitive strategy training were assessed in the effect studies presented in this thesis. The chapter presented the theories on which the treatment programme is based as well as the methods of assessment and treatment that are used in the treatment programme. In addition studies demonstrating the effectiveness of the training were reviewed. Based on the positive research findings, the training has been published as a guideline for stroke rehabilitation 
in the Netherlands and is therefore the conventional training method for stroke patients with apraxia.

In chapter 4 we presented a critical literature review on the occurrence and measurement of transfer of treatment effects in cognitive rehabilitation. It was found that a relatively small number of studies evaluated the occurrence of transfer of training effects. Thirty-nine papers, describing 41 studies were included in the review. Outcome measures to evaluate transfer that were used in these studies could be classified in three groups: (1) non-trained items (2) standardised daily tasks (3) daily life. Although most studies reported positive results with regard to the occurrence of transfer, some serious remarks concerning the methodological quality of the studies were made. First, almost half of the studies that reported transfer to occur, had not statistically tested these results. This was most apparent in the studies that claimed to have demonstrated transfer to daily life, where in three quarters of the studies the results were not statistically tested. Second, measuring transfer of treatment effects to daily life in an objective and standardised way was shown to be difficult, as adequate tests or instruments are lacking. In addition, several studies that reported the occurrence of transfer to daily life had not been able to measure transfer in a standardised way, since evaluating transfer effects had not been formulated as an aim of the study beforehand. In these studies, demonstration of transfer was based on coincidental observations and remarks. It was concluded that in order to evaluate the effectiveness of cognitive strategy training, more studies are needed, specifically designed for measuring transfer of treatment effects.

In chapter 5 the results of an exploratory study assessing the transfer effects of cognitive strategy training for stroke patients with apraxia were presented. This study evaluated the occurrence of transfer from trained to non-trained tasks. New analyses were conducted on data that had previously been collected in a randomised clinical trial (RCT) on the efficacy of the strategy training. A total of 113 left hemisphere stroke patients with apraxia were randomly assigned to the strategy training group and a group receiving occupational therapy as usual. In both treatment groups, the level of independent functioning on non-trained ADL tasks was significantly higher after eight weeks of training than before the start of the training, suggesting that both treatments showed transfer effects. However, change scores of non-trained activities were significantly larger in the strategy training group as compared with the usual treatment group, reflecting more transfer of the strategy training. It was concluded that indications for the occurrence of transfer of the strategy training had been found, although the study was not originally designed for the purpose of evaluating transfer. Thus, these results provided the rationale to design a new prospective study, specifically aimed at examining the transfer effects of this training programme.

In chapter 6 we evaluated the occurrence of transfer effects of cognitive strategy training for stroke patients with apraxia in a prospective effect study. Both transfer from trained to non-trained tasks and transfer from the rehabilitation 
setting to the patients' own homes were investigated. Twenty-nine apraxic stroke patients received eight weeks of cognitive strategy training to teach them to perform activities of daily living (ADL) as independently as possible, by using strategies to compensate for the apraxia. The performance of trained and nontrained ADL tasks was assessed at the rehabilitation centre at baseline and after eight weeks of training. In addition, after eight weeks of training and five months after the start of the training assessment took place at the patients' own homes. Patients performed trained tasks and non-trained tasks at the same level of independency at the rehabilitation centre as well as at home, indicating transfer of training effects. These effects turned out to be stable over time. The importance of the evaluation of transfer effects of cognitive rehabilitation treatment, and of rehabilitation programmes in general was emphasised, as it relates to the core goal of a rehabilitation treatment: teaching patients ways to function as independently as possible, resulting in the return to their own home and participation in society. The study presented in this chapter describes one of the first larger scale prospective studies that attempted to evaluate this issue.

In chapter 7 the effect of a change in environments on the performance of daily tasks in healthy middle aged adults was assessed. This age group was chosen because it matches the rehabilitation population. In addition, the influence of abstract reasoning skills and the influence of memory functioning on the ability to adapt to different environments were evaluated. Thirty healthy, middle aged adults were observed in two different settings (the participants' own kitchens and an unfamiliar kitchen) while performing two daily tasks. The performance of both tasks was significantly slower in the unfamiliar kitchen. In addition, for both tasks, the overall score on process skill abilities, reflecting the capacity to logically organise and adapt a series of actions over time in order to complete a task, was significantly lower in the unfamiliar setting. Variations in process skill scores were found in the unfamiliar kitchen only. Process skills observed in the participants' own kitchens were nearly optimal. No associations were found between environment effects and abstract reasoning skills or memory functioning. It was concluded that it is likely to assume that the environment effect in task performance that was demonstrated in this study, will be present in stroke patients as well. This would result in important implications for rehabilitation practice; during a rehabilitation programme, facilitating transfer of training effects to other environments should be addressed.

In chapter 8 an overview of the main results of the study has been presented and theoretical and methodological considerations have been discussed. Based on the results presented in this thesis it has been concluded that transfer of treatment effects of cognitive strategy training has been demonstrated. Therefore, the use of cognitive strategy training has been recommended, although more research is needed to evaluate the occurrence of transfer effects of specific strategy training programmes other than the apraxia training presented in this thesis. While transfer effects have been shown to occur, environment effects on the performance of daily tasks have been demonstrated as well. Thus, thera- 
pists working with brain injured patients should be aware of these environment effects that may impede the occurrence of transfer of treatment effects from one setting to another. Therefore, it is important that these environment effects are addressed during therapy in order to facilitate discharge from the rehabilitation setting to the patients' own homes. In addition, it was stated that more insight should be gained in the characteristics that can identify patients that will be able to transfer skills as opposed to patients that will not be able to do so. This would enable clinicians to better adjust rehabilitation treatments to individual patients since both groups require rehabilitation programmes that are structured in different ways, attuned to the capacities of the individual patients. 
Samenvatting 

Het doel van dit onderzoek is het evalueren van transfer effecten van cognitieve strategietraining na een cerebro vasculair accident (CVA). In dit proefschrift wordt het optreden van transfer van een training voor CVA patiënten met apraxia onderzocht. Twee soorten transfer zijn geanalyseerd, te weten transfer van getrainde naar niet-getrainde taken en transfer van de revalidatiesetting naar de thuissituatie.

In hoofdstuk 1 wordt uitleg gegeven over transfer, CVA, strategietraining en apraxie. Tevens worden de rationale, de doelstellingen en de opzet van dit proefschrift beschreven. Het optreden van transfer is op verschillende manieren onderzocht. De huidige staat van het onderzoek naar transfer in cognitieve revalidatie is geëvalueerd door middel van een literatuur onderzoek. Vervolgens is het optreden van transfer van de cognitieve strategietraining voor CVA patiënten met apraxie onderzocht. Daarnaast is nagegaan in hoeverre de omgeving invloed heeft op de taakuitvoer van gezonde volwassenen. Om de evaluatie van de apraxietraining te faciliteren worden eerst verschillende aspecten van apraxia en de apraxie test gepresenteerd. Tevens wordt de strategietraining voor CVA patiënten met apraxie beschreven.

In hoofdstuk 2 wordt de inter-beoordelaars betrouwbaarheid van een neuropsychologische apraxie test onderzocht. Daarnaast wordt in dit hoofdstuk de samenhang tussen apraxie en andere cognitieve stoornissen geëvalueerd en wordt de prevalentie van apraxie in een revalidatiesetting in kaart gebracht. In deze studie werd gebruik gemaakt van de resultaten van de cognitieve screening van 100 opeenvolgende patiënten die als gevolg van een eerste CVA waren opgenomen in een revalidatiecentrum in Nederland. De screening werd direct na opname in het revalidatiecentrum afgenomen en omvatte de belangrijkste cognitieve functies (praxis, visuospatieel functioneren, abstract redeneren, geheugen, aandacht, planning en taal). Het onderzoek toont aan dat de inter-beoordelaars betrouwbaarheid van de apraxie test goed is. Apraxie blijkt samen te gaan met afasie, geheugen problemen en mentale traagheid. Op basis van de score op de apraxie test wordt bij meer dan de helft van de patiënten met een CVA in de linker hemisfeer (51.3\%) de diagnose apraxie gesteld. Voor patiënten met een CVA in de rechter hemisfeer ligt dit percentage op 6\%. Deze resultaten wijzen op een onderschatting van de prevalentie van apraxie in revalidatiesettings wanneer slechts gebruik wordt gemaakt van een klinisch oordeel bij de diagnosticering van de stoornis.

In hoofdstuk 3 wordt de ergotherapie richtlijn voor diagnostiek en behandeling van apraxie bij CVA patiënten beschreven. Het behandelprogramma is gebaseerd op theorieën over herstel na een CVA en op leertheorieën die zijn afgeleid van revalidatieonderzoek. Deze theorieën worden besproken en de methoden van diagnostiek en behandeling die deel uitmaken van het programma worden gepresenteerd. Tevens geeft het hoofdstuk een overzicht van de resultaten van de interventiestudies waarin de effectiviteit van het behandelprogramma werd geëvalueerd. Naar aanleiding van de positieve resultaten van deze studies werd 
het behandelprogramma gepubliceerd als richtlijn voor CVA revalidatie in Nederland. Het behandelprogramma werd daardoor de standaard trainingsmethode voor CVA patiënten met apraxie.

In hoofdstuk 4 worden de resultaten gerapporteerd van een literatuurstudie (critical review) naar het optreden en het meten van transfer van trainingseffecten in de cognitieve revalidatie. Het optreden van transfer blijkt in een relatief klein aantal studies onderzocht te zijn. Negenendertig artikelen werden in de literatuurstudie opgenomen. Deze artikelen beschrijven in totaal 41 verschillende studies. De uitkomstmaten die gebruikt werden voor het meten van transfer kunnen worden verdeeld in drie groepen: (1) niet-getrainde items; (2) gestandaardiseerde dagelijkse taken; (3) dagelijks leven. Hoewel de meeste studies het optreden van transfer rapporteerden, dient een kritische kanttekening geplaatst te worden bij de methodologische kwaliteit van de studies. Ten eerste blijkt dat bijna de helft van alle studies die het optreden van transfer rapporteerden, deze resultaten niet statistisch had getoetst. Dit geldt met name voor de studies waarin transfer naar het dagelijks leven werd gerapporteerd; in driekwart van deze studies werden geen statistische toetsen beschreven. Ten tweede blijkt het problematisch om transfer naar het dagelijks leven objectief en gestandaardiseerd te meten aangezien geschikte meetinstrumenten ontbreken. Bovendien blijkt dat in verschillende studies waarin transfer naar het dagelijks leven werd gerapporteerd, transfer niet gestandaardiseerd gemeten kon worden omdat het evalueren van transfer niet vooraf was opgenomen als een doel van de studie. Deze studies toonden het optreden van transfer aan op basis van toevallige observaties en opmerkingen. Naar aanleiding van de literatuurstudie wordt geconcludeerd dat er behoefte is aan onderzoek dat specifiek is ontworpen voor het meten van transfer van behandeleffecten zodat de effectiviteit van cognitieve strategietraining verder geëvalueerd kan worden.

In hoofdstuk 5 presenteren we de resultaten van een exploratief onderzoek naar de transfer effecten van cognitieve strategietraining voor CVA patiënten met apraxie. In dit onderzoek wordt het optreden van transfer van getrainde naar niet-getrainde taken geëvalueerd. Daartoe werden nieuwe analyses uitgevoerd op data die eerder verzameld waren in het kader van een randomised clinical trial (RCT) naar de effectiviteit van de strategietraining. In totaal werden 113 patiënten met apraxie als gevolg van een CVA in de linker hemisfeer gerandomiseerd toegewezen aan een groep die strategietraining ontving en een groep die de standaard ergotherapie behandeling ontving. $\mathrm{Na}$ een behandeling van acht weken functioneren beide groepen op een significant hoger niveau van onafhankelijkheid bij het uitvoeren van dagelijkse taken dan bij de start van de behandeling. De verschilscores van niet-getrainde taken zijn echter significant groter in de strategiegroep dan in de groep die de standaard behandeling ontving. Dit resultaat toont aan dat de strategietraining een grotere transfer van trainingseffecten laat zien dan de standaard behandeling. Geconcludeerd wordt dat indicaties voor het optreden van transfer van de strategietraining gevonden zijn, hoewel de studie niet expliciet ontworpen was voor het evalueren van transfer. De 
resultaten van deze studie zijn daarom aanleiding voor het opzetten van een nieuwe prospectieve studie die specifiek gericht is op het onderzoeken van transfer effecten van deze training.

In hoofdstuk 6 wordt een prospectieve effectstudie beschreven waarin het optreden van transfer effecten van cognitieve strategietraining voor CVA patiënten met apraxie wordt onderzocht. Zowel het optreden van transfer van getrainde naar niet-getrainde taken als transfer van de revalidatiesetting naar de thuissituatie is geëvalueerd. Negenentwintig CVA patiënten met apraxie ontvingen gedurende acht weken cognitieve strategietraining. Met behulp van de training leren patiënten strategieën aan waarmee gecompenseerd kan worden voor de gevolgen van apraxie, zodat dagelijkse taken zo onafhankelijk mogelijk uigevoerd kunnen worden. Voor de start van de behandeling en na acht weken training werd het uitvoeren van getrainde en niet-getrainde taken in de revalidatiesetting geobserveerd. Tevens werd de uitvoer van deze taken bij de patiënten thuis geobserveerd, direct na acht weken training en vijf maanden na de start van de training. $\mathrm{Na}$ acht weken training blijken patiënten getrainde en nietgetrainde taken met hetzelfde niveau van onafhankelijkheid uit te voeren, zowel in de revalidatiesetting als thuis. Deze resultaten wijzen op transfer van trainingseffecten. Bovendien blijken de resultaten constant te blijven over de tijd. Dit onderzoek is een van de eerste grotere prospectieve studies dat het optreden van transfer van een cognitieve strategietraining tracht te evalueren.

In hoofdstuk 7 wordt het effect van een verandering in omgeving op de uitvoer van dagelijkse taken nagegaan in een groep gezonde volwassenen van middelbare leeftijd, een leeftijdsgroep die overeenkomt met de revalidatiepopulatie. Tevens wordt onderzocht of het abstract redeneervermogen en de geheugen functie invloed hebben op de aanpassing aan een nieuwe omgeving. Dertig gezonde personen van middelbare leeftijd werden geobserveerd tijdens het uitvoeren van twee taken in twee verschillende situaties (de eigen keuken en een voor de deelnemers onbekende oefenkeuken). De uitvoer van beide taken blijkt significant langzamer te zijn in de onbekende keuken. Bovendien is voor beide taken de score op procesvaardigheden, de cognitieve vaardigheden die gebruikt worden bij het uitvoeren van een taak, significant lager in de onbekende omgeving. Variaties in de score op procesvaardigheden treden slechts op bij taakuitvoer in de onbekende keuken; de procesvaardigheden bij taakuitvoer in de eigen keuken zijn nagenoeg optimaal. Associaties tussen omgevingseffecten en respectievelijk het abstract redeneervermogen en de geheugen functie zijn niet aangetoond. Geconcludeerd wordt dat de omgevingseffecten die in deze studie zijn aangetoond zeer waarschijnlijk ook zullen bestaan bij CVA patiënten. Dit heeft belangrijke implicaties voor de revalidatiepraktijk, aangezien transfer van behandeleffecten naar een nieuwe omgeving gefaciliteerd zal moeten worden.

In hoofdstuk 8 wordt een overzicht gegeven van de belangrijkste bevindingen van dit proefschrift en worden theoretische en methodologische overwegingen besproken, zoals het verband tussen het optreden van transfer en het inzicht 
dat patiënten hebben in hun eigen functioneren, en het ontbreken van een baseline meting in de thuissituatie. Op basis van de in dit proefschrift beschreven onderzoeksresultaten wordt geconcludeerd dat transfer van behandeleffecten van cognitieve strategietraining is aangetoond. Het gebruik van cognitieve strategietraining wordt daarom aangeraden, ofschoon verder onderzoek noodzakelijk is, waarin transfer van specifieke strategietrainingen, anders dan de in dit proefschrift beschreven apraxietraining, geëvalueerd wordt. Naast het optreden van transfer effecten zijn echter ook omgevingseffecten aangetoond bij de uitvoer van dagelijkse taken. Therapeuten dienen zich daarom bewust te zijn van deze omgevingseffecten die mogelijk de transfer van behandelresultaten naar andere situaties belemmeren. In dit opzicht is het van belang dat tijdens de therapieën aandacht wordt besteed aan de omgevingseffecten, zodat het ontslag van de patiënt van een revalidatiesetting naar de thuissituatie wordt gefaciliteerd. Daarnaast dient inzicht te worden verkregen in karakteristieken waarmee patiënten die in staat zijn tot transfer onderscheiden kunnen worden van andere patiënten. Hierdoor kan de revalidatiebehandeling beter aangepast worden aan de specifieke patiënten, aangezien voor beide groepen verschillende behandelprogramma's geïndiceerd zijn, afgestemd op de capaciteiten van de individuele patiënten. 
Dantwoord 

Als een soort Alice in Wonderland stapte ik precies zes jaar geleden de wereld van het revalidatieonderzoek binnen. Net als Alice was ik erg nieuwsgierig en wilde ik graag veel leren, maar wist ik niet zo goed wat me te wachten stond. Daarom was het erg fijn dat ik tijdens mijn avonturen veel mensen heb ontmoet die het op allerlei verschillende manieren mogelijk hebben gemaakt dat dit proefschrift er uiteindelijk is gekomen. De laatste bladzijden van dit boekje zijn bedoeld om deze mensen te bedanken.

Allereerst wil ik mijn promotieteam bedanken; mijn beide promotoren Wim van den Heuvel en Jelle Jolles en mijn co-promotor Caroline van Heugten. Naast de 'gebruikelijke' beslommeringen die het begeleiden van een promovendus met zich meebrengt, werden jullie geconfronteerd met een promovendus die in de afrondingsfase van haar onderzoek voor een aantal maanden naar het buitenland vertrok. Ik wil jullie graag bedanken voor jullie flexibiliteit en inzet waardoor dit proefschrift in die tijd toch afgerond kon worden. Beste Wim, jij hield als geen ander de grote lijn van het onderzoek voor ogen. Je waakte over de planning maar leerde me ook dat deadlines er zijn om overschreden te worden. Het was prettig om met je samen te werken, al blijven we van mening verschillen over de afstand van Maastricht tot Groningen. Beste Jelle, jij zorgde voor de begeleiding vanuit de universiteit. Je gaf me veel vrijheid bij de invulling van het onderzoek, terwijl je bij onduidelijkheden precies tot de kern van de zaak wist door te dringen. Beste Caroline, zonder jou had dit proefschrift niet bestaan. Ik voel me vereerd dat ik, als jouw eerste 'echte' promovendus, heb mogen voortborduren op jouw eigen promotieonderzoek. Hoeveel aio's dromen niet van een dagelijkse begeleider waarbij de deur altijd open staat? Jouw aanstekelijke enthousiasme voor revalidatieonderzoek en jouw praktische insteek zijn in dit proefschrift terug te zien. Ik heb genoten van onze samenwerking en hoop van harte dat we deze in de toekomst kunnen voortzetten.

Ik ben veel dank verschuldigd aan alle CVA patiënten en hun families die hebben meegewerkt aan dit onderzoek. $\mathrm{Zij}$ stonden toe dat we hen niet alleen in het revalidatiecentrum, maar ook thuis op de vingers kwamen kijken wanneer zij hun dagelijkse activiteiten uitvoerden. Zonder hun medewerking hadden we de onderzoeksvragen in dit proefschrift niet kunnen beantwoorden.

Andere personen die een belangrijke rol hebben gespeeld bij het tot stand komen van dit proefschrift zijn de artsen, de onderzoekscoördinatoren en de directies van de centra die hebben meegewerkt aan het in dit proefschrift beschreven onderzoek. Mijn dank is groot voor het feit dat $u$ allen de uitvoer van dit onderzoek in uw centra mogelijk heeft gemaakt.

Het legioen ergotherapeuten dat vanuit de deelnemende centra aan dit onderzoek heeft meegewerkt is van onschatbare waarde geweest. Jullie hielden in de gaten of er mogelijke deelnemers voor het onderzoek op de afdeling waren, jullie wisten de patiënten en hun families te motiveren om mee te doen en jullie voerden de behandeling uit. Met veel plezier denk ik terug aan de warme ontvangst 
die ik in de centra van jullie kreeg en aan het enthousiasme waarmee jullie de vlaaien tegemoet zagen. Janneke en ik hebben ons bij jullie altijd erg welkom gevoeld.

Janneke, wat had ik zonder jou moeten beginnen? Het onderzoek dat in dit boekje beschreven wordt voelt voor mij echt als 'ons onderzoek'. Met een grote stressbestendigheid, veel logistiek inzicht en een nauwkeurigheid die ik altijd erg heb gewaardeerd heb jij alle patiëntmetingen gepland en uitgevoerd. Jij weet als geen ander dat het uitvoeren van een multi-center onderzoek behoorlijk a-praktisch kan zijn. Keer op keer stapte je in de trein om het land te doorkruisen, vaak op een veel te vroeg tijdstip. Want tja, wassen en aankleden gebeurt nu eenmaal 's ochtends... Bedankt voor je grote inzet! Ook Edith trok er voor het onderzoek op uit. Zij was met name actief in het zuiden van het land, waar ze familie, vrienden en collega's wist te overtuigen om voor haar een aantal keer een kopje koffie te zetten en een boterham te smeren. Edith, dankzij jouw inspanningen werden de gegevens voor het 'gezonden onderzoek' in korte tijd verzameld en daarvoor ben ik je erg dankbaar.

Angelique Zwinkels en Peter van de Sande ben ik erkentelijk voor het feit dat ik met hen mee mocht publiceren. De co-auteurs Mireille Donkervoort, Els van den Ende, Fieneke Stehmann en professor Joost Dekker wil ik bedanken voor de feedback op de artikelen die ik van hen heb mogen ontvangen. Beste Mireille, ook jij ziet jouw promotieonderzoek gecontinueerd in dit proefschrift. Bedankt dat je me wegwijs hebt willen maken in de RCT datafile en in de opzet van jouw onderzoek. Beste Fieneke, jouw enthousiasme en bereidheid om mee te denken zijn onuitputtelijk. Jij staat aan het hoofd van de apraxie-familie en hebt haar zien uitgroeien tot wat zij nu is. Ik ben er trots op dat ik als jongste telg deel mag uitmaken van jouw familie.

Ook Martin van Boxtel heeft een bijdrage geleverd aan dit proefschrift. Martin, hoewel het jouw taak niet was om je bezig te houden met het apraxie onderzoek, vond je altijd tijd om mijn vragen over methodologie en statistiek te beantwoorden. Dank voor je hulp en je interesse.

Beste mensen van het consortium cognitieve revalidatie, nu ik terug ben in $\mathrm{Ne}-$ derland hoop ik weer aanwezig te kunnen zijn bij de vergaderingen zodat ik op de hoogte kan blijven van al jullie onderzoeksactiviteiten. Extra benieuwd ben ik natuurlijk naar de resultaten van mijn collega-aio's. Heel veel succes met de afronding van jullie projecten!

A special thank you goes out to the therapists and co-workers of the Center for Neuro Skills in Bakersfield. Visiting CNS has been a very special experience, not only because of the interesting things I have seen and learnt, but also because of your kindness and hospitality. You showed me the concept of environmentally valid rehabilitation and really got me thinking. 
Lieve (oud) iRv-ers, bij jullie vond ik een fijne werkplek, gezelligheid, interesse en begrip. Velen van jullie hebben als proefpersoon meegewerkt aan het 'gezonden onderzoek' dat in dit boekje wordt beschreven, waarvoor mijn dank. Met veel plezier denk ik terug aan het lunchwandelen en aan de spelletjesavonden (die voor het donker afgelopen moesten zijn). Ook de PV vergaderingen en activiteiten zorgden voor de nodige afleiding en hilariteit. Twee oud-collega's wil ik graag in het bijzonder noemen. Sascha, mijn werkzaamheden binnen het wetenschappelijk onderzoek zijn begonnen toen ik als stagiaire op de UM bij jou aan de slag ging. Hoe vaak heb je me niet gevraagd of een promotietraject niet ook wat voor mij zou zijn? Hoewel ik dat stellig bleef ontkennen heeft jouw tomeloze enthousiasme toch zijn invloed op me gehad; het bewijs hiervan ligt nu voor je. Ieke, eigenlijk val je binnen veel groepjes die ik eerder in dit dankwoord al noemde. Daaruit blijkt wel hoe verweven jij bent met mijn aio-periode. We deelden de worstelingen die horen bij het opzetten van een patiëntgebonden onderzoek en bij het schrijven van een review, maar we delen ook veel leuke herinneringen aan de UM en het iRv. Daar komen binnenkort leuke herinneringen aan twee promotiefeestjes bij!

I would like to thank the staff of both the psychology department and the movement science research group at Oxford Brookes University for their support when I was finishing my thesis. My time in Oxford has been wonderful because of you, but surely also because of the nice homes I found in England. Dear Derick and Liz, your hospitality was overwhelming. You offered me a place to stay although you did not know me all that well. Derick, I feel honoured that you are now part of my exam committee. The second home I found was at number 34. Dear housemates, thank you so much for keeping up with me during those hard last months of my PhD project. Our dinner parties and Six Feet marathons proved to be the perfect distracters. Let's pick a nice country to meet up soon!

Veel dank gaat uit naar mijn vrienden die de afgelopen jaren zoveel interesse hebben getoond in mijn onderzoek. Lieve Key Chain Friends, Matagne, Leontine, Susan J, Patricia en alle anderen, bedankt voor jullie steun en voor de afleiding die jullie me hebben gegeven. Ik kom snel op bezoek om bij te kletsen, nieuwe huizen te bekijken en om het nageslacht te bewonderen!

Lieve Pascal, ook jij verdient een plaatsje in dit dankwoord. Je zorgde vooral voor veel praktische steun. Jouw kamer in Delft was een gezellig en smakelijk logeeradres wanneer ik voor mijn onderzoek weer eens in de randstad moest zijn (jouw lasagna is onovertroffen). Ook knutselde je in no-time een mooie kaft voor me in elkaar. Bedankt voor alle moeite! Zullen we snel weer eens samen koken?

Tijdens de verdediging van dit proefschrift verkeer ik in de unieke positie niet alleen te worden bijgestaan door mijn paranimf Jos, maar ook door mijn nimf Wonneke. Lieve Jos, wij waren lot- en kamergenoten tijdens de afronding van 
onze proefschriften. Het voelt daarom erg goed dat je ook bij de allerlaatste (feestelijke) horde nauw betrokken bent. Lieve Wonneke, dat jij paranimf zou worden was meteen na mijn sollicitatiegesprek bij het $i R v$ al duidelijk. Je helpt me om zaken te relativeren, en dat blijkt, zeker tijdens het uitvoeren van een promotieonderzoek, van groot belang.

Lieve pappa en mamma, dankzij jullie onvoorwaardelijke steun en vertrouwen, maar ook dankzij de vrijheid die jullie me altijd gegeven hebben ben ik geworden wie ik ben. Jullie staan altijd voor me klaar en daar wil ik jullie graag voor bedanken. Dankzij jullie weet ik, there really is no place like home. 
Curriculum Vitae 

Chantal Geusgens werd geboren op 9 november 1977 te Maastricht. In 1996 behaalde zij haar VWO diploma aan het Jeanne d'Arc college in Maastricht. Vervolgens begon ze aan haar studie psychologie aan wat thans de Universiteit van Tilburg heet. In 2002 behaalde Chantal cum laude haar doctoraal diploma in zowel de klinische neuropsychologie als de psychologie in de gezondheidszorg. Vervolgens werd ze als promovendus aangesteld bij het iRv, Kenniscentrum voor Revalidatie en Handicap, te Hoensbroek, waar zij tot juli 2006 aan dit proefschrift werkte. Tevens was zij in deze periode als assistent in opleiding verbonden aan de vakgroep Psychiatrie en Neuropsychologie van de Universiteit Maastricht. Daarna wekte Chantal negen maanden als docent neuropsychologie bij Oxford Brookes University in Engeland. 
